\title{
Estimating global carbon uptake by lichens and bryophytes with a process-based model
}

\author{
P. Porada ${ }^{1}$, B. Weber ${ }^{2}$, W. Elbert ${ }^{2}$, U. Pöschl ${ }^{2}$, and A. Kleidon ${ }^{1}$ \\ ${ }^{1}$ Max Planck Institute for Biogeochemistry, P.O. Box 1001 64, 07701 Jena, Germany \\ ${ }^{2}$ Max Planck Institute for Chemistry, P.O. Box 3060, 55020 Mainz, Germany \\ Correspondence to: P. Porada (pporad@bgc-jena.mpg.de) \\ Received: 14 January 2013 - Published in Biogeosciences Discuss.: 28 February 2013 \\ Revised: 24 July 2013 - Accepted: 23 August 2013 - Published: 5 November 2013
}

\begin{abstract}
Lichens and bryophytes are abundant globally and they may even form the dominant autotrophs in (sub)polar ecosystems, in deserts and at high altitudes. Moreover, they can be found in large amounts as epiphytes in old-growth forests. Here, we present the first process-based model which estimates the net carbon uptake by these organisms at the global scale, thus assessing their significance for biogeochemical cycles. The model uses gridded climate data and key properties of the habitat (e.g. disturbance intervals) to predict processes which control net carbon uptake, namely photosynthesis, respiration, water uptake and evaporation. It relies on equations used in many dynamical vegetation models, which are combined with concepts specific to lichens and bryophytes, such as poikilohydry or the effect of water content on $\mathrm{CO}_{2}$ diffusivity. To incorporate the great functional variation of lichens and bryophytes at the global scale, the model parameters are characterised by broad ranges of possible values instead of a single, globally uniform value. The predicted terrestrial net uptake of 0.34 to $3.3 \mathrm{Gt} \mathrm{yr}^{-1}$ of carbon and global patterns of productivity are in accordance with empirically-derived estimates. Considering that the assimilated carbon can be invested in processes such as weathering or nitrogen fixation, lichens and bryophytes may play a significant role in biogeochemical cycles.
\end{abstract}

\section{Introduction}

Lichens and bryophytes are different from vascular plants: Lichens are not real plants, but a symbiosis of a fungus and at least one green alga or cyanobacterium, whereas bryophytes, such as mosses or liverworts, are plants which have no spe- cialised tissue such as roots or stems. Both groups are poikilohydric, which means that they cannot actively control their water content because they do not have an effective epidermal tissue, a cuticle or stomata. Mainly due to their ability to tolerate desiccation, combined with large functional variation, they are extremely adaptive organisms that can cope with a great range of climatic conditions (Nash III, 1996). They grow as epiphytes on the bark or even on the leaves of trees, they cover rock outcrops and they form carpets on the forest floor at high latitudes. As a part of biological soil crusts, they also populate the surface of desert soils (Belnap and Lange, 2003).

In spite of their global abundance, however, the effect of lichens and bryophytes on global biogeochemical cycles has been examined only by a few studies. The work of Elbert et al. (2012), for instance, suggests a significant contribution of cryptogamic covers, which largely consist of lichens and bryophytes, to global cycles of carbon and nitrogen. They use a large amount of data from field experiments or lab measurements to estimate characteristic mean values of net carbon uptake and nitrogen fixation for each of the world's biomes. By multiplying these mean values with the area of the respective biome, they arrive at global numbers for uptake of carbon and nitrogen. While their estimate for global net carbon uptake amounts to $7 \%$ of terrestrial net primary productivity (NPP), the derived value of nitrogen fixation corresponds to around $50 \%$ of the total terrestrial biological nitrogen fixation (BNF), representing a large impact on the global nitrogen cycle.

Lichens and bryophytes may have also played an important role with respect to biogeochemical cycles in the geological past. From the early Paleozoic on, the predecessors 
of today's lichens and bryophytes have likely contributed to the enhancement of surface weathering rates (Lenton et al., 2012). The organisms accelerate chemical weathering reactions of the substrate by releasing organic acids, complexing agents, hydroxide ions or respiratory $\mathrm{CO}_{2}$ (Jackson and Keller, 1970; Berthelin, 1988; Chen et al., 2000; Büdel et al., 2004; Weber et al., 2011). On long timescales, weathering rates of silicates control atmospheric $\mathrm{CO}_{2}$ concentration and thus have a large influence on global climate. The work of Schwartzmann and Volk (1989) shows, for example, that without biotic enhancement of weathering in the course of evolution, atmospheric $\mathrm{CO}_{2}$ would have remained at a high level. The surface temperature associated with this $\mathrm{CO}_{2}$ level would probably have been too high for complex life to evolve. Lenton et al. (2012) focus on the effect of the predecessors of modern bryophytes on atmospheric $\mathrm{CO}_{2}$ concentration during the Ordovician. According to their experiments, these early non-vascular plants could have caused a considerable drawdown in atmospheric $\mathrm{CO}_{2}$ levels via the silicate weathering feedback and, consequently, a decrease in global surface temperature. Furthermore, the release of phosphorus from the weathered rocks into the oceans could have led to a rise in marine productivity and therefore to further cooling. According to Lenton et al. (2012), this could explain two temporary glaciations at the end of the Ordovician period.

Here, we present the first process-based modelling approach to estimate net carbon uptake of lichens and bryophytes at the global scale. In this way, we are able to assess the role of these organisms regarding global biogeochemical cycles.

Most previous modelling studies that include lichens and bryophytes focus on net primary productivity (NPP) of moss in boreal and arctic regions, especially in peatlands (see, e.g. Wania et al., 2009; Frolking et al., 2002; Yurova et al., 2007). Others focus on ecosystem responses to climate change (Bond-Lamberty and Gower, 2007; Euskirchen et al., 2009; Zhuang et al., 2006; Turetsky et al., 2012), simulating peat accumulation (Frolking et al., 2010) or peatland microtopography (Nungesser, 2003). Our model aims at a more general representation of lichens and bryophytes that makes it possible to estimate the productivity of these organisms under a broad range of environmental conditions around the globe.

The model is called "LiBSi" (Lichen and Bryophyte Simulator). It is similar to many global vegetation models (see Fig. 1). These models describe plants in a simplified way instead of simulating them with all their detailed structures. Vegetation is usually represented by a reservoir of biomass, which changes as a function of exchange flows of carbon. These exchange flows depend on processes such as photosynthesis and respiration, which are represented by a set of equations. The equations use environmental factors such as radiation or water supply as input values, which are either prescribed or derived from climate forcing data. In spite of their simplicity, global vegetation models are capable of predicting NPP to a reasonable accuracy (Randerson et al., 2009).

Similar to these models, our model describes lichens and bryophytes as reservoirs of biomass located either on the soil or in the canopy and it is based on equations to represent photosynthesis and other physiological processes. These concepts are combined with properties and processes specific to lichens and bryophytes, such as the decrease of diffusivity for $\mathrm{CO}_{2}$ with increasing water content or the proportional relationship between metabolic activity and water saturation. The model differs from most other vegetation models with respect to the parameters contained in the model equations. Most models use parameter values that describe an "average" organism, such as a typical rain forest tree, for example. Our model uses ranges of possible parameter values which are derived from the literature. This approach is similar to the one used in the JeDi-DGVM (Jena Diversity-Dynamic Global Vegetation Model), which predicts global biogeochemical flows as well as biodiversity patterns (Pavlick et al., 2012). In this way, the model accounts for the large functional variation of lichens or bryophytes at the global scale concerning properties such as photosynthetic capacity or specific area.

The paper is structured in the following way: Sect. 2 contains a description of the model, including an overview of the reservoirs and exchange flows as well as the environmental factors that control these flows. In addition, the method for simulating functional variation of lichens and bryophytes by parameter ranges is explained. Estimates of net carbon uptake are presented in Sect. 3 together with an evaluation of the model performance. The model is evaluated by comparing simulated productivity of lichens and bryophytes with observational data. Furthermore, the uncertainty regarding the values of model parameters is assessed through a sensitivity analysis. In Sect. 4 the plausibility of the simulated patterns of productivity is discussed. Also the limitations of the approach presented here are analysed considering the outcomes of model evaluation and sensitivity analysis. Several potential improvements of the model and its applicability to further research are discussed.

Note that we use the term "net carbon uptake" throughout the manuscript instead of "net primary productivity" (NPP). While NPP is a standard term for vascular vegetation which is frequently used in the modelling community, "net carbon uptake" is more general and descriptive. In the context of this manuscript, it corresponds to NPP.

We abbreviate "carbon" with a capital "C" and place it next to the corresponding unit symbol throughout the manuscript. This is done in order to avoid confusion with biomass or $\mathrm{CO}_{2}$. To distinguish " $\mathrm{C}$ " from another unit symbol, we put " $\mathrm{C}$ " and the associated unit symbol in brackets. In the appendix, we use further abbreviations to clarify the units of model parameters and variables where necessary. These are $\mathrm{CO}_{2}, \mathrm{O}_{2}$, "Rubisco", $e^{-}$(electrons) and $\mathrm{H}_{2} \mathrm{O}$. 


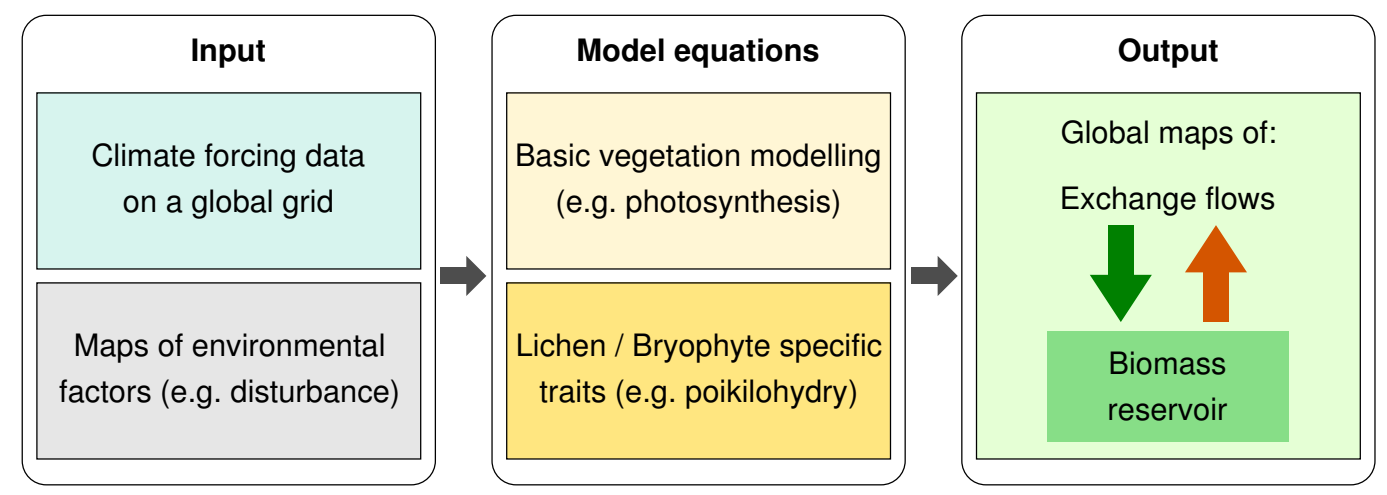

Fig. 1. Overview of the functioning of the model. Input data are translated via model equations into exchange flows of carbon, which are used to calculate changes in the biomass reservoir.

\section{Model description}

Lichens and bryophytes are described in the model by a reservoir approach, which means that they are represented by pools of chemical substances. These are biomass, sugar reserves, water and internal $\mathrm{CO}_{2}$ concentration. Regarding lichens, the biomass of the fungal and the algal/cyanobacterial partner are simulated in an aggregated form as one pool of biomass with average properties.

Changes in the size of the pools are due to input and output flows of carbon or water. Carbon is assimilated by photosynthesis from the atmosphere and temporarily stored as sugars. The sugars are then respired for maintenance or transformed into biomass. Water is taken up and evaporates via the thallus surface. The water content of the thallus influences several physiological processes, such as $\mathrm{CO}_{2}$ diffusion.

The processes which determine the carbon and water flows are driven by climate. In addition to the climate forcing, properties of the living environment also affect lichens and bryophytes in the model. These properties depend on the location of growth, which is either the canopy or the ground, as well as the surrounding vegetation, which is described by a biome classification.

\subsection{Model processes}

In the following, we describe the physiological processes implemented in the model. First, we name the effects of the living environment on lichens and bryophytes. Then, we explain how water content and climatic factors relate to physiological properties of the organism. Finally, we describe the exchange flows between the organism and its environment.

For simplicity, we will not present any equations. All equations used in the model can be found in Appendix B and are explained there. The parameters associated with the equations are listed in Tables B7 to B13 in the appendix.

\subsubsection{Living environment}

In the model, lichens and bryophytes can be located either in the canopy or on the ground. The location of growth is important for the radiation and precipitation regime the organism is exposed to (see Fig. 2). Lichens and bryophytes living in the upper part of the canopy, for example, may receive more shortwave radiation than those living beneath the canopy. Additionally, the location of growth determines the available area for growth. The available area in the canopy is assumed to be the sum of leaf area index (LAI) and stem area index (SAI). The available area on the ground depends on (a) the amount of soil not occupied by other vegetation and (b) LAI, since the litter layer resulting from leaf fall impedes the growth of lichens and bryophytes (see Fig. 2). Once a lichen or bryophyte covers the available area completely, it cannot grow anymore. Since the biomass of an organism is related to its surface area, biomass is also limited by the available area.

Another factor that shapes the living environment of lichens and bryophytes is the biome where the organisms are located. In the model, the biome controls the frequencies of disturbance events, such as fire or treefall, for instance. Furthermore, both location of growth and biome determine the aerodynamic roughness of the surface where lichens or bryophytes grow. A forest, for example, has a higher roughness than a flat desert. Together with wind speed, surface roughness has a large impact on the aerodynamic resistance to heat transfer between the surface and the atmosphere (Allen et al., 1998). Lichens and bryophytes in the canopy of an open forest, for instance, exchange heat faster than those on the flat surface of a desert.

\subsubsection{Water relations}

The water saturation of a lichen or bryophyte is the ratio of actual water content to water storage capacity of the thallus, 


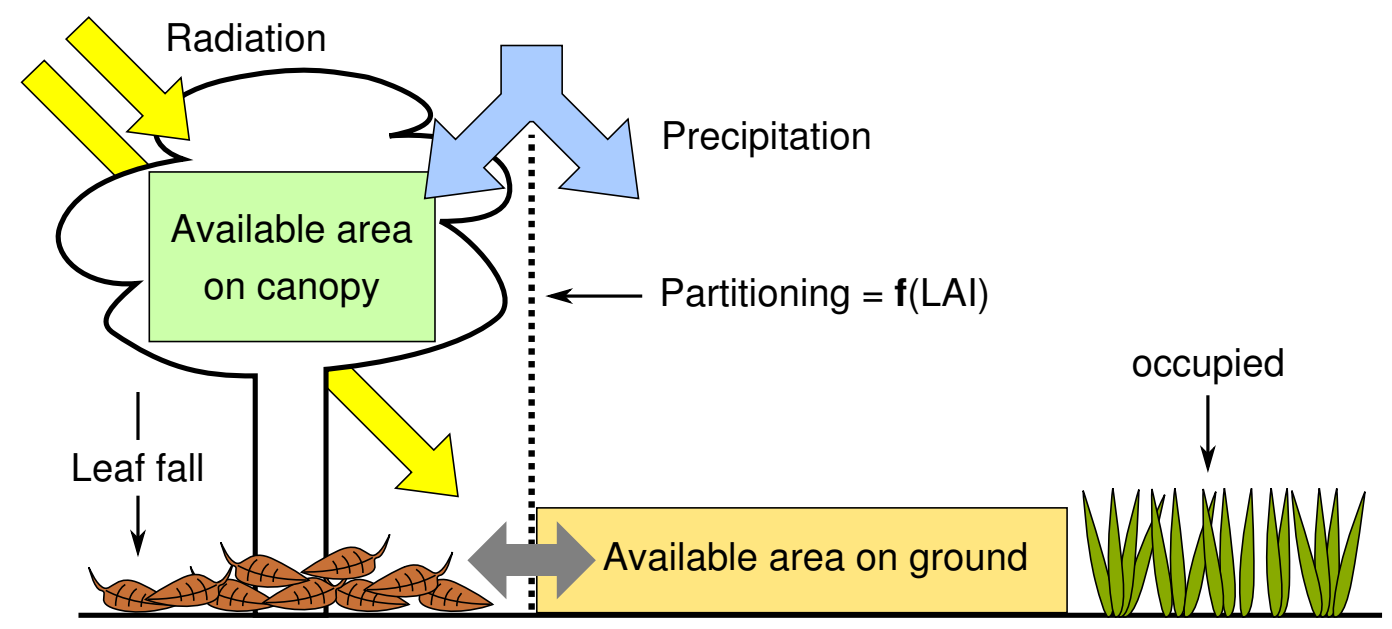

Fig. 2. Effect of the leaf area index (LAI) on area for growth and climate forcing. Available area on ground is a linearly decreasing function of LAI. The same function is used to partition precipitation between canopy and soil. The vertical distribution of light is calculated according to Beer's law as a function of LAI.

where the latter is proportional to biomass. The water saturation controls three important physiological properties:

1. The diffusivity of the thallus for $\mathrm{CO}_{2}$, which is inversely related to water saturation since water leads to a swelling of cells and thus to a narrowing of the diffusion pathways (Cowan et al., 1992);

2. The water potential, which increases from $-\infty$ at zero water saturation to a maximum value of 0 at a certain threshold saturation. If the water saturation is above this threshold, all cells in the thallus are fully turgid and extracellular water may exist inside the thallus or on its surface; and

3. The metabolic activity of a lichen or bryophyte, which determines both the relative strength of photosynthesis as well as that of respiration as a function of water saturation (Lange, 1980, 2002; Lidén et al., 2010; Williams and Flanagan, 1998). The metabolic activity is assumed to increase linearly from 0 at zero water saturation to 1 at the threshold saturation. It remains 1 if the water saturation exceeds the threshold saturation. This relation accounts for the fact that water is needed in the cells of the organism to activate enzymes and to enable chemical reactions.

Note that the water relations implemented in the model allow for representation of the species-specific dependency of photosynthesis on water content. At low water content, photosynthesis is limited by metabolic activity, while at higher water content it is limited by the diffusivity of the thallus for $\mathrm{CO}_{2}$. Depending on the relative strength of these limitations, different shapes of the relation between photosynthesis and water content can be simulated.

\subsubsection{Climate relations}

The climate forcing consists of air temperature, wind speed, relative humidity, precipitation and downwelling short- and longwave radiation. These climatic factors influence exchange flows of carbon and water between lichens and bryophytes and their environment. Furthermore, the climatic factors directly control two physiological properties of lichens and bryophytes, namely potential evaporation and surface temperature.

Both potential evaporation and surface temperature are calculated according to Monteith (1981) as a function of four factors:

1. Net radiation, which is the sum of downwelling shortand longwave radiation, upwelling longwave radiation and the ground heat flux;

2. Saturation vapour pressure, which is calculated as a function of air temperature (Allen et al., 1998). It is also influenced by the water potential of a lichen or bryophyte (Nikolov et al., 1995);

3. Aerodynamic resistance to heat transfer; and

4. Relative humidity.

Additionally to the climate forcing, physiological processes of lichens and bryophytes are affected by the presence of snow. If the snow layer exceeds a certain thickness, it is assumed that the metabolism of the organisms is reduced due to lack of light and low temperature.

\subsubsection{Exchange flows}

A schematic of the exchange flows of carbon and water between lichens and bryophytes and their environment is shown 
in Fig. 3 together with relations to climate forcing and reservoirs inside the thallus.

The inflow of $\mathrm{CO}_{2}$ into the pore space of the lichen or bryophyte depends on the gradient between the partial pressure of $\mathrm{CO}_{2}$ in the atmosphere and in the pore space as well as the diffusivity of the thallus for $\mathrm{CO}_{2}$.

The uptake of $\mathrm{CO}_{2}$ from the pore space (gross primary productivity, GPP) is computed as a minimum of a lightlimited rate, which depends on intercepted shortwave radiation, and a $\mathrm{CO}_{2}$-limited rate, which is a function of pore space $\mathrm{CO}_{2}$ (Farquhar and von Caemmerer, 1982). Both rates also depend on the surface temperature of the organism (Medlyn et al., 2002) and its metabolic activity status. Photosynthesis is assumed to peak around an optimum surface temperature (June et al., 2004).

Respiration is modelled by a $\mathrm{Q}_{10}$ relationship as a function of biomass and temperature (Kruse et al., 2011). Same as GPP, it too depends on metabolic activity. The respired $\mathrm{CO}_{2}$ is released into the pore space.

Hence, the $\mathrm{CO}_{2}$ balance of the lichen or bryophyte pore space is controlled by inflow, GPP and respiration. GPP is added to the sugar reservoir, while respiration is subtracted. Then, a certain fraction of the sugar reservoir is transformed into biomass with a certain efficiency. This constitutes the net primary productivity (NPP). The balance of the biomass reservoir is then determined by NPP and biomass loss, which includes regular processes such as tissue turnover or leaching of carbohydrates (Melick and Seppelt, 1992). Additionally, disturbance events which occur at characteristic time intervals lead to a reduction of biomass.

Evaporation from the lichen or bryophyte thallus is computed as a minimum of water content and potential evaporation. Since lichens and bryophytes cannot actively control water loss, evaporation is not affected by the activity status of the organism. Water uptake takes place via the thallus surface. Where water input exceeds maximum storage capacity, surplus water is redirected to runoff. The water balance of the lichen or bryophyte is thus determined by evaporation and water uptake.

\subsection{Model parameters}

The equations that describe physiological processes in the model are parameterised and the parameters can be subdivided into two categories: (1) properties of lichens and bryophytes, and (2) characteristics of the environment of the organisms. Since lichens and bryophytes have a large functional variation, the parameters that represent their properties, such as specific area or photosynthetic capacity, are characterised by large ranges of possible values. To incorporate the functional variation of lichens and bryophytes into the model, many physiological strategies are generated by randomly sampling the ranges of possible parameter values. We call these parameterisations "strategies" and not "species" because they do not correspond exactly to any species that can be found in nature. Nevertheless, these strategies are assumed to represent the physiological properties of real lichen and bryophyte species in a realistic way. Hence, the functional variation of the organisms can be simulated without knowing the exact details of each species.

The model is then run with all strategies, but not every strategy is able to maintain a positive biomass in each grid cell, which is necessary to survive. The results are computed by averaging only over the surviving strategies of each grid cell. Thus, climate is used as a filter to narrow the ranges of possible parameter values in each grid cell and therefore to make the results more accurate (see Fig. 4).

The studies of Bloom et al. (1985); Hall et al. (1992) analyse from a theoretical perspective the relations between the "strategy" of an organism and the success of this organism regarding natural selection in a certain environment. Follows and Dutkiewicz (2011) apply this approach to marine ecosystems, while Kleidon and Mooney (2000) use it to predict biodiversity patterns of terrestrial vegetation. The applicability of this method to modelling biogeochemical fluxes of terrestrial vegetation has been successfully demonstrated by the JeDi-DGVM (Pavlick et al., 2012).

The 15 model parameters which are included in the random sampling method are listed in Table B9 in the appendix. They represent structural properties of the thallus of a lichen or bryophyte, such as specific area or water storage capacity. They also describe implications of the thallus structure, such as the relation between water content and water potential. Furthermore, characteristics of the metabolism are considered, such as optimum temperature. Parameters which have categorical values are also used: a lichen or bryophyte can either live in the canopy or at the soil surface (see Sect. 2.1.1). Another categorical parameter determines if the organism has a carbon concentration mechanism (CCM) or not. For the model, it is assumed that the CCM in lichens works similarly to those in free-living cyanobacteria. Based on this assumption, the CCM implemented in our model represents an advantage for the organisms in cases of low internal $\mathrm{CO}_{2}$ concentrations in a water saturated thallus. Although regulation of the CCM has been observed (Miura et al., 2002), the model contains a fixed representation of the CCM for simplicity.

Some of the 15 parameters mentioned above are related to further lichen or bryophyte parameters. The respiration rate at a certain temperature, for instance, is assumed to be related to Rubisco content and turnover rate. Hence, the parameters Rubisco content and turnover rate are not sampled from ranges of possible values, but determined by the value of the parameter respiration rate. The reason for this relationship is an underlying physiological constraint, in this case, maintenance costs of enzymes. A lichen or bryophyte with a high concentration of Rubisco, for example, has to maintain these enzymes and therefore also shows a high respiration rate and a high turnover rate. Note that in lichens, fungal as well as algal/cyanobacterial biomass contribute to 


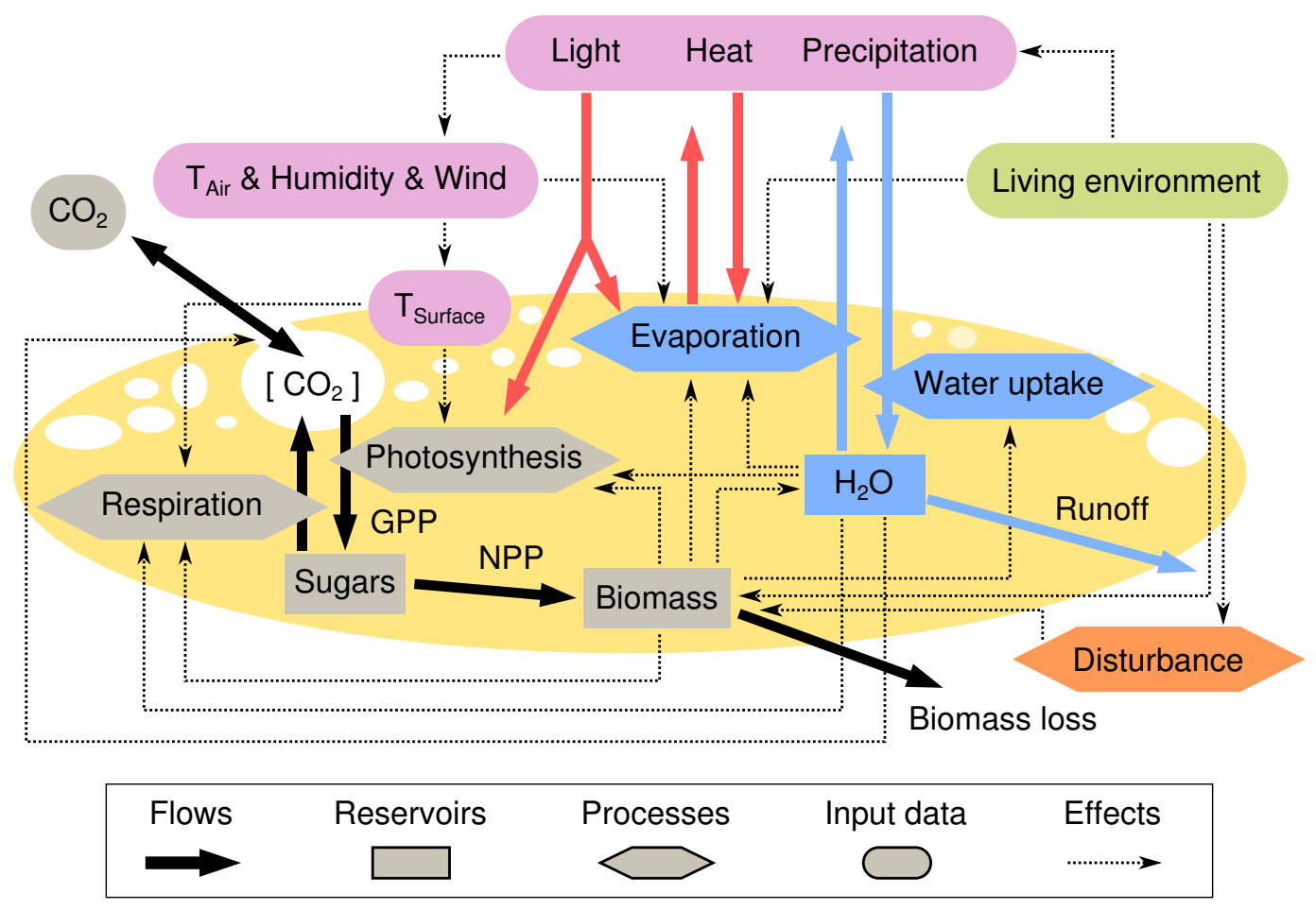

Fig. 3. Schematic of the carbon and water relations of a lichen or bryophyte simulated by the model. Dotted arrows illustrate effects of climate forcing, living environment and state variables on physiological processes of a lichen or bryophyte. These processes are associated with exchange flows (solid arrows) of carbon (black), water (blue) and energy (red).

respiration, while only the algal/cyanobacterial biomass contains Rubisco. In the model, however, lichen respiration is assumed to be controlled by the Rubisco content averaged over the total biomass.

The relationships between parameters are called tradeoffs and they are assumed to have constant values. This means that although the value of one parameter (e.g. Rubisco content) may vary across species, the tradeoff-function which relates this parameter to another one (e.g. respiration) should be more or less the same for many different species.

Six tradeoffs are implemented in the model. The first tradeoff describes the relation between Rubisco content, respiration rate and turnover rate explained above. The second tradeoff relates the diffusivity for $\mathrm{CO}_{2}$ to the metabolic activity of the lichen or bryophyte via its water content. This means that a high diffusivity is associated with a low water content, which results in a low activity. The third tradeoff describes the positive correlation between the maximum electron transport rate of the photosystems $\left(J_{\max }\right)$ and the maximum carboxylation rate $\left(V_{\mathrm{C} \text {, max }}\right)$. Since both rates represent costs for the organism and photosynthesis is the minimum of the two, it would be inefficient if they were independent from each other. The fourth tradeoff is associated with the carbon concentration mechanism (CCM). In case a lichen or bryophyte possesses a CCM, a part of the energy acquired by the photosystems is not used to fix $\mathrm{CO}_{2}$, but rather to increase the $\mathrm{CO}_{2}$ concentration in the photobionts. If the organism is limited by low $\mathrm{CO}_{2}$ but enough light is available, a CCM can lead to higher productivity. The fifth and sixth tradeoffs concern the Michaelis-Menten constants of the carboxylation and oxygenation reactions of Rubisco. They relate these constants to the molar carboxylation and oxygenation rates of Rubisco. One tradeoff is usually associated with more than one parameter. The model parameters that describe tradeoffs are listed in Table B10.

The model contains several additional lichen or bryophyte parameters which are not directly associated with tradeoffs, but which represent physiological or physical constraints. Therefore, they are assumed to have constant values. They can be found in Table B11.

In addition to the parameters that describe properties of the lichens and bryophytes, the model contains parameters that represent environmental conditions. They describe the extinction of light as a function of LAI, the interception efficiency for precipitation of the canopy, characteristics of the snow cover, thermal properties of the upper soil layer, roughness of the surface regarding wind and the time intervals for disturbance in the different biomes. For the sake of simplicity, no ranges are specified for these parameters; only average values of the corresponding variables are used. The density of snow, for instance, varies typically from $100-500 \mathrm{~kg} \mathrm{~m}^{-3}$ (Domine et al., 2011), depending on many factors, such as 


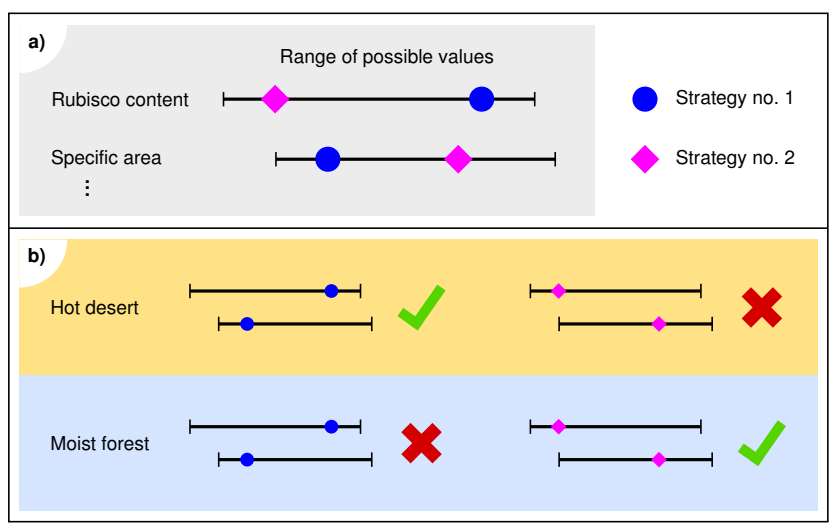

Fig. 4. Generation of physiological strategies and their survival. (a) Many random parameter combinations (strategies) are sampled from ranges of possible values. The strategies are then run in each grid cell of the model. (b) Example: In a hot desert, strategy 1 survives because a small specific area reduces water loss by evaporation and a high Rubisco content is adequate to high intensities of light. Strategy 2, however, dies out since too much water evaporates due to a large specific area. In a moist forest, strategy 1 dies out because a high Rubisco content is associated with high respiration costs which cannot be covered by low light conditions under a canopy. Strategy 2 can survive since it does not have high respiration costs. Note that these examples are not generally applicable. High specific area, for instance, could also be useful in a desert to collect dew.

age, for example, which are not considered in the model. Hence, snow density is set to a constant global average value. For a list of parameters related to environmental conditions, see Table B8.

\subsection{Simulation setup}

The model runs on a global rectangular grid with a resolution of 2.8125 degrees (T42); hence, all input data are remapped to this resolution. The land mask and the climate forcing are taken from the WATCH data set (Weedon et al., 2011). This data set comprises shortwave radiation, downwelling longwave radiation, rainfall, snowfall, air temperature at $2 \mathrm{~m}$ height, wind speed at $10 \mathrm{~m}$ height, surface pressure and specific humidity. The latter two variables are used to compute relative humidity. The temporal resolution of the data is $3 \mathrm{~h}$ and the years 1958-2001 are used. Since the model runs on an hourly time step, the data are interpolated. In addition to the climate forcing, the model uses maps of LAI and SAI in a monthly resolution and a temporally constant map of bare soil area, all of which are taken from the Community Land Model (Bonan et al., 2002). They are used to provide estimates for the available area for growth and the light environment. A biome map taken from Olson et al. (2001) is used to represent disturbance by assigning characteristic disturbance intervals to each biome (see Table B3). Furthermore, surface roughness is determined as a function of the biome.
The model provides output for each surviving strategy in a grid cell independently. Hence, to obtain an average output value for a certain grid cell, the different strategies have to be weighted. Since ecological interactions between species are not considered in the model, it is not possible to determine the relative abundance and thus the weight of each strategy. Therefore, the uncertainty due to the unknown weights of the strategies has to be included into the results. As a lower bound for net carbon uptake in a certain grid cell, we assume that all strategies are equally abundant and the estimate thus corresponds to equal weights for all surviving strategies. This weighting method is called "average". Since strategies that do not grow much are probably not as abundant as strongly growing strategies, the true net carbon uptake is probably underestimated by this method. As an upper bound we assume a weight of one for the strategy with the highest growth and zero for all other strategies. This weighting method is called "maximum" and it is probably an overestimate of the true value since competition between species would have to be very strong to reduce diversity to such an extent. The upper and lower bounds derived from the two weighting methods are then used for the evaluation of the model.

The model is evaluated by comparing model estimates to observational data for several biomes. Hence, for each biome the spatial average of simulated net carbon uptake is compared to a "characteristic", observation-based value of net carbon uptake on an order-of-magnitude basis. This rough method of model-data comparison results from the difference in scale between model estimates and observations: the observational data are spatially and temporally discrete point-scale measurements which show a high variation, e.g. $8-1450$ (g biomass) $\mathrm{m}^{-2} \mathrm{yr}^{-1}$ for Sphagnum (Gunnarsson, 2005). It is very problematic to extrapolate from these variable point measurements to large regions, such as a model grid cell, which is about $50000 \mathrm{~km}^{2}$ at $45^{\circ} \mathrm{N}$. In order to quantify net carbon uptake at the large scale of a model grid cell, the point-scale values would have to be weighted by area coverage. High-resolution data that relate coverage to net carbon uptake, however, are not available at large scales. Therefore, we try to estimate a characteristic value of net carbon uptake for a large region instead. This region should not be a grid cell of the model since the grid is an artificial segmentation of the landscape. Instead, we use the biome classification as a basis for our model-data comparison. Biomes are homogeneous regarding climate and ecology at the large-scale. Hence, they allow for the estimation of a characteristic, observation-based value of net carbon uptake.

To obtain a characteristic value of net carbon uptake for each biome, we compute the median of all measurements listed in the studies associated with this biome. We use the median instead of the mean of all values because computing the mean implicitly assumes equal weights for all values. As discussed above, these weights are not known. 
The studies selected for the model-data comparison are limited to those which report estimates of average, long-term net carbon uptake based on surface coverage of lichens or bryophytes. Studies which estimate only maximum rates of carbon uptake or carbon uptake per area lichen/bryophyte or per gram biomass cannot be used. To include such studies, we would have to make assumptions about the active time of lichens and bryophytes throughout the year, about their ground coverage, etc. Hence, we would not compare our modelled estimates to data but to another, empirical model. Our criteria lead to the exclusion of many studies which measure productivity of lichens and bryophytes. Consequently, only 4 out of 14 biomes are represented in the field studies: tundra, boreal forest, desert and tropical rainforest.

For a list of studies used in the model-data comparison, see Table 1. The list does not comprise all existing studies which provide observational data on net carbon uptake of lichens and bryophytes. In our opinion, however, it is sufficient to illustrate the order of magnitude of net carbon uptake.

The model is run for $2000 \mathrm{yr}$ with an initial number of 3000 strategies. The simulation length of $2000 \mathrm{yr}$ is sufficient to reach a dynamic steady state regarding the carbon balance of every strategy, which also implies that the number of surviving strategies has reached a constant value. Furthermore, the initial strategy number of 3000 is high enough to achieve a representative sampling of the ranges of possible parameter values. This means running the model with 3000 different strategies leads to a very similar result. The model output is averaged over the last 100 years of the simulation, since this period corresponds to the longest disturbance interval in the model. The simulation described above takes 7 days on 48 processors of a parallel computer. The source code (written in Fortran 95) is available on request.

\section{Results}

The model presented here is designed to predict global net carbon uptake by lichens and bryophytes. The predicted values are shown in the form of maps as well as global average numbers. Additionally, further properties of lichens and bryophytes estimated by the model are presented to illustrate the large range of possible predictions. To assess the quality of the predictions, the model estimates are compared to observational data.

To estimate the effect of uncertain model parameter values on the predictions of the model, a sensitivity analysis is performed.

\subsection{Modelled net carbon uptake}

The global estimate of net carbon uptake by lichens and bryophytes amounts to $0.34(\mathrm{Gt} \mathrm{C}) \mathrm{yr}^{-1}$ for the averageweighting method and 3.3 (Gt C) $\mathrm{yr}^{-1}$ for the maximum-
Table 1. Overview of the studies used to evaluate the model. The value in brackets in the column "Net carbon uptake" corresponds to the number of observations contained in the respective study. A *-symbol denotes studies which provide one or more ranges instead of single values. In these cases, we calculated the mean value of the upper and lower bound of each range and show the range of these calculated mean values in the table. If net carbon uptake was reported in units of gram biomass, we used a factor of 0.4 (relative weight of carbon in $\mathrm{CH}_{2} \mathrm{O}$ ) as a conversion factor for carbon.

\begin{tabular}{llr}
\hline Study & Biome & $\begin{array}{r}\text { Net carbon uptake } \\
{\left[(\mathrm{g} \mathrm{C}) \mathrm{m}^{-2} \mathrm{yr}^{-1}\right]}\end{array}$ \\
\hline (Billings, 1987) & Tundra & 10 \\
(Lange et al., 1998) & Tundra & $4.7-20.4(4)$ \\
(Oechel and Collins, 1976) & Tundra & $38.5-171(2)$ \\
(Schuur et al., 2007) & Tundra & $12-60(3)$ \\
(Shaver and Chapin III, 1991) & Tundra & $2-68(4)$ \\
(Uchida et al., 2006) & Tundra & 1.9 \\
(Uchida et al., 2002) & Tundra & 6.5 \\
(Billings, 1987) & Boreal forest & $9.7-78(2)$ \\
(Bisbee et al., 2001) & Boreal forest & 25 \\
(Camill et al., 2001) & Boreal forest & $9.2-75.9(8)$ \\
(Gower et al., 1997) & Boreal forest & 12 \\
(Grigal, 1985) & Boreal forest & $128-152(2)$ \\
(Harden et al., 1997) & Boreal forest & $60-280(3)^{\star}$ \\
(Bond-Lamberty et al., 2004) & Boreal forest & $0-297.1(14)$ \\
(Mack et al., 2008) & Boreal forest & $0.4-16.2(7)$ \\
(Oechel and Van Cleve, 1986) & Boreal forest & $40-44(2)$ \\
(Reader and Stewart, 1972) & Boreal forest & 14.4 \\
(Ruess et al., 2003) & Boreal forest & $29.2-31.2(2)$ \\
(Swanson and Flanagan, 2001) & Boreal forest & 104 \\
(Szumigalski and Bayley, 1996) & Boreal forest & $15.2-81.2(10)$ \\
(Thormann, 1995) & Boreal forest & $23.2-73.2(3)$ \\
(Vogel et al., 2008) & Boreal forest & $12-32(9)$ \\
(Wieder and Lang, 1983) & Boreal forest & $216-316(3)$ \\
(Brostoff et al., 2005) & Desert & 11.7 \\
(Garcia-Pichel and Belnap, 1996) & Desert & 0.54 \\
(Jeffries et al., 1993) & Desert & $0.07-1.5(3)^{\star}$ \\
(Klopatek, 1992) & Desert & $5.3-29(4)^{\star}$ \\
(Clark et al., 1998) & Tropical forest & $37-64(2)$ \\
\hline & &
\end{tabular}

weighting method (for a description of these weighting methods see Sect. 2.3). The global biomass is 4.0 (Gt C) (average) and 46 (Gt C) (maximum), respectively.

We show maps of the global net carbon uptake by lichens and bryophytes, biomass, surface coverage, number of surviving strategies and two characteristic parameters, the optimum temperature of gross photosynthesis and the fraction of organisms with a carbon concentration mechanism (CCM). These maps are created from time averages over the last $100 \mathrm{yr}$ of the simulation described in Sect. 2.3. The maps are based on the average-weighting method. The maximumweighting shows very similar patterns and the corresponding maps are shown in Fig. A1a-d.

The net carbon uptake by lichens and bryophytes is shown in Fig. 5a. In some areas, such as Greenland and the driest parts of deserts, none of the simulated lichen and bryophyte strategies (see Sect. 2.2) is able to survive and net carbon uptake is equal to zero there. The biomes differ largely with respect to carbon uptake. While deserts are characterised by 
the lowest productivity, the highest values are reached in the boreal zone and in the moist tropics. In the tropical rainforest the high productivity is mainly due to the high carbon uptake by epiphytic lichens and bryophytes (see Fig. 5c). In the boreal zone, lichens and bryophytes in the canopy as well as on the ground contribute significantly to carbon uptake (see Fig. 5d). Biomass (Fig. 5b) exhibits a global pattern similar to carbon uptake. At high latitudes, however, the ratio of biomass to carbon uptake seems to be slightly higher than in the tropics.

Figure 6a shows the global absolute cover of lichens and bryophytes in $\mathrm{m}^{2}$ projected surface area of the organisms per $\mathrm{m}^{2}$ ground. Since the available area can be higher than one in the canopy, high values of absolute cover do not necessarily mean high fractional cover. On the contrary, the fractional cover is highest in regions with low absolute cover, especially grasslands and agricultural areas, since the available area in these regions is very small. A map of fractional cover is shown in Fig. A2. Figure $6 \mathrm{~b}$ shows the number of surviving strategies at the end of the simulation. The global pattern is slightly different from the pattern of carbon uptake. Although forested regions show the highest number of strategies, the high latitudes are richer in strategies than the tropics.

Figures $6 \mathrm{c}$ and $\mathrm{d}$ show the global patterns of two characteristic lichen and bryophyte parameters. As described in Sect. 2.2, these parameters are sampled randomly from ranges of possible values to create many artificial strategies. Thus, at the start of a simulation, possible values from the range of a certain parameter are present in equal measure in each grid cell. During the simulation, however, parameter values from certain parts of the range might turn out to be disadvantageous in a certain climate and the corresponding strategies might die out. This leads to a narrowing of the range and consequently to global patterns of characteristic parameters. These patterns reflect the influence of climate on properties of surviving strategies. Figure $6 \mathrm{c}$ shows the optimum temperature of gross photosynthesis of lichens and bryophytes living on the ground. The optimum temperature shows a latitudinal pattern, with high values in the tropics and low values towards the poles or at high altitudes. Figure $6 \mathrm{~d}$ shows the fraction of organisms on the ground that have a carbon concentration mechanism (CCM). This parameter is also characterised by a latitudinal pattern. The fraction of organisms with a CCM is almost one in the tropics, while it is approximately 0.5 in polar regions. Lichens and bryophytes living in the canopy exhibit global patterns of optimum temperature and CCM fraction similar to those living on the ground. The corresponding maps are shown in Fig. A2.

\subsection{Evaluation}

Figure 7 shows a comparison between model estimates and observational data with regard to net carbon uptake for four biomes. As discussed in Sect. 2.3, the observational data are point-scale measurements which show high variation. Therefore, the median of the observed values from a biome is used as a characteristic value of net carbon uptake. This median value is compared to the upper and lower bound of simulated net carbon uptake averaged over the biome (see Sect. 2.3 for a description of how the bounds are derived). Also shown is the variation of carbon uptake between the most- and the least-productive grid cell in a biome for both bounds of the model estimates. Figure 7 illustrates that the model estimates are characterised by high variation. The range between the upper and lower bound of net carbon uptake is around one order of magnitude. The range of productivity of the grid cells in a biome is up to four orders of magnitude.

Considering the upper and lower bounds of simulated net carbon uptake in each biome, the model estimates agree relatively well with the characteristic values of net carbon uptake derived from observational data. For the boreal zone and the tropical rainforest, the characteristic values are closer to the upper bound of net carbon uptake. In the boreal zone, the data-based value matches the simulated upper bound; in the tropical rainforest it exceeds the upper bound. Possible reasons for these patterns are discussed in Sect. 4.

\subsection{Sensitivity analysis}

As described in Sect. 2.2, model parameters that describe tradeoffs, physiological constraints or environmental properties are assumed to have constant values. Some of these parameter values have already been estimated in other studies and thus they can be taken directly from the literature. Others, however, have yet to be determined. A reliable estimate of these unknown parameter values would require a considerable amount of experimental data, which is beyond the scope of this study. Therefore, the parameter values were derived by educated guess using the available information from the literature (see Appendix B). To assess the impact of these parameter values on the model result we perform a sensitivity analysis (see Table 2). Note that some of the parameters tested in the sensitivity analysis are aggregated into a single process. For a detailed overview of the parameters see Tables B8 and B10.

In general, the model is not very sensitive to the parameter values, which applies both for the average- and maximumweighting methods. Regarding the environmental parameters, a change by $50 \%$ leads to a $10 \%$ or less change in the modelled net carbon uptake in most cases. Only disturbance interval and rain interception efficiency have a slightly larger influence. The parameters that describe tradeoffs have a larger impact. Changing the relation of water content to diffusivity for $\mathrm{CO}_{2}$ by $50 \%$, for instance, leads to a change in average net carbon uptake by almost $50 \%$. The effect of the respiratory costs associated with Rubisco content is similarly strong. The climate forcing has only a moderate influence on the simulated net carbon uptake. Note that the variation in climate forcing is only $20 \%$ compared to $50 \%$ for 
a)

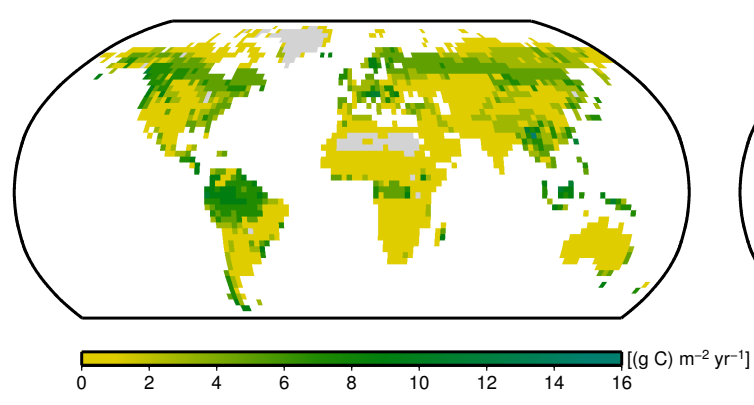

c)

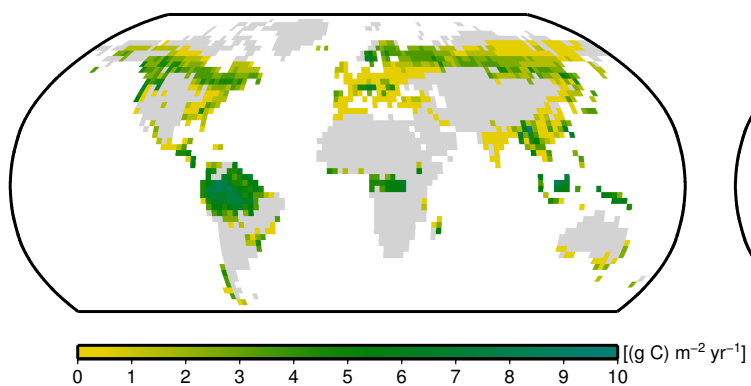

b)

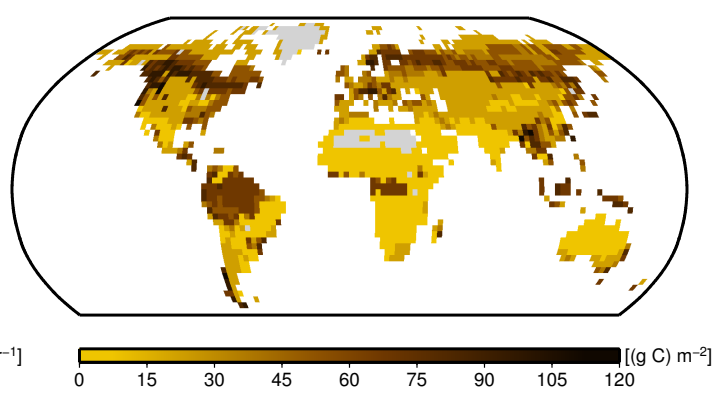

d) Net carbon uptake on ground

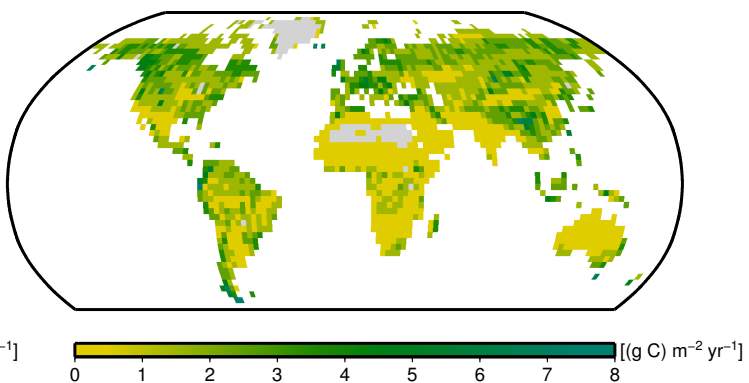

Fig. 5. Global maps of model estimates. (a) Net carbon uptake by lichens and bryophytes. (b) Biomass of lichens and bryophytes. (c) Net carbon uptake by lichens and bryophytes living in the canopy. (d) Net carbon uptake by lichens and bryophytes living on the ground. The estimates are based on time averages of the last $100 \mathrm{yr}$ of a 2000 -yr run with 3000 initial strategies. They correspond to the average-weighting method (see Sect. 2.3). Areas where no strategy has been able to survive are shaded in grey.

the parameters. This is done to avoid generating unrealistic climatic regimes.

The turnover parameter affects maximum and average net carbon uptake in opposite ways. Moreover, the effects of the parameters $J_{\max } / V_{\mathrm{C} \text {,max }}$, light extinction and surface roughness on carbon uptake are not straightforward to explain. These points are discussed in Sect. 4. For reasons of computation time we used a different simulation setup ( $400 \mathrm{yr}, 300$ strategies) for the sensitivity analysis. Therefore, the net carbon uptake values for the control run (Table 2) differ from the ones presented above. The pattern of productivity, however, is very similar to those of the longer run with more strategies (see Fig. A2). We thus assume that the sensitivity of the model does not change significantly with increased simulation time and number of initial strategies.

\section{Discussion}

In this study we estimate global net carbon uptake by lichens and bryophytes using a process-based model. In the following, we discuss the plausibility of the model estimates with respect to the patterns and the absolute values. Furthermore, we give an overview of the limits of our approach with a focus on the different sources of uncertainty in the model and possible improvements.

\subsection{Global patterns of net carbon uptake}

The model predicts plausible patterns of productivity and biomass (see Fig. 5) as well as cover, number of surviving strategies and characteristic parameters (see Fig. 6). The productivity of lichens and bryophytes in deserts seems to be generally limited by low water supply while the boreal zone and the moist tropics and subtropics are characterised by high values of productivity. The vertical pattern of productivity in tropical forests is different from the one in boreal forests and it probably can be attributed to forest structure and temperature: the boreal forests have a relatively open canopy with large, sunlit areas in between that allow for lichen or bryophyte growth. Since this is not the case in the dense tropical lowland forests, carbon uptake on the ground is lower than in the boreal zone. Furthermore, in the moist lowland forest, high temperatures at night together with high humidity near the soil surface cause high respiratory losses for lichens and bryophytes and therefore constrain their growth (Nash III, 1996). This is also reflected in the ratio of biomass to carbon uptake, which is slightly lower in the tropics than at high latitudes. Tropical cloud forests, however, which also exist in the lowland (Gradstein, 2006), may facilitate high productivity of lichens and bryophytes near the ground. Our description of topographic and climatic conditions, however, is not specific enough to account for 
a)

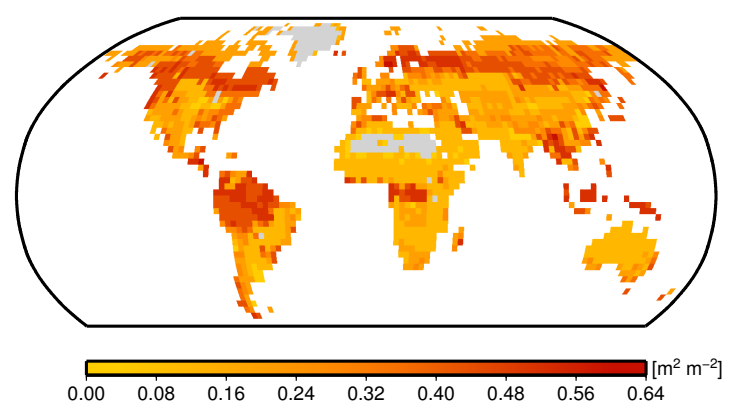

c) $\mathrm{T}_{\mathrm{opt}}$ of gross photosynthesis

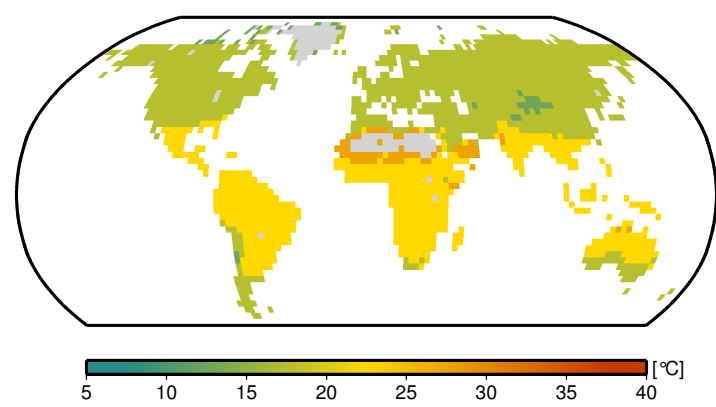

b) Number of strategies

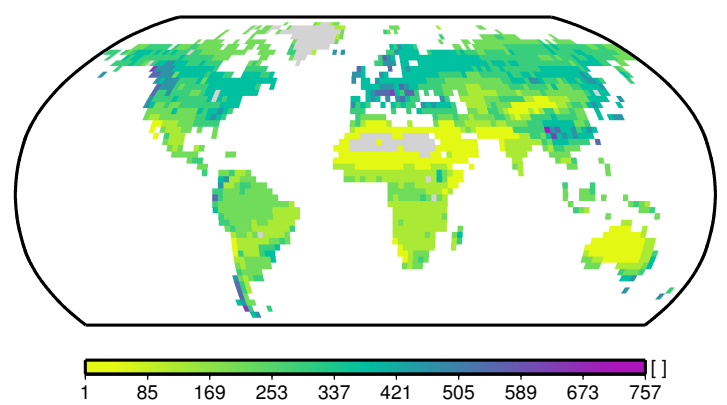

d) Fraction of organisms with $\mathrm{CCM}$

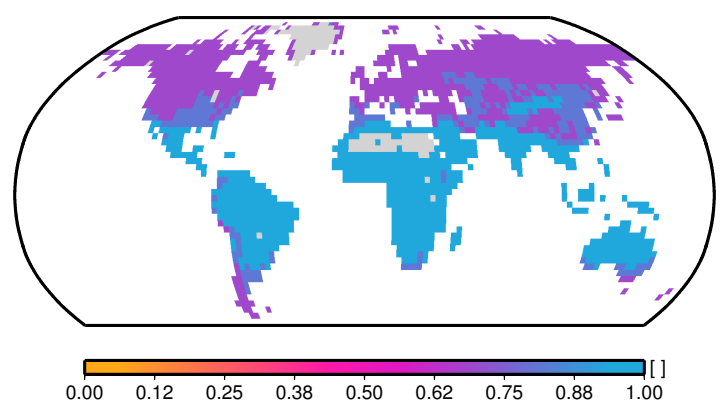

Fig. 6. Global maps of model estimates. (a) Area covered by lichens and bryophytes per $\mathrm{m}^{2}$ ground. (b) Number of surviving strategies at the end of a model run. (c) Optimum temperature of gross photosynthesis of lichens and bryophytes on the ground. (d) Fraction of lichens and bryophytes on the ground with a carbon concentration mechanism (CCM). The estimates are based on time averages of the last $100 \mathrm{yr}$ of a $2000 \mathrm{yr}$ run with 3000 initial strategies. They correspond to the average-weighting method (see Sect. 2.3). Areas where no strategy has been able to survive are shaded in grey.

these ecosystems. Hence, at a large spatial scale, the climate of the high latitudes seems to be more favourable for a large range of lichen and bryophyte growth strategies than the tropical climate, which is also illustrated by the higher number of strategies of the boreal forest zone compared to the tropical one. Nevertheless, the potential for productivity seems to be highest in the moist tropics, although survival in this region is more difficult.

The surface coverage shows a plausible range of values. In deserts, it is in the order of $10 \%$ or lower and in (sub)polar regions, it is around $30 \%$, which seems realistic. In forested regions, it ranges from 40 to $65 \%$, which is plausible since the available area is larger than $1 \mathrm{~m}^{2}$ per $\mathrm{m}^{2}$ ground for lichens and bryophytes living in the canopy.

The latitudinal pattern of the optimum temperature of gross photosynthesis is realistic since the mean climate in the tropics is warmer than in polar regions or at high altitudes. The fact that the edges of the parameter range are not represented on the map can be explained as follows: extreme climatic conditions, which could be associated with extreme values of the optimum temperature of gross photosynthesis, often do not persist for long time periods. Lichens and bryophytes are usually inactive during these periods and are therefore not affected by them. Extreme temperatures that last for longer periods of time are probably only present at the microclimatic scale and are therefore absent from the grid cell climate. Same as optimum temperature, the latitudinal pattern of the fraction of organisms with a CCM also makes sense. The form of the CCM implemented in the model is useful in situations where $\mathrm{CO}_{2}$ is limited, either due to low supply from the atmosphere or due to the negative effect of high temperatures on cellular $\mathrm{CO}_{2}$ concentration. These conditions are met in the tropics. The moist climate in the rainforest generally leads to high water content of the thallus, which results in a low diffusivity for $\mathrm{CO}_{2}$. Additionally, the high temperatures in the tropics result in low cellular solubility of $\mathrm{CO}_{2}$ compared to $\mathrm{O}_{2}$, further reducing $\mathrm{CO}_{2}$ available for photosynthesis. Although the global pattern is plausible, the fraction of lichens and bryophytes with a CCM seems to be generally too high. The reason for this could be that the metabolic costs of a CCM are underestimated in the model. As mentioned in Sect. 3.3, the parameters describing the costs of the CCM are not very well known. Moreover, this parameterisation is based on free-living cyanobacteria. The CCM in lichens and bryophytes could work differently. Furthermore, it has to be pointed out that the CCM which cyanobacteria and some algae possess is not necessarily the reason why they are part of the symbiosis. Not enough is 
Table 2. Influence of uncertain model parameters on simulated net carbon uptake. "Average" and "maximum" correspond to two different weighting methods for the results (see Sect. 2.3). The "+" signs denote an increase in the value of a parameter and "-" signs denote a decrease. The rightmost column shows the type of increase or decrease.

\begin{tabular}{|c|c|c|c|c|c|}
\hline \multirow{2}{*}{$\begin{array}{l}\text { Net carbon uptake }\left[(\mathrm{g} \mathrm{C}) \mathrm{m}^{-2} \mathrm{yr}^{-1}\right] \\
\text { Change in parameter value }\end{array}$} & \multicolumn{2}{|c|}{ Average } & \multicolumn{2}{|c|}{ Maximum } & \multirow[b]{2}{*}{ Type } \\
\hline & - & + & - & + & \\
\hline \multicolumn{6}{|l|}{ Lichen or bryophyte parameters } \\
\hline CCM response & 0.20 & 0.28 & 0.9 & 1.3 & $50 \%$ \\
\hline Ratio $J_{\max } / V_{\mathrm{C}, \max }$ & 0.19 & 0.27 & 0.8 & 1.3 & $50 \%$ \\
\hline Diffusivity for $\mathrm{CO}_{2}$ & 0.15 & 0.35 & 0.6 & 1.7 & $50 \%$ \\
\hline Turnover per respiration & 0.19 & 0.29 & 1.3 & 1.0 & $50 \%$ \\
\hline Rubisco per respiration & 0.16 & 0.32 & 0.6 & 1.6 & $50 \%$ \\
\hline \multicolumn{6}{|l|}{ Environmental parameters } \\
\hline Disturbance interval & 0.21 & 0.27 & 0.9 & 1.3 & $50 \%$ \\
\hline Light extinction in canopy & 0.25 & 0.24 & 1.2 & 1.1 & $50 \%$ \\
\hline Rain interception efficiency & 0.23 & 0.27 & 1.0 & 1.3 & $50 \%$ \\
\hline Max. snow depth for activity & 0.25 & 0.25 & 1.2 & 1.2 & $50 \%$ \\
\hline Heat conductivity of snow & 0.25 & 0.25 & 1.2 & 1.2 & $50 \%$ \\
\hline Turnover of ice sheets & 0.25 & 0.25 & 1.2 & 1.2 & $50 \%$ \\
\hline Soil heat conductivity & 0.25 & 0.25 & 1.2 & 1.2 & $50 \%$ \\
\hline Soil heat capacity & 0.25 & 0.25 & 1.2 & 1.2 & $50 \%$ \\
\hline Surface roughness & 0.26 & 0.25 & 1.2 & 1.1 & $50 \%$ \\
\hline \multicolumn{6}{|l|}{ Climate forcing } \\
\hline Shortwave radiation & 0.25 & 0.25 & 1.1 & 1.2 & $20 \%$ \\
\hline Air temperature & 0.26 & 0.25 & 1.2 & 1.2 & $2 \mathrm{~K}$ \\
\hline Rainfall / snowfall & 0.25 & 0.25 & 1.2 & 1.2 & $20 \%$ \\
\hline Surface wind speed & 0.26 & 0.25 & 1.2 & 1.1 & $20 \%$ \\
\hline Control run & \multicolumn{2}{|c|}{0.25} & \multicolumn{2}{|c|}{1.2} & \\
\hline
\end{tabular}

known about how the CCM works in lichens and bryophytes to make definitive statements. Thus, although the global patterns of optimum temperature and CCM cannot be evaluated on a quantitative basis, these patterns help to assess qualitatively the plausibility of the model results given the assumptions made in the model.

\subsection{Comparison of model estimates to data}

The observational data used to evaluate the model show high variation.

As explained in Sect. 2.3 it is therefore problematic to extrapolate from these point-scale measurements of carbon uptake to a value for a large region, such as a model grid cell. The characteristic, observation-based values of net carbon uptake should therefore be interpreted as order-of-magnitude estimates.

In the boreal zone and in the moist tropics, the characteristic values are closer to the upper bound of simulated net carbon uptake than to the lower one (see Fig. 7). This indicates that the more productive model strategies may represent a better approximation of the net carbon uptake by real lichens and bryophytes in these regions. A possible explanation for this result is that the lichen and bryophyte species occurring in these ecosystems are influenced by competition and are consequently driven towards high productivity. Another explanation would be that the model underestimates productivity in these regions.

For the tropics, it is difficult to make definitive statements due to the low number of observations available. In the study of Elbert et al. (2012), net carbon uptake in the tropical rainforest canopy is estimated to be only 15.2 (g C) $\mathrm{m}^{-2} \mathrm{yr}^{-1}$. This value compares well to our estimated range. As discussed in Sect. 2.3, however, the estimates from Elbert et al. (2012) are based on assumptions about active time and coverage of lichens and bryophytes.

In the boreal zone, the "characteristic" value is more robust due to the large number of observations. The fact that it matches the upper bound of the spatial average model estimate may be explained by the lack of an explicit simulation of the peat in the model. The peat layer may represent an additional water storage for bryophytes that is not associated with respiration costs. This is not reflected in the model, where the strategies have to "pay" for the water storage in biomass via the respiration cost of biomass. Hence, the model may underestimate the water supply in regions where 


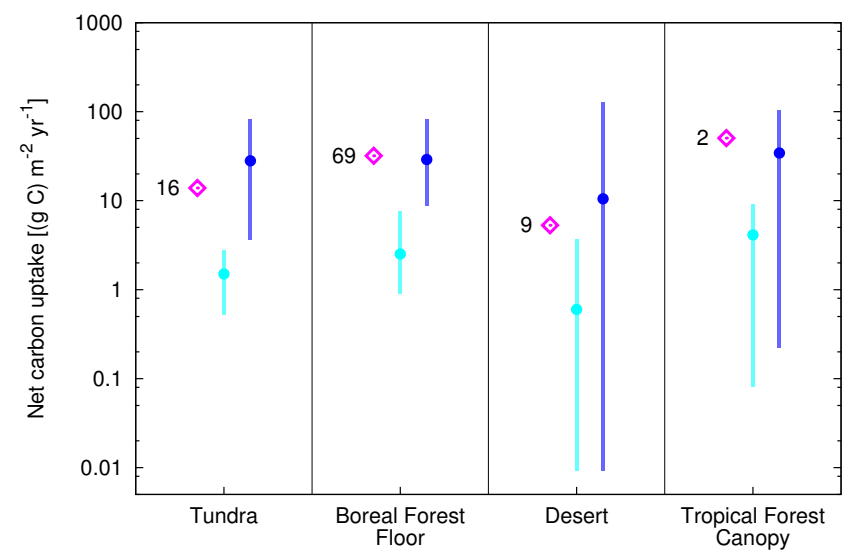

Fig. 7. Comparison of net carbon uptake estimated by the model to observational data. A magenta diamond corresponds to the median of the observed values in the respective biome. The number left to the diamond is the number of observed values. See Table 1 for an overview of the studies on which the observations are based. The light blue colour corresponds to the lower bound of the model estimate and the dark blue colour to the upper bound. The vertical bars represent the range between the most and least productive grid cell in a certain biome, while the dots show the mean productivity of all grid cells in this biome. To be consistent with the measurements from the field studies, only the simulated carbon uptake in the canopy was considered for the biome "Tropical Forest", while for the other biomes only carbon uptake on the ground was considered. The model results are derived from a $2000 \mathrm{yr}$ run with 3000 initial strategies.

peat occurs. This effect is probably most pronounced in peatlands which are not explicitly simulated in the model but included in the boreal forest biome. Given the limitations of the model regarding simulating peat water storage, we think the model estimates for the boreal zone averaged over the whole boreal landscape are reasonable.

\subsection{Sensitivity analysis}

Considering the sensitivity analysis, the general behaviour of the model is plausible. Increasing the Rubisco content per base respiration rate, for example, leads to an increase in net carbon uptake and vice versa (see Table 2). Some effects, however, require further explanation:

1. The turnover parameter affects net carbon uptake based on maximum- and average-weighting in opposite ways. The maximum estimate is as expected: a higher turnover rate leads to lower biomass and therefore lower productivity. The average estimate could be explained by a statistical effect: a higher turnover rate causes the death of many less productive strategies, thereby increasing the average value of productivity compared to lower turnover rates.
2. The ratio $J_{\max } / V_{\mathrm{C}, \max }$ is positively correlated with productivity, which is not self-evident. The correlation is due to the fact that in the model, $J_{\max }$ is derived from a given $V_{\mathrm{C} \text {,max }}$ via the ratio of the two. Hence, changing this ratio only affects $J_{\max }$.

3. The light extinction parameter is negatively correlated with total productivity of lichens and bryophytes. Since the parameter partitions the light input between canopy and soil surface, the ground receives less light if the canopy absorbs more and vice versa. Hence, the impact of this parameter on productivity can be explained by assuming that the decrease in carbon uptake on the ground overcompensates the increase in the canopy.

4. Surface roughness and wind speed are both negatively correlated with the aerodynamic resistance to heat transfer. They consequently have a positive effect on potential evaporation. Therefore the lichens and bryophytes are more frequently desiccated and their productivity decreases.

The overall outcome of the sensitivity analysis of the model is satisfactory. Parameters that describe environmental conditions do not have a large impact on simulated net carbon uptake. This means that it is not absolutely necessary to specify ranges for the environmental parameters in order to obtain a good estimate of the uncertainty of the model results. The model is, however, quite sensitive to parameters that describe tradeoffs. Since these parameters are assumed to have constant values (Sect. 2.2), they should be determined as accurately as possible.

\subsection{Limitations and possible improvements}

Our modelling approach has several limitations which lead to uncertainty regarding the estimate of net carbon uptake. We discuss the different aspects of the limitations of the model, namely spatial resolution, interactions of strategies, parameter uncertainty and simplifying assumptions and we mention possible improvements.

\subsubsection{Spatial resolution}

The spatial resolution of the model grid is too coarse to represent microclimatic or microtopographic features. It has been shown, however, that variation of environmental conditions at the small scale can have an effect on carbon uptake of lichens and bryophytes (e.g. Nungesser, 2003; Lange et al., 1998). This leads to the question if these differences in carbon uptake cancel out for large regions or not. The differences in productivity would probably not cancel out if the relations between climate and carbon uptake were strongly nonlinear. Then, the value of carbon uptake derived from the mean climate of a large region would differ from the mean 
of the values of net carbon uptake based on all the microclimates within that region. In this case, neglecting sub-grid scale variation would lead to systematic biases in the model estimates.

To assess the effect of variation in environmental conditions on the model estimates we performed a sensitivity analysis (see Table 2). The model does not seem to show strong nonlinear behaviour. Compared to the effect of the parameters which describe tradeoffs, the model estimates are rather insensitive to changes in environmental/climatic conditions. Of course, we cannot rule out that small-scale variation has some effect on the model estimates, but the lack of microclimatic and microtopographic data at the global scale makes it impossible to quantify this effect.

\subsubsection{Interactions of strategies}

As shown in Fig. 7, the unknown relative abundance of the strategies (see Sect. 2.3) leads to large differences between the average and the maximum estimates of net carbon uptake. Hence, a significant reduction in the uncertainty of the model estimates could be achieved by quantifying the relative abundance of the strategies. This could be done, for instance, by implementing a scheme that simulates competition between lichen or bryophyte strategies. Such a scheme would be a promising perspective for extending the model. At the moment, however, not enough quantitative data are available about competition and other ecological interactions between different lichen and bryophyte species to integrate these processes into the model.

\subsubsection{Parameter uncertainty}

The model has been shown to be sensitive to the parameters which describe tradeoffs (see Sect. 3.3). For some of these tradeoff parameters, the data available in the literature currently only allow educated guesses. Determining accurate values for these parameters, however, is not difficult per se. Only one study, for instance, has measured both Rubisco content and base respiration rate simultaneously, but in many studies one of them has been determined. Considering the diffusivity of the thallus for $\mathrm{CO}_{2}$, a large body of studies describes the relation between productivity and water content, but we found only one study that quantified the diffusivity for $\mathrm{CO}_{2}$ as a function of water saturation. The latter, however, is much more useful for modelling $\mathrm{CO}_{2}$ diffusion through the thallus on a process basis. Hence, accumulating more empirical data that is suitable to determine the values of the parameters that describe tradeoffs with higher accuracy would be a very efficient way to improve the model. One example of a such a study is the work of Wullschleger (1993), which analyses the ratio between $J_{\max }$ and $V_{\mathrm{C} \text {,max }}$. For a large number of vascular plants this ratio is approximately 2 . The reason for this constant ratio is the fact that a high $J_{\max }$ is not useful if the $V_{\mathrm{C}, \max }$ is low, and vice versa, since productivity is the minimum of the two rates. As both rates are associated with metabolic costs, a tradeoff emerges.

Even if relations between two parameters can be derived from data in a quantitative way, they are usually characterised by some scatter. This is due to additional factors which influence the relation but which are not considered in the model. Differences in specific respiration across strategies, for example, are assumed to result only from differences in the Rubisco content of the strategies or properties that correlate with Rubisco content, such as photosynthetic capacity (Palmqvist et al., 1998). This simple tradeoff is an approximation, as illustrated by the scatter in the relation between Rubisco content and respiration across lichen species (Palmqvist et al., 2002). There seem to be some factors that contribute to respiration in lichens which are not correlated with Rubisco content but which differ across species. It is, however, impractical to implement all these factors into the model, since already the simple tradeoff-relation between Rubisco content and respiration had to be established by educated guess.

\subsubsection{Simplifying assumptions}

To focus on the goal of modelling lichen and bryophyte productivity at the global scale, several simplifying assumptions are made in the model. In the following we discuss some of these assumptions which concern the representation of the organisms in the model as well as the implementation of environmental conditions.

In the model, it is assumed that lichen respiration only depends on the Rubisco content averaged over the total biomass of the organism. Hence, a lichen with a high fraction of algal/cyanobacterial biomass which has a low Rubisco content should have a respiration similar to a lichen with a low fraction of algal/cyanobacterial biomass which has a high $\mathrm{Ru}-$ bisco content because the Rubisco content of the whole total biomass would be similar. This assumption is valid as long as those components of fungal and algal/cyanobacterial biomass which are not related to Rubisco content exhibit similar specific respiration. This might not be the case for all lichen species. Some of the observed variation in the relation between Rubisco content and specific respiration rate (Palmqvist et al., 2002) might be explained by different respiration rates of some components of fungal and al$\mathrm{gal} /$ cyanobacterial tissue which are not correlated with $\mathrm{Ru}-$ bisco content. It is difficult, however, to separately quantify all components of lichen and bryophyte biomass that contribute to respiration.

Another important aspect of lichen and bryophyte physiology is the relation between water content and metabolic activity. Not all facets of this relation were included in the model. Lichens with cyanobacterial photobionts, for instance, need liquid water to activate their metabolism. This physiological constraint seems to be a disadvantage for the cyanolichens since it shortens the time available for carbon 
uptake. The disadvantage, however, could be compensated by some other property of cyanobacteria that is beneficial for the lichens, such as nitrogen fixation, for instance. We cannot account for this property because nutrient limitation is not implemented in the model. Thus, since we cannot consistently represent all distinct properties of cyanobacteria and the associated tradeoffs in our model, we decided not to model cyanolichens explicitly. They may, however, be implicitly simulated by model strategies which have physiological properties similar to cyanolichens.

A further property of the relation between water content and metabolic activity is that in some species, the metabolic activity corresponding to a certain water content is only reached after a time delay (Jonsson et al., 2008; Jonsson Čabrajić et al., 2010; Lidén et al., 2010). The delay is not only species-specific, but it also depends on the length of the preceding dry period (Ried, 1960; Gray et al., 2007; Proctor, 2010). Possible reasons for the delay of photosynthetic activation are the removal of protection mechanisms against drying or the repair of damage resulting from dry conditions (Lidén et al., 2010). These mechanisms are probably associated with carbon costs for the organism, which means that the duration of the delay may be dependent on the amount of carbon invested in repair or protection. Hence, there may be a tradeoff between the benefit of a short delay of activation and the cost of investment into different mechanisms which facilitate a short delay. Therefore, implementing the delay of activation into the model is problematic since the carbon costs of the various protection or repair mechanisms are not known.

As discussed in Sect. 4.2 the model does not explicitly simulate a peat layer. The difficulty with including peat into the model lies in the additional information on environmental conditions that is necessary to predict peat formation. The ability to form an additional water storage which is not accompanied by respiration costs could be assigned to the strategies in the model. If this ability for water storage was set to be independent of environmental conditions, however, the strategies which have the ability of increased water storage would grow everywhere. Since peat formation depends on anoxic conditions, however, it cannot take place everywhere. Thus, productivity would be largely overestimated. Consequently, a model that simulates the hydrological conditions at the global land surface would be needed to determine which regions are suitable for peat formation (see, e.g. Wania et al., 2009). This would add another level of complexity to our model and it would shift the focus from simulating net carbon uptake of lichens and bryophytes towards land surface modelling.

\section{Conclusions and outlook}

In this paper, we present the first process-based model of global net carbon uptake by lichens and bryophytes. The model explicitly simulates processes such as photosynthesis and respiration to quantify exchange flows of carbon between organisms and environment. The predicted global net carbon uptake of 0.34-3.3 (Gt C) $\mathrm{yr}^{-1}$ has a realistic order of magnitude compared to empirical studies (Elbert et al., 2012). The values of productivity correspond to approximately 1$6 \%$ of the global terrestrial net primary productivity (NPP) (Ito, 2011). Furthermore, the model represents the large functional variation of lichens and bryophytes by simulating many different physiological strategies. The performance of these strategies under different climatic regimes is used to narrow the range of possible values of productivity. This method is an efficient way to incorporate the effects of biodiversity on productivity into a vegetation model (Pavlick et al., 2012). The predicted global patterns of surviving strategies are plausible from a qualitative perspective. To further reduce the number of possible values for productivity, competition between the different strategies could be implemented. This would also make the representation of functional variation of lichens and bryophytes in the model more realistic.

The uptake of carbon is only one of many global biogeochemical processes where lichens and bryophytes are involved. They probably also play an important role in the global nitrogen cycle due to the ability of some lichens to fix nitrogen (around $50 \%$ of total terrestrial biological nitrogen fixation) (Elbert et al., 2012). The fixation of nitrogen, however, is relatively expensive from a metabolic viewpoint. It would be interesting to quantify the costs of this process at the global scale and its relation to nutrient limitation.

While nitrogen can be acquired from the atmosphere, phosphorus usually has to be released from rocks by weathering. Thus, lichens and bryophytes might increase their access to phosphorus or other important nutrients by enhancing weathering rates at the surface through exudation of organic acids and complexing agents. Since weathering rates control atmospheric $\mathrm{CO}_{2}$ concentration on geological timescales, lichens and bryophytes might have influenced global climate considerably throughout the history of the earth (Lenton et al., 2012).

Lichens and bryophytes have to invest carbon in order to fuel nitrogen fixating enzymes or produce organic acids necessary for weathering. Hence, these investments could be implemented as a cost function into the model, making it possible to quantify the associated processes at the global scale. Quantifying the carbon budget of lichens and bryophytes can thus be seen as a first step towards estimating the impact of these organisms on other biogeochemical cycles. 


\section{Appendix A}

\section{Additional model output}

a)

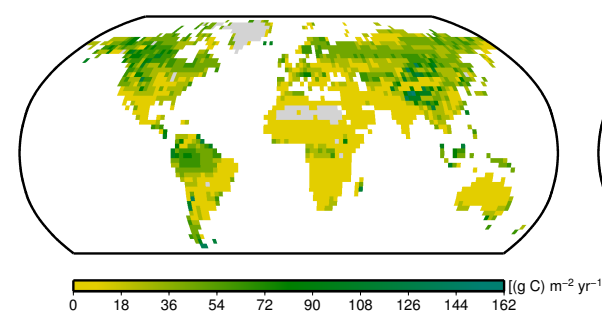

c)

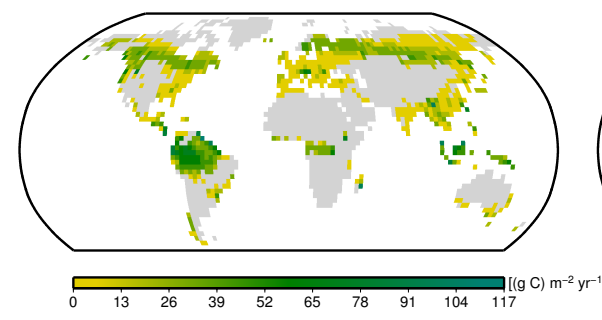

b)

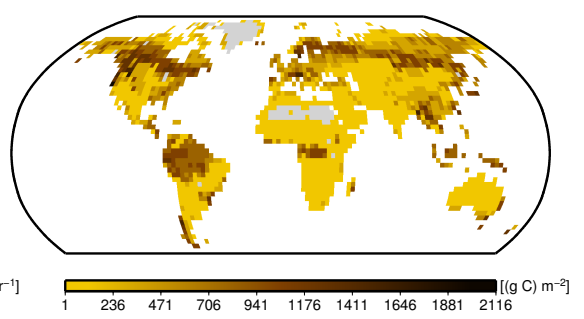

d) Net carbon uptake on ground

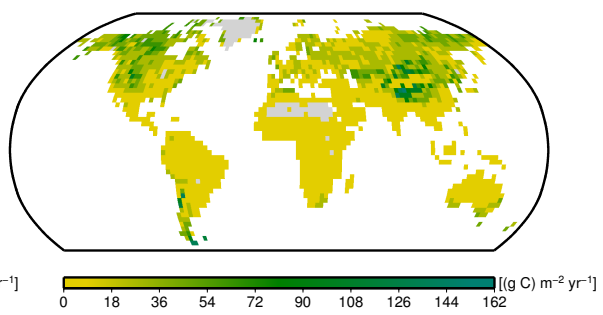

Fig. A1. Global maps of model estimates based on time averages of the last $100 \mathrm{yr}$ of a $2000-\mathrm{yr}$ run with 3000 initial strategies. The estimates shown in (a-d) to are based on the maximum-weighting method while the ones shown in Fig. 5 are based on the average-weighting method. Areas where no strategy has been able to survive are shaded in grey.

a)

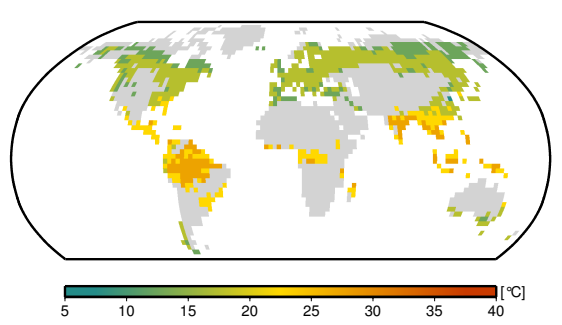

c)

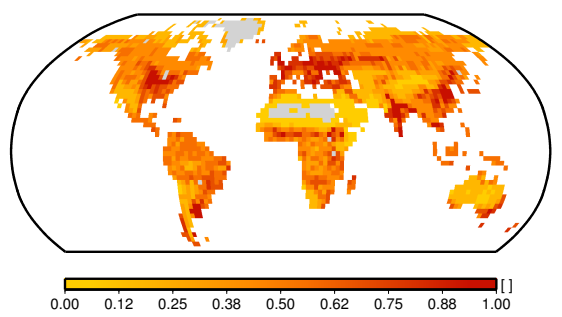

b) Fraction of organisms with CCM

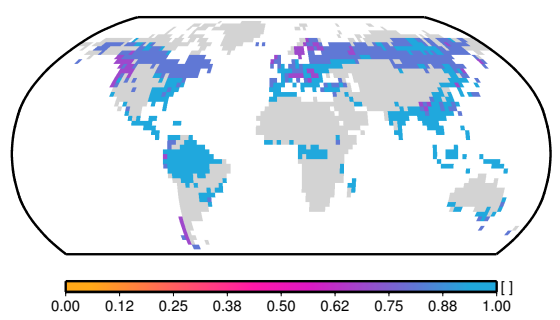

d)

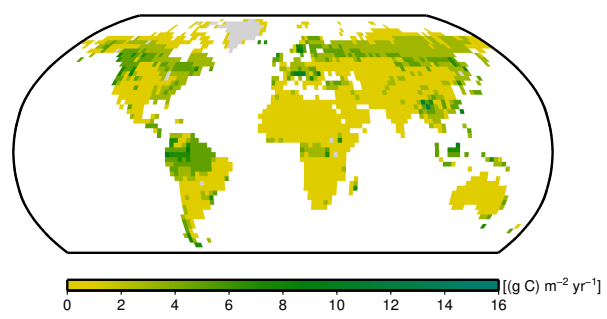

Fig. A2. (a-c) are global maps of model estimates derived by time averages of the last $100 \mathrm{yr}$ of a $2000 \mathrm{yr}$ run with 3000 initial strategies and they are based on the average-weighting method. (a) and (b) show optimum temperature and CCM fraction of lichens and bryophytes living in the canopy, which adds to Fig. 6, where the corresponding estimates for the ground are shown. In (c) the fraction of available area covered by lichens and bryophytes is shown, which is highest in regions where available area on ground is limited due to agriculture. In (d) carbon uptake by lichens and bryophytes is shown for a 400-run with 300 initial strategies. This run is used for the sensitivity analysis. The estimate is based on the average-weighting method. Areas where no strategy has been able to survive are shaded in grey. 


\section{Appendix B}

\section{Model details}

In the following sections, the technical details of the model are explained. Section B1 describes how strategies are generated from parameter ranges. Moreover, references are provided for these parameter ranges. Sections B2 to B7 contain all model equations that are associated with physiological processes of lichens and bryophytes. Furthermore, references are given for the theoretical background and the parameterisation of the equations. The equations are ordered according to the structure of Sect. 2. The values and the units of the parameters and variables used in the model equations are tabulated in Tables B7 to B16. The tables contain references to the respective equations. To make the equations more easily readable, characteristic prefixes are added to the model parameters and the associated tables are structured accordingly. The prefixes, the type of parameter and the associated table(s) can be found in Table B1.

For further details on the implementation of parameters and equations in the model, we refer to the source code of the model, which is available on request.

\section{B1 Generation of strategies}

To account for the large functional variability of lichens and bryophytes, many strategies are generated in the model, which differ from each other in 15 characteristic parameters (see Sect. 2.2). To create the strategies, these 15 characteristic parameters are assigned through randomly sampling ranges of possible values. The parameters and the corresponding ranges are listed in Table B9. Assignment of parameter values is performed in two steps: (a) for each strategy, a set of 15 random numbers uniformly distributed between 0 and 1 is sampled. The random numbers are generated by a Latin Hypercube algorithm (McKay et al., 1979). This facilitates an even sampling of the 15-dimensional space of random numbers, since the space is partitioned into equal subvolumes from which the random numbers are then sampled. (b) The 15 random numbers are then mapped to values from the ranges of the parameters. Since the purpose of the sampling is to represent the whole range of a parameter as evenly as possible, two different mapping methods are used, a linear one for parameters that have only a small range of possible values, and an exponential one for parameters that span more than one order of magnitude.

If the possible values of a parameter $x$ span a relatively small range, a random number between 0 and 1 is linearly mapped to this range according to

$x=N\left(x_{\max }-x_{\min }\right)+x_{\min }$

where $N$ is a random number between 0 and 1. $x_{\max }$ and $x_{\min }$ are the maximum and the minimum value from the range of possible values for the parameter $x$. To ensure that the ranges are sufficiently broad, more extreme values than those found in the literature are used as limits. For this purpose, the mean of the literature-based parameter values is computed. $x_{\min }$ is then calculated by subtracting the distance between the mean and the lowest value found in the literature from this lowest value. $x_{\max }$ is calculated by adding the distance between mean and highest value found in the literature to this highest value. A precondition for this procedure is that the parameter values span a relatively small range, as mentioned above. Otherwise, subtracting the above mentioned distance from the mean would result in negative values.

If the possible values of a parameter span a large range, the mapping from a random number between 0 and 1 to this range is exponential and written as

$x=x_{\min } \mathrm{e}^{N \log \left(\frac{x_{\max }}{x_{\min }}\right)}$

where the symbols have the same meaning as in Eq. (B1). The exponential function is used to represent each order of magnitude of the range equally. If the limits of the range were 1 and 10000, for instance, using Eq. (B1) would result in $90 \%$ of the values lying between 1000 and 10000 . Hence, values from the range 1 to 1000 would be strongly under represented. By using Eq. (B2) this problem is avoided, which is particularly important if the model is run with low numbers of strategies. In this case, the under-representation of strategies with parameter values from the lower end of the range could lead to unrealistic model results. To be consistent with the exponential mapping, the limits of the range are also calculated differently than for Eq. (B1): $x_{\min }$ is assumed to be half the lowest value found in the literature, while $x_{\max }$ is set to the double of the highest value found in the literature.

Additionally, random numbers can be transformed into categorical values. This is done by assigning a lichen or bryophyte to a certain category if the corresponding random number is below a threshold, and otherwise to another category. The threshold is a number between 0 and 1 .

In the following, each of the 15 strategy parameters is shortly described together with references for the range of possible values.

\section{B1.1 Albedo}

The albedo $x_{\alpha}$ of a lichen or bryophyte is assumed to vary from 0 to 1 . The reason for this assumption is that lichens and bryophytes show a large variety of colours and therefore a large range of possible values for the albedo (Kershaw, 1975). For simplicity, each strategy has a fixed value of $x_{\alpha}$. In reality, species can adapt their albedo to different environmental conditions. This can be represented in the model by strategies differing only in the value of $x_{\alpha}$.

A linear mapping is used for the parameter range since we found no reason to assume a priori that a certain value of the albedo is more frequent than the others. 
Table B1. Overview of the nomenclature of parameters and variables in the model.

\begin{tabular}{lll}
\hline Prefix & Parameter or variable & Table(s) \\
\hline$c$ & Natural constant & B7 \\
$p$ & Parameter & B8 (environment) \\
& & B11 (lichens and bryophytes) \\
$x$ & Strategy parameter & B9 \\
$w$ & Tradeoff parameter & B10 \\
$s$ & State variable & B14 \\
$f$ & Flow variable & B15 \\
none & Other variable & B12 (boundary conditions) \\
& & B13 (environment) \\
& & B16 (lichens and bryophytes) \\
\hline
\end{tabular}

\section{B1.2 Specific water storage capacity}

The specific water storage capacity $x_{\Theta_{\max }}$ represents the maximum amount of water per gram carbon a lichen or bryophyte can store (Fig. B1). An exponential mapping is used for the range of possible values.

\section{B1.3 Specific projected area}

The specific projected area $x_{A_{\text {spec }}}$ represents the surface area per gram carbon of a lichen or bryophyte projected onto a plane (Fig. B2). An exponential mapping is used for the range of possible values.

\section{B1.4 Location of growth}

The location of growth $x_{\text {loc }}$ of a lichen or bryophyte is a categorical variable. Two categories are possible: canopy and ground. Since no data could be found about the relative abundance of lichens and bryophytes living in the canopy and the ones living on the ground, the probability for each location of growth is $50 \%$.

\section{B1.5 Threshold saturation and shape of water potential curve}

As described in Sect. 2.1.2, the water potential $\Psi_{\mathrm{H}_{2} \mathrm{O}}$ is an increasing function of the water saturation of the thallus, $\Phi_{\Theta}$, which is described below in Sect. B3.1. $\Psi_{\mathrm{H}_{2} \mathrm{O}}$ has a value of $-\infty$ at zero water content and reaches a maximum value of 0 at a certain threshold saturation (see Fig. B3). This threshold saturation represents the partitioning between water stored in the cells of the thallus and extracellular water. It is described by the parameter $x_{\Phi_{\Theta} \text {,sat }}$. The theoretical limits of $x_{\Phi_{\Theta, \text { sat }}}$ are 0 and 1 , where 0 would mean that the lichen or bryophyte stores all its water extracellularly and 1 would mean that no extracellular storage capacity exists. A lower limit of 0 is physiologically unrealistic. Some mosses have, however, a relatively large capacity to store water extracellularly (Proctor, 2000). Hence, the lower limit of $x_{\Phi_{\Theta} \text { sat }}$ is set to 0.3 An upper limit of 1.0 seems realistic since signif- icant amounts of extracellular water do not seem to occur in many lichens under natural conditions (Nash III, 1996, p. 161). Due to the small range of possible values for $x_{\Phi_{\Theta}, \text { sat }}$, a linear mapping is used for this parameter.

A second parameter, $x_{\Psi_{\mathrm{H}_{2} \mathrm{O}}}$, determines the shape of the water potential curve from zero water content to the threshold saturation. Given a certain value of $x_{\Phi_{\Theta, \text { sat }}}$, the parameter $x_{\Psi_{\mathrm{H}_{2} \mathrm{O}}}$ controls the water content of the thallus in equilibrium with a certain atmospheric vapour pressure deficit. Since the range of possible values of $x_{\Psi_{\mathrm{H}_{2} \mathrm{O}}}$ is quite limited, a linear mapping is used. The limits for this range are estimated using the data points in Fig. B3 and are set to 5.0 and 25.0, respectively. The calculation of the water potential $\Psi_{\mathrm{H}_{2} \mathrm{O}}$ is given below in Sect. B3.3.

Furthermore, the relation between water content and water potential influences the tradeoff between $\mathrm{CO}_{2}$ diffusivity and metabolic activity. This is explained in detail below in Sect. B3.5.

\section{B1.6 Molar carboxylation rate of Rubisco}

The molar carboxylation rate of Rubisco $x_{V_{\mathrm{C}, \max }}$ represents the maximum carboxylation velocity of a Rubisco molecule (Fig. B4). The data are taken from a study that analyses a broad range of photoautotrophs. An exponential mapping is used for the range of possible values.

\section{B1.7 Molar oxygenation rate of Rubisco}

The molar oxygenation rate of Rubisco $x_{V_{0, \max }}$ represents the maximum oxygenation velocity of a Rubisco molecule (Fig. B5). The data are taken from a study that analyses a broad range of photoautotrophs. A linear mapping is used for the range of possible values.

\section{B1.8 Reference maintenance respiration rate and $Q_{10}$ value of respiration}

The specific respiration rate of lichens and bryophytes, $R_{\mathrm{spec}}$, is controlled by two parameters: the reference respiration rate at $10^{\circ} \mathrm{C}, x_{R_{\text {ref }}}$; and the $Q_{10}$ value of respiration, $x_{Q_{10}}$. The distributions of these parameters are shown in Figs. B6 and B7. For $x_{R_{\text {ref }}}$ an exponential mapping is used while for $x_{Q_{10}}$ a linear mapping is used. The limits of $x_{Q_{10}}$ are not calculated by the method described for Eq. (B1) since the resulting range would be physiologically unrealistic. Instead, the values were rounded to the nearest integer. The influences of the two parameters on respiration rate are shown in Fig. B8.

Moreover, the respiration rate is related to Rubisco content and turnover rate of the thallus, as described in Sect. 2.2. The details of these relationships are explained below in Sect. B5.2 and B5.6. 


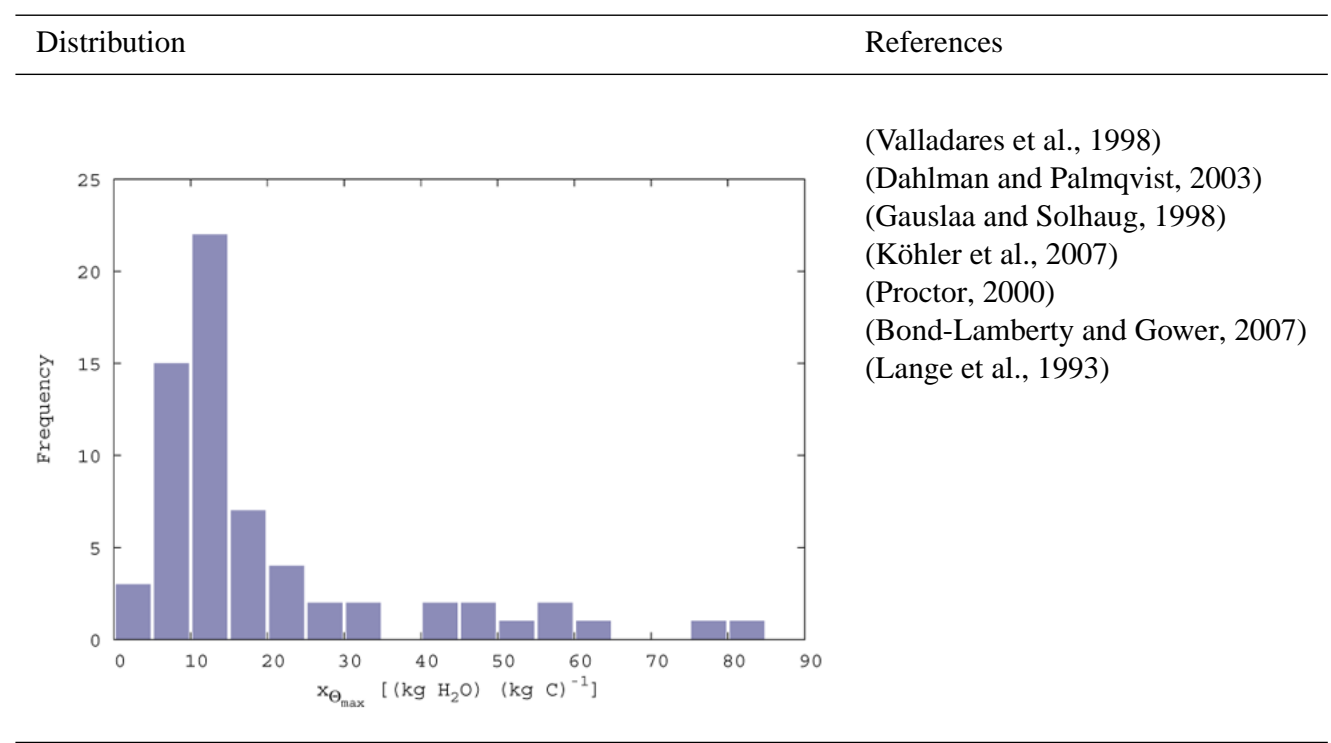

Fig. B1. Overview of the distribution of specific water storage capacity $x_{\Theta_{\max }}$.

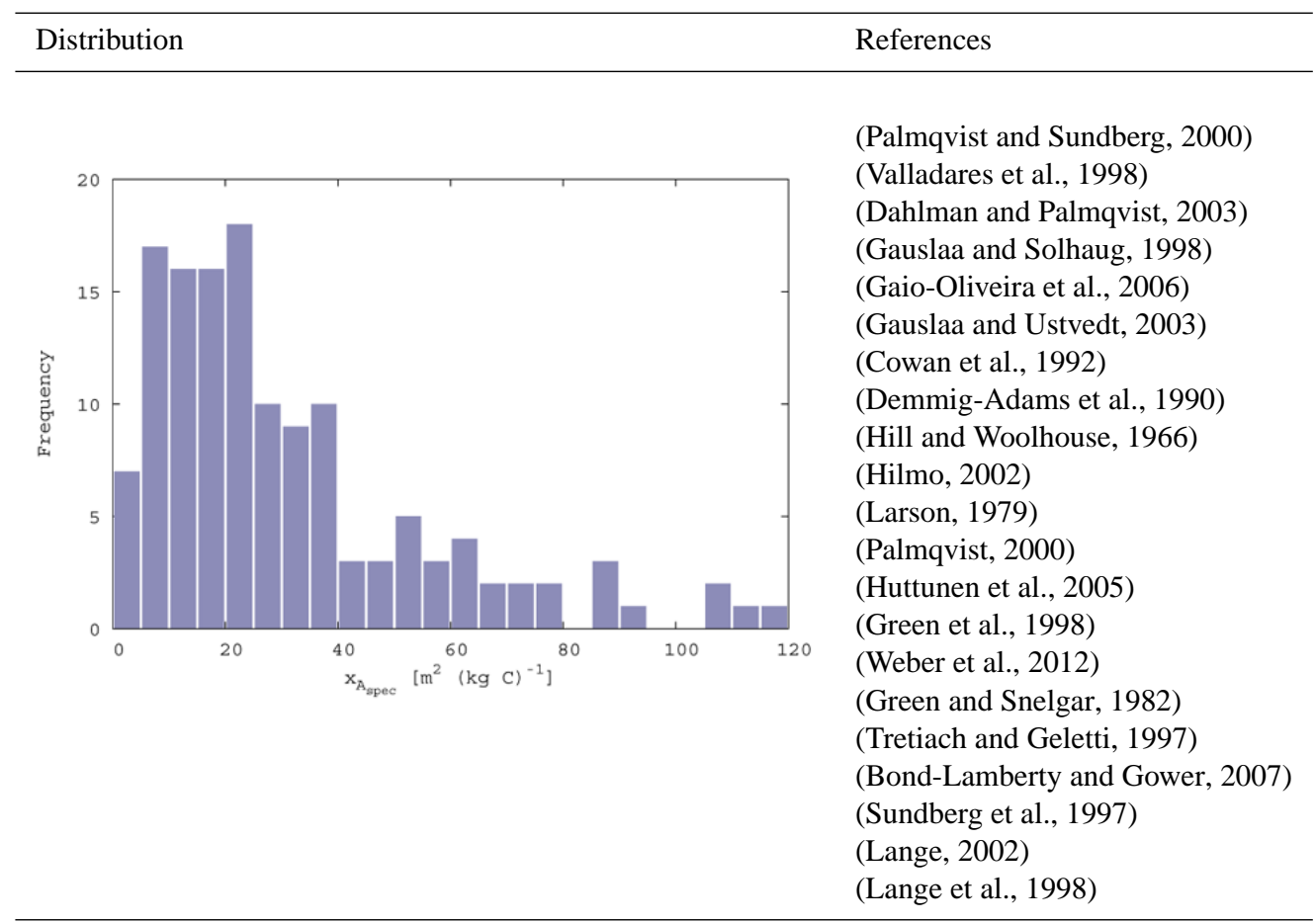

Fig. B2. Overview of the distribution of specific projected area $x_{A_{\text {spec }}}$.

\section{B1.9 Optimum temperature of photosynthesis}

The optimum temperature of photosynthesis $x_{T_{\mathrm{opt}, \mathrm{PS}}}$ represents the temperature at which gross photosynthesis shows a maximum (Fig. B9). A linear mapping is used for the range of possible values. The range is not calculated by the method described for Eq. (B1) since the resulting values would be physiologically unrealistic. Instead, the limits derived from the data were extended by 10 and 5 Kelvin, respectively.

\section{B1.10 Enzyme activation energy of $K_{C}$ and $K_{O}$}

$K_{\mathrm{C}}$ and $K_{\mathrm{O}}$ are the Michaelis-Menten constants of the carboxylation and oxygenation reactions of Rubisco. The enzyme activation energies $x_{E_{\mathrm{a}}, K_{\mathrm{C}}}$ and $x_{E_{\mathrm{a}}, K_{\mathrm{O}}}$ control the temperature response of $K_{\mathrm{C}}$ and $K_{\mathrm{O}}$. The available data 


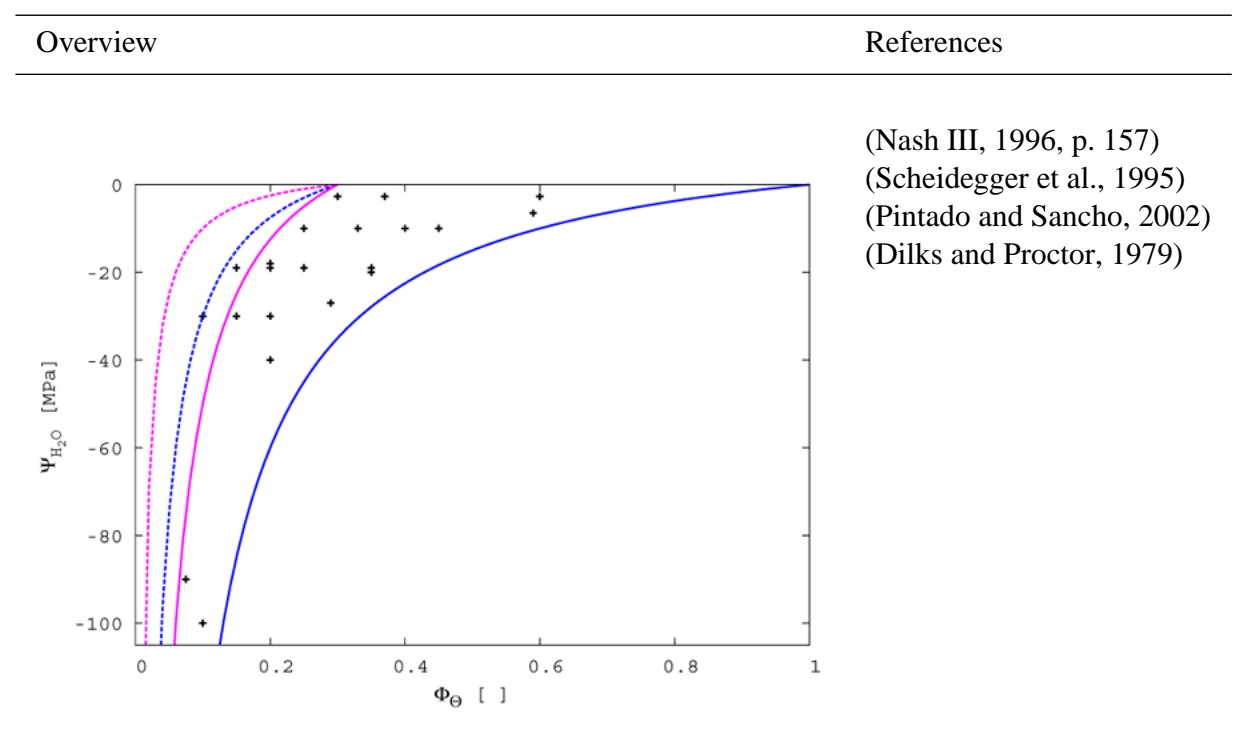

Fig. B3. Water potential $\Psi_{\mathrm{H}_{2} \mathrm{O}}$ as a function of water saturation $\Phi_{\Theta}$. Four example curves are shown. The two blue curves correspond to a value of $x \Psi_{\mathrm{H}_{2} \mathrm{O}}=15.0$, which represents the middle of the range of possible values. The dashed blue curve corresponds to $x_{\Phi_{\Theta} \text {,sat }}=0.3$ and the solid blue curve to $x_{\Phi_{\Theta, \text { sat }}}=1.0$. The two magenta curves correspond to a value of $x_{\Theta, \text { sat }}=0.3$. The dashed magenta curve corresponds to $x_{\Psi_{\mathrm{H}_{2} \mathrm{O}}}=5.0$ and the solid magenta curve to $x_{\Psi_{\mathrm{H}_{2} \mathrm{O}}}=25.0$. The black data points are derived from the studies listed in the right column.

\begin{tabular}{ll}
\hline Distribution & References \\
\hline
\end{tabular}

(Savir et al., 2010)

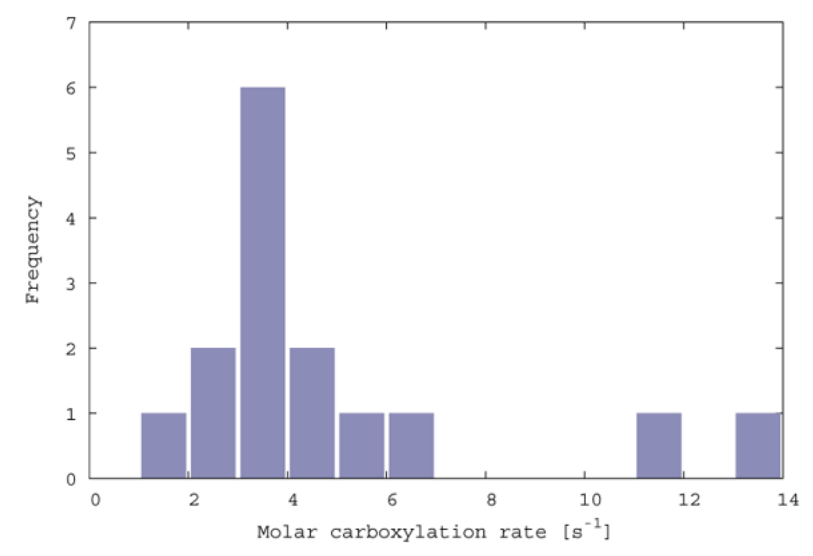

Fig. B4. Overview of the distribution of the molar carboxylation rate of Rubisco.

(see Table B2) are not sufficient to estimate the shapes of the ranges of $x_{E_{\mathrm{a}}, K_{\mathrm{C}}}$ and $x_{E_{\mathrm{a}}, K_{\mathrm{O}}}$. We assume that the parameters do not span several orders of magnitude and hence apply a linear mapping. The limits of the parameter ranges are calculated according to the method described for Eq. (B1).

\section{B1.11 Carbon concentration mechanism (CCM)}

The parameter $x_{\mathrm{CCM}}$ is a categorical variable. It controls if a lichen or bryophyte possesses a carbon concentration mechanism (CCM) or not. If a CCM is present, a part of the energy acquired by the photosystems is not used to fix $\mathrm{CO}_{2}$, but is used instead to increase the $\mathrm{CO}_{2}$ concentration in the photobionts. Since no data could be found about the relative abundance of lichens and bryophytes with and without a CCM, the probability to possess a CCM is set to $50 \%$.

\section{B1.12 Fraction of carbon allocated to growth}

The parameter $x_{\text {alloc }}$ represents the fraction of the sugar reservoir that is allocated to growth each day. $x_{\text {alloc }}$ therefore describes the partitioning of assimilated carbon between 


\begin{tabular}{ll}
\hline Distribution & References \\
\hline
\end{tabular}

(Savir et al., 2010)

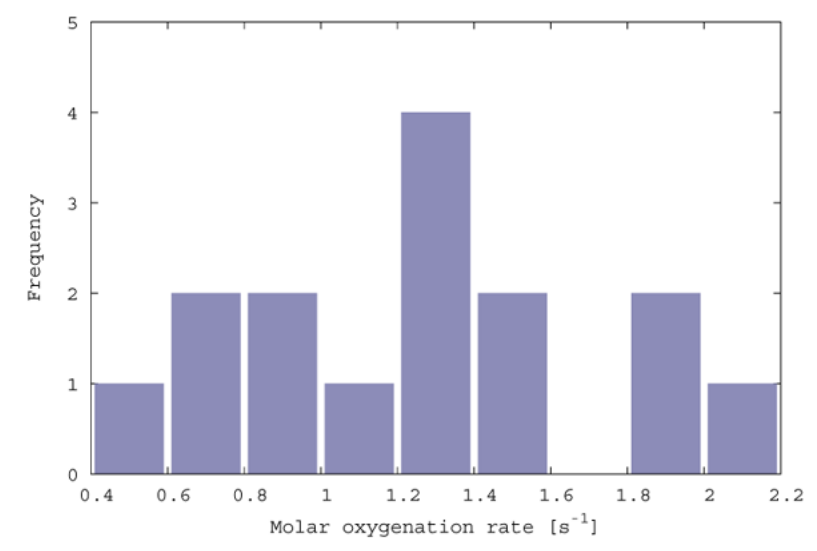

Fig. B5. Overview of the distribution of the molar oxygenation rate of Rubisco.

\begin{tabular}{ll}
\hline Distribution & References \\
\hline
\end{tabular}

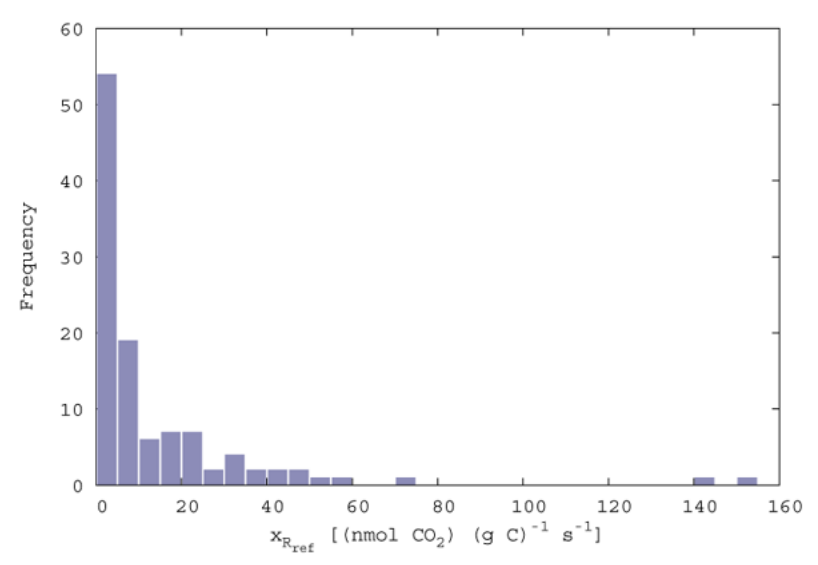

(Nash III, 1996)

(Sundberg et al., 1999)

(Lange and Green, 2005)

(Palmqvist and Sundberg, 2000)

(Sundberg et al., 1997)

(Lange, 2002)

(Lange et al., 1998)

(Uchida et al., 2006)

(Palmqvist, 2002)

(Tretiach and Geletti, 1997)

(Kappen et al., 1989)

(Green et al., 1998)

(Lange et al., 1977)

(Oechel and Collins, 1976)

Fig. B6. Overview of the distribution of the reference maintenance respiration rate at $10^{\circ} \mathrm{C}, x_{R_{\text {ref }}}$.

Table B2. Overview of the enzyme activation energies $E_{\mathrm{a}}$ of the Michaelis-Menten constants $K_{\mathrm{C}}$ and $K_{\mathrm{O}}$.

\begin{tabular}{llr}
\hline \multicolumn{2}{c}{$E_{\mathrm{a}}\left[\mathrm{J} \mathrm{mol}^{-1}\right]$} & Reference \\
$K_{\mathrm{C}}$ & $K_{\mathrm{O}}$ & \\
\hline 79430 & 36380 & (Medlyn et al., 2002) \\
59536 & 35948 & $\prime \prime$ \\
109700 & 14500 & $\prime \prime$ \\
80500 & - & $\prime$ \\
\hline
\end{tabular}

storage pools and biomass. Since we found no reason for a fixed value of $x_{\text {alloc }}$ for all strategies, the possible values are assumed to range from 0 to 1 and a linear mapping is used.

\section{B2 Living environment}

The location of growth of a lichen or bryophyte strongly influences its radiation and precipitation regime and the available area for growth (Sect. 2.1.1). The equations describing these influences are listed and explained below in Sects. B2.1 and B2.2. Further environmental effects on lichens and bryophytes depend not only on the location of growth but also on the biome. These are disturbance frequency, 


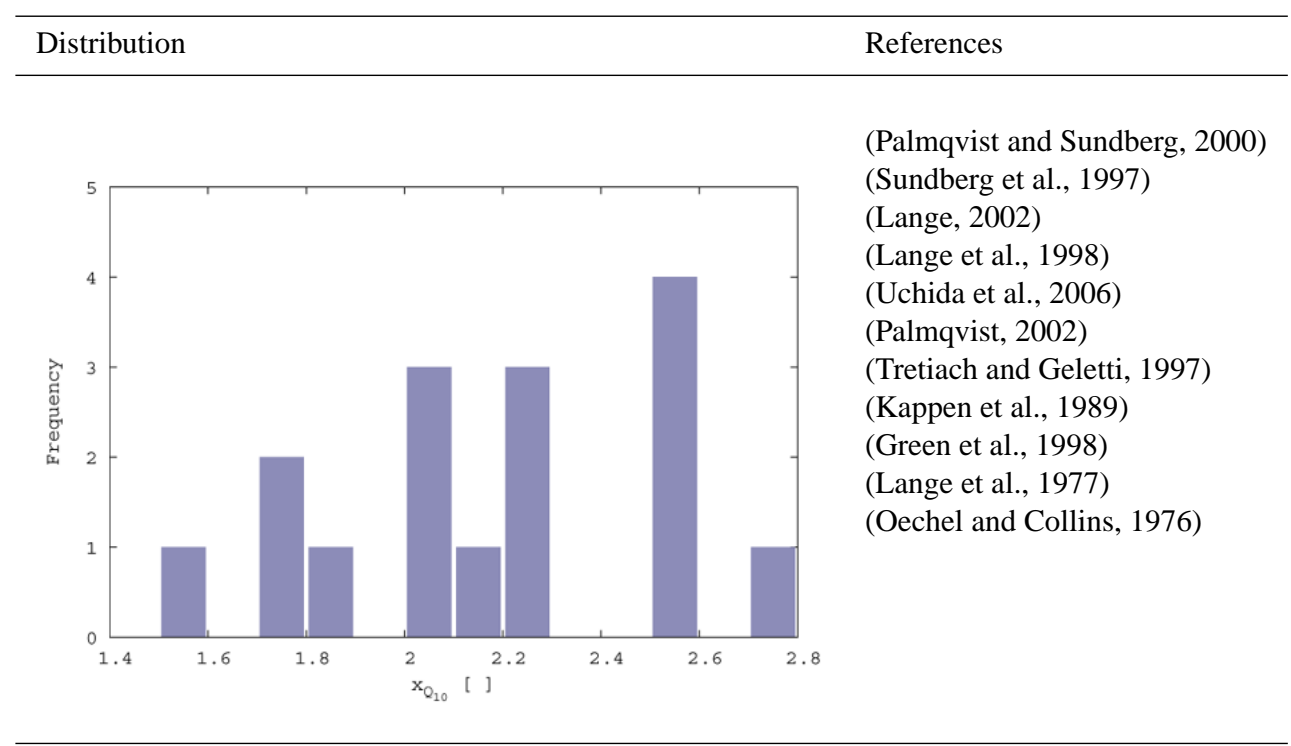

Fig. B7. Overview of the distribution of the $Q_{10}$ value of respiration $x_{Q_{10}}$.

\begin{tabular}{ll}
\hline Overview & References \\
\hline
\end{tabular}

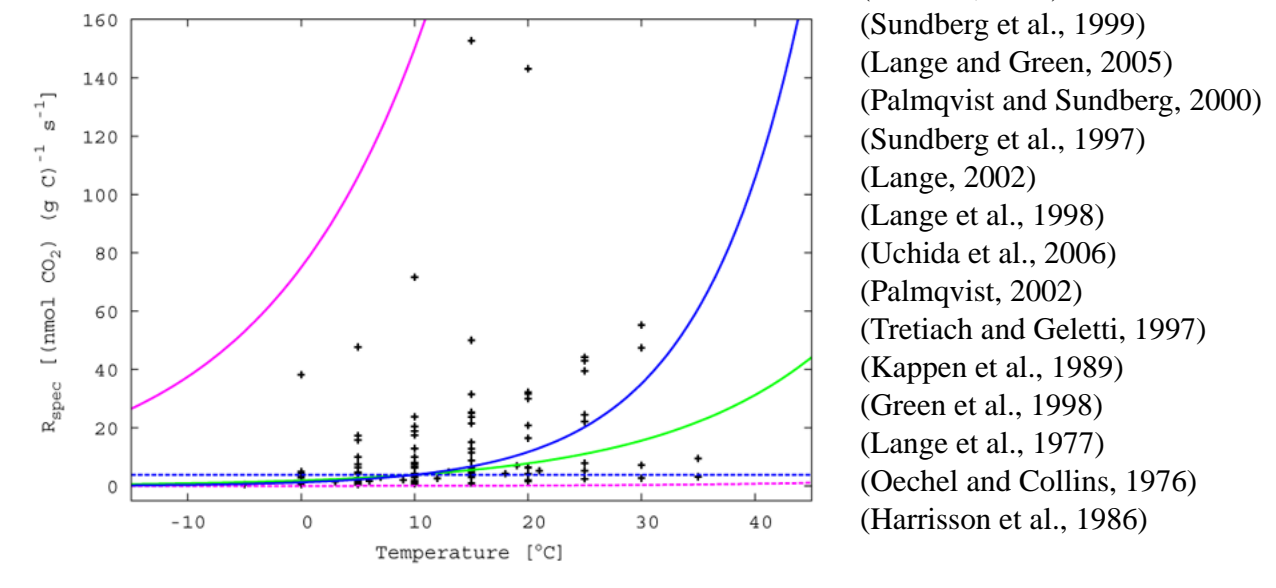

Fig. B8. Influence of reference maintenance respiration $x_{R_{\text {ref }}}$ and $Q_{10}$ value of respiration $x_{Q_{10}}$ on specific respiration rate $R_{\mathrm{spec}}$. The green line shows the response of respiration to temperature for values of $x_{R_{\text {ref }}}$ and $x_{Q_{10}}$, which are both in the middle of their respective ranges. The blue lines show the effect of the $Q_{10}$ value $x_{Q_{10}}$ : the dashed blue line corresponds to $x_{Q_{10}}=1$ while the solid blue line corresponds to $x_{Q_{10}}=3$. The magenta lines illustrate the effect of reference respiration rate $x_{R_{\text {ref }}}$ at $10^{\circ} \mathrm{C}$ : the dashed magenta line corresponds to $x_{R_{\text {ref }}}=1 \times 10^{-7}\left(\mathrm{molCO}_{2}\right)\left(\mathrm{kg} \mathrm{C}^{-1} \mathrm{~s}^{-1}\right.$ while the solid magenta line corresponds to $x_{R_{\mathrm{ref}}}=1.5 \times 10^{-4}\left(\mathrm{~mol} \mathrm{CO}_{2}\right)\left(\mathrm{kg} \mathrm{C}^{-1} \mathrm{~s}^{-1}\right.$. The black data points are derived from the studies listed in the right column.

aerodynamic resistance to heat transfer and soil thermal properties as well as ground heat flux. The equations related to these effects can be found below in Sects. B2.3 to B2.5.

\section{B2.1 Radiation and precipitation regime}

Radiation and precipitation flows are partitioned between the canopy and the ground. This partitioning is described by factors which represent the fraction of the flow that reaches the surface of a lichen or bryophyte. For the partitioning of radiation, Beer's law is used (Bonan, 2008, p. 254) and the associated factors for shortwave radiation $\phi_{\mathrm{rad}_{\mathrm{S}}}$ and longwave radiation $\phi_{\mathrm{rad}_{\mathrm{L}}}$ are calculated by 


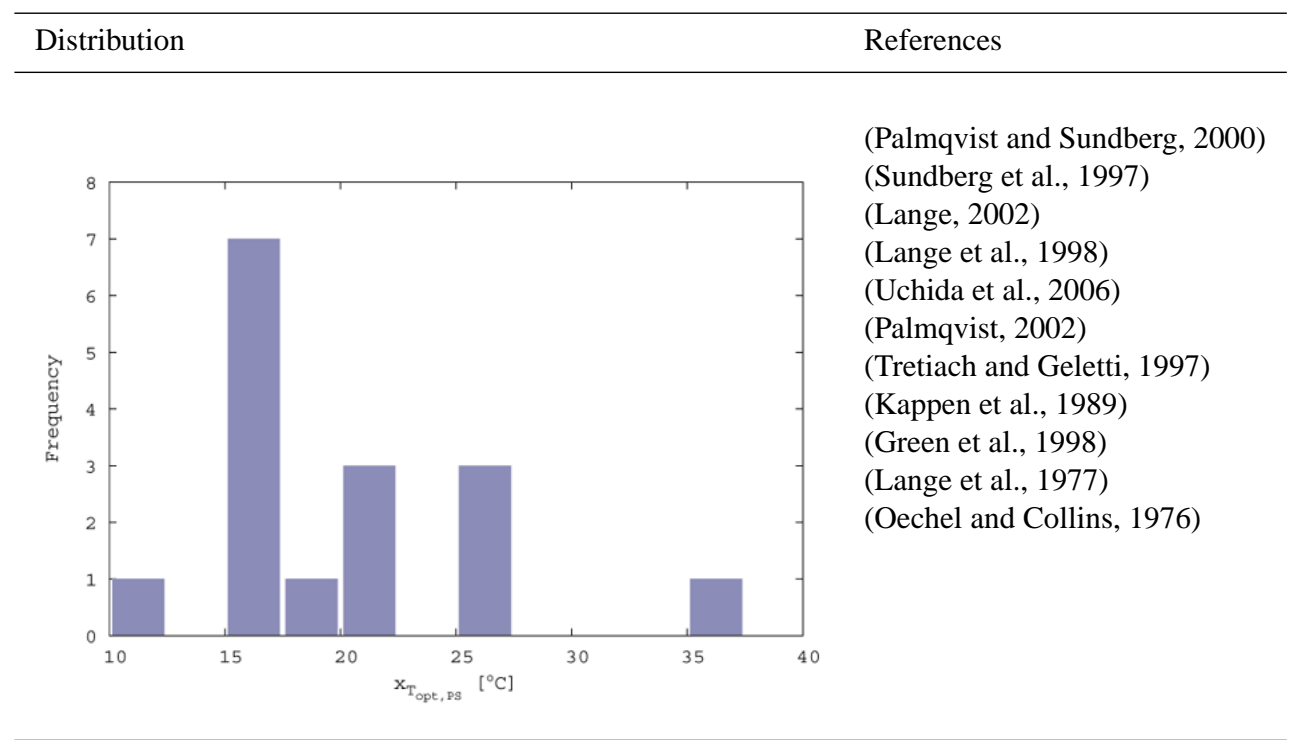

Fig. B9. Overview of the distribution of the optimum temperature of photosynthesis $x_{T_{\mathrm{opt}, \mathrm{PS}}}$.

and

$\phi_{\mathrm{rad}_{\mathrm{L}}}= \begin{cases}p_{\epsilon}\left(1.0-\mathrm{e}^{-p_{\lambda_{\mathrm{I}}}\left(A_{\mathrm{LAI}}+A_{\mathrm{SAI}}\right)}\right) & \text { if organism in canopy } \\ p_{\epsilon} \mathrm{e}^{-p_{\lambda_{\mathrm{I}}}\left(A_{\mathrm{LAI}}+A_{\mathrm{SAI}}\right)} & \text { if organism on ground }\end{cases}$

where $x_{\alpha}$ is the albedo of a lichen or bryophyte for shortwave radiation and $p_{\epsilon}$ is the emissivity of an organism for longwave radiation. $p_{\lambda_{\mathrm{s}}}$ and $p_{\lambda_{1}}$ are extinction coefficients for shortwave radiation (Bonan, 2008, p. 254) and longwave radiation (Kustas and Norman, 2000), respectively. $A_{\text {LAI }}$ and $A_{\text {SAI }}$ are leaf area index (LAI) and stem area index (SAI).

The partitioning of precipitation is assumed to be a linearly decreasing function of LAI and the fraction of precipitation that reaches a lichen or bryophyte is

$\phi_{\text {prec }}= \begin{cases}p_{\eta_{\text {rain }} \frac{A_{\mathrm{LAI}}}{p_{\mathrm{LAI}}}} & \text { if organism in canopy } \\ 1.0-\frac{A_{\mathrm{LAI}}}{p_{\mathrm{LAI} \text { max }}} & \text { if organism on ground }\end{cases}$

where $p_{\eta_{\text {rain }}}$ is the interception efficiency of the canopy for precipitation, $A_{\mathrm{LAI}}$ is leaf area index and $p_{\mathrm{LAI}_{\max }}$ is the maximum LAI in the data set, both derived from Bonan et al. (2002).

\section{B2.2 Available area}

The available area for growth of a lichen or bryophyte per $\mathrm{m}^{2}$ ground depends on its location of growth, which is either the ground or the canopy (see Sect. 2.1.1). The available area on the ground, $A_{\text {ground,max }}$, is determined by two factors: (a) the amount of bare soil, which means soil surface that is not occupied by herbaceous vegetation, such as grasses or crops. Bare soil area is highest in non-vegetated areas such as deserts or mountain tops, and also in forested areas since the ground is not occupied there per se. For simplicity, the area occupied by tree trunks is neglected. The second determining factor is (b) leaf area index (LAI), which affects the available area on ground through leaf fall by trees: under dense canopies (high LAI), a constantly renewed litter layer impedes the growth of lichens and bryophytes. Under open canopies (low LAI), a certain fraction of the soil surface is not affected by leaf fall, thus providing area for growth.

The available area on the ground is calculated according to

$A_{\text {ground, } \max }=\min \left(A_{\text {baresoil }}, 1.0-\frac{A_{\mathrm{LAI}}}{p_{\mathrm{LAI}_{\max }}}\right)$

where $A_{\text {baresoil }}$ is the area of soil not occupied by herbaceous vegetation derived from Bonan et al. (2002). $A_{\text {LAI }}$ is leaf area index and $p_{\mathrm{LAI}_{\max }}$ is the maximum LAI in the data set.

The available area in the canopy, $A_{\text {canopy, max }}$, is assumed to be the sum of LAI and stem area index (SAI). This means that the strategies are assumed to grow on all parts of the canopy, which means stems (i.e. trunks and twigs) and leaves. Growth on leaves, however, is assumed to be possible only for evergreen vegetation (see Sect. B2.3 for details). Thus, the available area for growth is written as

$A_{\text {canopy, } \max }=A_{\mathrm{LAI}}+A_{\mathrm{SAI}}$

where $A_{\mathrm{SAI}}$ is SAI.

The surface area of a lichen or bryophyte per $\mathrm{m}^{2}$ ground, $A_{\text {thallus }}$, is calculated according to

$A_{\text {thallus }}= \begin{cases}\min \left(x_{A_{\text {spec }}} s_{\mathrm{B}}, A_{\text {canopy, max }}\right) & \text { if organism in canopy } \\ \min \left(x_{A_{\text {spec }}} s_{\mathrm{B}}, A_{\text {ground, max }}\right) & \text { if organism on ground }\end{cases}$

where $x_{A_{\text {spec }}}$ is the specific area of a lichen or bryophyte, $s_{\mathrm{B}}$ is the biomass per $\mathrm{m}^{2}$ ground and $A_{\text {canopy, max }}$ and $A_{\text {ground, max }}$ 
Table B3. Overview of the disturbance intervals $\tau_{\mathrm{veg}}$ of different biomes. The ${ }^{\star}$-symbol means that values from other biomes are used, since no original references could be found. A "_" in the column "Leaves" means that lichens and bryophytes cannot grow on the leaves of the respective vegetation type. The values are derived by calculating the median of a set of values from the literature. These are shown in Tables B4 and B5 below. Disturbance intervals for stems \& ground are calculated as the minimum of the median of fire intervals, the median of treefall intervals and the herbivory interval, if present (see Tables B4 and B5).

\begin{tabular}{|c|c|c|}
\hline \multirow[t]{2}{*}{ Biome } & \multicolumn{2}{|c|}{$\tau_{\text {veg }}[$ years $]$} \\
\hline & Stems \& ground & Leaves \\
\hline Tropical rainforest & 100 & 1.4 \\
\hline Tropical dry forest & 32 & - \\
\hline Tropical needleleaf forest & $100^{\star}$ & $6.0^{\star}$ \\
\hline Temperate broadleaf forest & 100 & - \\
\hline Temperate evergreen forest & $100^{\star}$ & $1.4^{\star}$ \\
\hline Boreal forest & 100 & 6.0 \\
\hline Savanna & 5 & - \\
\hline Grassland, desert \& tundra & 15 & - \\
\hline Mediterranean vegetation & 50 & 2.3 \\
\hline
\end{tabular}

are the available area in the canopy and on the ground, respectively. This means that $A_{\text {thallus }}$ is limited by the available area. Since biomass is related to surface area via the specific area, also biomass is limited by available area.

The fraction of available area that is covered by a lichen or bryophyte is described by the variable $\Phi_{\text {area }}$. This variable is necessary to obtain flows per $\mathrm{m}^{2}$ ground instead of $\mathrm{m}^{2}$ lichen or bryophyte. If the respiration flow per $\mathrm{m}^{2}$ thallus is known, for instance, multiplication by $\Phi_{\text {area }}$ gives the respiration flow per $\mathrm{m}^{2}$ ground. This is important because the purpose of the model is to predict global flows of carbon and water per $\mathrm{m}^{2}$ ground. $\Phi_{\text {area }}$ is calculated according to

$\Phi_{\text {area }}= \begin{cases}\frac{A_{\text {thallus }}}{\max \left(A_{\text {canopy,max }}, 1.0\right)} & \text { if organism in canopy } \\ A_{\text {thallus }} & \text { if organism on ground }\end{cases}$

where $A_{\text {thallus }}$ is the surface area of a lichen or bryophyte and $A_{\text {canopy, max }}$ is the available area in the canopy. The maximum function is used in Eq. (B9) to ensure that the reference for the exchange flows is a $\mathrm{m}^{2}$ ground, not a $\mathrm{m}^{2}$ of lichen or bryophyte. If, for example, the available area in the canopy was $0.8 \mathrm{~m}^{2}$ per $\mathrm{m}^{2}$ ground and the thallus area was $0.6 \mathrm{~m}^{2}$ per $\mathrm{m}^{2}$ ground, the exchange flows per $\mathrm{m}^{2}$ ground should be multiplied by a $\Phi_{\text {area }}$ of 0.6 , and not by $0.6 / 0.8$.

\section{B2.3 Disturbance interval}

The disturbance interval $\tau_{\text {veg }}$ is assigned according to biome and location of growth (see Table B3). Disturbance leads to an instantaneous loss of biomass. The following processes are represented in the model:
1. Fire or tree fall. In this case the biomass of a strategy is set back to the initial value each time a disturbance takes place. Fire and tree fall are assumed to affect both strategies living on the ground as well as those living in the canopy.

2. Leaf fall, which affects only strategies living in the canopy. As described in Sect. B2.2, strategies in the canopy are assumed to live on trunks and twigs as well as on leaves. If leaf fall takes place, the biomass of a strategy is reduced to the fraction that is sustained by stem area, while the fraction that was growing on the leaf area is set to zero. Growth on leaves from deciduous forests is precluded since the leaves are all shed at the same time of year. Although leaf fall is not a disturbance, its effect on biomass is represented similarly to a disturbance event in the model. Hence, leaf fall is listed here.

3. Herbivory, which is restricted in the model to largescale grazing by herds of animals. It is thus assumed to affect only strategies living on the ground of savanna, grassland, desert or tundra. Other types of herbivory, which take place on smaller scales and also more frequently, are included in the biomass loss term (e.g. epiphytic herbivory by snails).

The implementation of disturbance used here leads to an oscillation of biomass over time, with a slow build-up between disturbance events and an instantaneous reduction during the event. Such an oscillation is unrealistic on the scale of a grid cell where the ecosystem is usually in a "shifting mosaic steady state". This means that fires, tree fall and leaf fall do not affect the whole grid cell but only a small fraction of it. The purpose of the model, however, is to predict mean biomass. It does not matter if this mean value is derived by averaging over many individuals in a grid cell, which are in different states of a disturbance cycle, or if the mean is derived by the time average over a whole cycle for just one individual. Hence, if the averaging period is at least as long as one disturbance interval, the mean value is correct.

\section{B2.4 Aerodynamic resistance to heat transfer}

The aerodynamic resistance to heat transfer, $r_{\mathrm{H}}$, controls exchange flows of heat between the surface of lichens or bryophytes and the atmosphere. It is calculated according to Allen et al. (1998):

$r_{\mathrm{H}}=\frac{\log \left(\frac{p_{\Delta_{\mathrm{u}}}-\Delta_{\mathrm{d}}}{z_{0}}\right) \log \left(\frac{p_{\Delta_{\mathrm{u}}}-\Delta_{\mathrm{d}}}{z_{0, h}}\right)}{p_{\kappa}^{2} u}$

where $p_{\kappa}$ is the von Karman constant, $u$ is near surface wind speed, $p_{\Delta_{\mathrm{u}}}$ is the measurement height for wind speed, $\Delta_{\mathrm{d}}$ is the displacement height for wind speed, and $z_{0}$ and $z_{0, \mathrm{~h}}$ are the roughness length of momentum and humidity, respectively. The stability corrections which are used in some cases 
Table B4. References for the disturbance intervals $\tau_{\text {veg }}$ [years] of different biomes regarding fire and tree fall. A "-" means that the corresponding type of disturbance probably does not play a significant role for lichens and bryophytes living in the biome.

\begin{tabular}{|c|c|c|c|c|}
\hline \multirow[t]{2}{*}{ Biome } & \multicolumn{2}{|r|}{ Fire } & \multicolumn{2}{|r|}{ Treefall } \\
\hline & $\tau_{\text {veg }}$ & Reference & $\tau_{\text {veg }}$ & Reference \\
\hline Tropical rainforest & $\begin{array}{l}>100 \\
>800\end{array}$ & $\begin{array}{l}\text { (Mouillot and Field, 2005) } \\
\text { (Thonicke et al., 2001) }\end{array}$ & $\begin{array}{l}\sim 100 \\
\sim 50 \\
138 \\
83 \\
\sim 240\end{array}$ & $\begin{array}{l}\text { (Lawton and Putz, 1988) } \\
\text { (Martinez-Ramos et al., 1988) } \\
\text { (Bongers et al., 1988) } \\
\text { (Chandrashekara and Ramakrishnan, 1994) } \\
\text { (Jans et al., 1993) }\end{array}$ \\
\hline Tropical dry forest & 32 & (Martin and Fahey, 2006) & 98 & (Ferreira de Lima et al., 2008) \\
\hline $\begin{array}{l}\text { Temperate broad- } \\
\text { leaf forest }\end{array}$ & $\begin{array}{l}>100 \\
>200\end{array}$ & $\begin{array}{l}\text { (Mouillot and Field, 2005) } \\
\text { (Thonicke et al., 2001) }\end{array}$ & $\begin{array}{l}\sim 100 \\
\sim 45 \\
\sim 145\end{array}$ & $\begin{array}{l}\text { (Turner et al., 1993) } \\
\text { (Payette et al., 1990) } \\
\text { (Tanaka and Nakashizuka, 1997) }\end{array}$ \\
\hline Boreal forest & $\begin{array}{l}\sim 100 \\
140 \\
>100 \\
\sim 100\end{array}$ & $\begin{array}{l}\text { (Angelstam, 1998) } \\
\text { (Harvey et al., 2002) } \\
\text { (Mouillot and Field, 2005) } \\
\text { (Thonicke et al., 2001) }\end{array}$ & 303 & (Foster and Reiners, 1986) \\
\hline Savanna & $\begin{array}{l}\sim 5 \\
\sim 5\end{array}$ & $\begin{array}{l}\text { (Mouillot and Field, 2005) } \\
\text { (Thonicke et al., 2001) }\end{array}$ & - & - \\
\hline $\begin{array}{l}\text { Grassland, } \\
\text { desert \& tundra }\end{array}$ & - & - & - & - \\
\hline $\begin{array}{l}\text { Mediterranean } \\
\text { vegetation }\end{array}$ & $\sim 50$ & (Thonicke et al., 2001) & - & - \\
\hline
\end{tabular}

Table B5. References for the disturbance intervals $\tau_{\text {veg }}$ [years] of different biomes regarding leaf fall and herbivory. A “-” means that the corresponding type of disturbance probably does not play a significant role for lichens and bryophytes living in the biome. The value for herbivory was estimated by best guess due to lack of data.

\begin{tabular}{llll}
\hline Biome & & \multicolumn{1}{c}{ Leaf fall } & $\begin{array}{l}\text { Herbivory } \\
\tau_{\text {veg }}\end{array}$ \\
\hline Tropical rainforest & 1.4 & (Condit et al., 1996) & - \\
& 1.4 & (Reich et al., 1998) & \\
& 2.0 & (Walters and Reich, 1999) &
\end{tabular}

\begin{tabular}{llll}
\hline Tropical dry forest & - & - & - \\
\hline Temperate broadleaf forest & - & - & - \\
& & & \\
\hline Boreal forest & 5.8 & (Withington et al., 2006) & - \\
& 6.2 & (Reich et al., 1998)
\end{tabular}

\begin{tabular}{llll}
\hline Savanna & - & - & 15 \\
& & & 15 \\
\hline Grassland, desert \& tundra & - & - & - \\
\hline Mediterranean vegetation & 1.6 & $\begin{array}{l}\text { (Navas et al., 2003) } \\
\text { (Escudero and Mediavilla, 2003) }\end{array}$ & \\
\hline
\end{tabular}


to make Eq. (B10) more accurate (Liu et al., 2007) are neglected here for simplicity.

The roughness length $z_{0}$ describes the impact of the surface on the flow of air above it. $z_{0}$ is parameterised as one of three possible values (Stull, 1988, p. 380):

$z_{0}= \begin{cases}p_{z_{0, \mathrm{canopy}}}, & \text { if organism in canopy } \\ p_{z_{0, \mathrm{floor}},}, & \text { if organism on forest floor } \\ p_{z_{0, \mathrm{GDT}}}, & \text { if organism on ground outside forest }\end{cases}$

Note that this parameterisation implies that large-scale structures such as forests dominate the aerodynamic properties of the surface. The shape of lichens or bryophytes growing on that surface is assumed to have only a small impact on the roughness length and is consequently neglected in the model.

$z_{0}$ is related to $z_{0, \mathrm{~h}}$ according to

$z_{0, h}=p_{z_{0, m h}} z_{0}$

where $p_{z_{0, m h}}$ is the ratio between the roughness length of humidity and momentum (Allen et al., 1998).

The displacement height is related to roughness length via

$\Delta_{\mathrm{d}}=p_{z_{0, \mathrm{~d}}} z_{0}$

where $p_{z_{0, \mathrm{~d}}}$ is the ratio between displacement height and roughness length. The value of $p_{z 0, \mathrm{~d}}$ is derived from the relations $\Delta_{\mathrm{d}}=2 / 3$ vegetation height and $z_{0}=0.123$ vegetation height. These relations are adapted from Allen et al. (1998) and represent rough approximations. Determining average values for displacement height for the each biome, however, would be beyond the scope of this study.

\section{B2.5 Soil thermal properties}

The ground heat flux $f_{\mathrm{G}}$ affects the energy balance of a lichen or bryophyte if the organism is living on the ground. Typically, the soil temperature is lower than the surface temperature during the day and higher during the night, leading to heat exchange between thallus and soil. If a lichen or bryophyte is living in the canopy, heat exchange with the soil is neglected since it is assumed that thallus of the organism is in a thermal equilibrium with the canopy layers below. The effect of location of growth on $f_{\mathrm{G}}$ is represented by the variable $\chi_{\mathrm{G}}$ :

$\chi_{\mathrm{G}}= \begin{cases}0 & \text { if organism in canopy } \\ 1 & \text { if organism on ground }\end{cases}$

The ground heat flux is not only affected by the temperature gradient between thallus and soil, but also by soil properties: the soil heat capacity $C_{\text {soil }}$ and the thermal conductivity of the soil $k_{\text {soil }}$ (Lawrence and Slater, 2008; Anisimov et al., 1997; Peters-Lidard et al., 1998). Since they depend on the average water content of the soil, desert soils are parameterised differently from non-desert soils in the model:

$C_{\text {soil }}= \begin{cases}p_{C_{\text {soil, }},}, & \text { if organism in desert } \\ p_{C_{\text {soil, }},}, & \text { if organism not in desert }\end{cases}$

$k_{\text {soil }}= \begin{cases}p_{k_{\text {soil, }},}, & \text { if organism in desert } \\ p_{k_{\text {soil, }},}, & \text { if organism not in desert }\end{cases}$

\section{B3 Water relations}

The water saturation of a lichen or bryophyte is defined in Sect. B3.1. It controls three physiological properties: diffusivity for $\mathrm{CO}_{2}$ (Sect. B3.2), water potential (Sect. B3.3), and metabolic activity (Sect. B3.4).

\section{B3.1 Water saturation}

The water storage capacity $\Theta_{\max }$ describes how much water a lichen or bryophyte can store per $\mathrm{m}^{2}$ ground. $\Theta_{\max }$ is assumed to be proportional to biomass per $\mathrm{m}^{2}$ ground:

$\Theta_{\max }=\frac{x_{\Theta_{\max }} s_{\mathrm{B}}}{c_{\rho_{\mathrm{H}_{2} \mathrm{O}}}}$

where $x_{\Theta_{\max }}$ is the specific water storage capacity, $s_{\mathrm{B}}$ is the biomass of a lichen or bryophyte and $c_{\rho_{\mathrm{H}_{2} \mathrm{O}}}$ is the density of liquid water. The water saturation $\Phi_{\Theta}$ is then calculated as the ratio of the actual water content $s_{\Theta}$ and the water storage capacity:

$\Phi_{\Theta}=\frac{s_{\Theta}}{\Theta_{\max }}$

\section{B3.2 Diffusivity for $\mathrm{CO}_{2}$}

The diffusivity of the thallus for $\mathrm{CO}_{2}$ is represented by the variable $D_{\mathrm{CO}_{2}}$. It decreases from a maximum value to a minimum value with increasing water saturation (see Fig. B10) and it is calculated according to

$D_{\mathrm{CO}_{2}}=\left(w_{D_{\mathrm{CO}_{2}, \text { max }}}-w_{D_{\mathrm{CO}_{2}, \text { min }}}\right)\left(1.0-\Phi_{\Theta}\right)^{w_{\mathrm{CO}_{2}}}+w_{D_{\mathrm{CO}_{2}, \text { min }}}$

where $w_{D_{\mathrm{CO}_{2}} \text {, min }}$ is the minimum value of $\mathrm{CO}_{2}$ diffusivity, $w_{D_{\mathrm{CO}_{2} \text {, max }}}$ is the maximum value of $\mathrm{CO}_{2}$ diffusivity, $\Phi_{\Theta}$ is the water saturation of the thallus and $w_{\mathrm{DO}_{2}}$ is a parameter that determines the shape of the diffusivity curve. $w_{D_{\mathrm{CO}_{2}}}$ is estimated using the data points in Fig. B10, while $w_{D_{\mathrm{CO}_{2} \text {, min }}}$ and $w_{D_{\mathrm{CO}_{2} \text {, max }}}$ are taken from the literature (Cowan et al., 1992).

The relation between $D_{\mathrm{CO}_{2}}$ and $\Phi_{\Theta}$ is an important component of the tradeoff between $\mathrm{CO}_{2}$ diffusivity and metabolic activity. This is explained below in Sect. B3.5.

\section{B3.3 Water potential}

The water potential $\Psi_{\mathrm{H}_{2} \mathrm{O}}$ is an increasing function of water saturation and it is calculated according to

$\Psi_{\mathrm{H}_{2} \mathrm{O}}=\min \left(0.0, x_{\Psi_{\mathrm{H}_{2} \mathrm{O}}}\left(1.0-\frac{x_{\Phi_{\Theta, \text { sat }}}}{\Phi_{\Theta}}\right)\right)$ 


\begin{tabular}{ll}
\hline Overview & Reference \\
\hline
\end{tabular}

(Cowan et al., 1992)

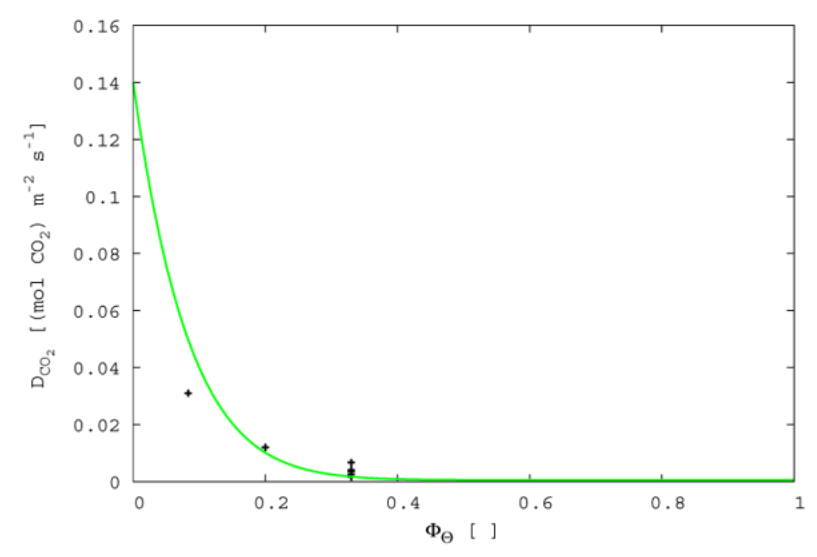

Fig. B10. Diffusivity for $\mathrm{CO}_{2}, D_{\mathrm{CO}_{2}}$, as a function of water saturation $\Phi_{\Theta}$. The black data points are derived from the study listed in the right column.

where $\Phi_{\Theta}$ is the water saturation. The parameter $x_{\Phi_{\Theta, \text { sat }}}$ is the threshold saturation. If $\Phi_{\Theta}$ is above this threshold, all cells in the thallus are fully turgid. Additional water is assumed to be stored extracellularly. $x_{\Psi_{\mathrm{H}_{2} \mathrm{O}}}$ is a parameter that determines the shape of the water potential curve. The parameters of the water potential curve are discussed in further detail in Sect. B1.5 and the curve is shown in Fig. B3. The influence of the relation between water saturation and water potential on the tradeoff between $\mathrm{CO}_{2}$ diffusivity and metabolic activity is explained below in Sect. B3.5.

\section{B3.4 Metabolic activity}

The metabolic activity of a lichen or bryophyte is represented by the variable $\Phi_{\text {act }}$ and it relates the processes photosynthesis and respiration to the water content of the organism (Nash III, 1996, p. 157). The papers of Lange (1980, 2002), for instance, show how dark respiration increases with water content at constant temperature, while the studies by Jonsson Čabrajić et al. (2010); Williams and Flanagan (1998) show an increase of photosynthetic activity/capacity with water content. A common feature of these experiments with different species is that dark respiration as well as photosynthetic activity saturate and assume a constant value above a species-specific threshold water content. The shape of the activity curve from zero water content to this threshold water content is nonlinear and it shows species-specific variation. The extent of the nonlinearity, however, is relatively small and can be approximated by a linear relationship where the strategy parameter threshold saturation, $x_{\Phi_{\Theta}, \text { sat }}$, captures some variation. Hence, the metabolic activity is assumed to increase linearly from 0 at zero water content to 1 at the threshold saturation (Fig. B11). $\Phi_{\text {act }}$ is then written as

$\Phi_{\text {act }}=\min \left(1.0, \frac{\Phi_{\Theta}}{x_{\Phi_{\Theta, \text { sat }}}}\right)$

where $\Phi_{\Theta}$ is the water saturation of the thallus and $x_{\Phi_{\Theta} \text {,sat }}$ is the threshold saturation.

The relation between $\Phi_{\text {act }}$ and $\Phi_{\Theta}$ is an important component of the tradeoff between $\mathrm{CO}_{2}$ diffusivity and metabolic activity. This is explained below in Sect. B3.5.

\section{B3.5 Tradeoff between $\mathrm{CO}_{2}$ diffusivity and metabolic activity}

The $\mathrm{CO}_{2}$ diffusivity of the thallus, $D_{\mathrm{CO}_{2}}$, decreases with increasing water saturation $\Phi_{\Theta}$ (see Sect. B3.2). The metabolic activity of a lichen or bryophyte $\Phi_{\text {act }}$, however, increases with $\Phi_{\Theta}$ (see Sect. B3.4). This leads to a tradeoff: at low $\Phi_{\Theta}$ the potential inflow of $\mathrm{CO}_{2}$ in the thallus and thus potential productivity are high, but the low $\Phi_{\text {act }}$ limits the actual productivity. At high $\Phi_{\Theta}$ productivity is limited by low $D_{\mathrm{CO}_{2}}$, although the lichen or bryophyte is active. Since both the relation between $D_{\mathrm{CO}_{2}}$ and $\Phi_{\Theta}$ and the relation between $\Phi_{\text {act }}$ and $\Phi_{\Theta}$ are controlled by underlying physiological constraints, the associated parameters, such as $w_{D_{\mathrm{CO}_{2}}}$, are assumed to have constant values (see Sect. 2.2).

The tradeoff is illustrated in Fig. B12: to maximise productivity, a lichen or bryophyte should try to spend most of the time near the optimum water saturation. It can achieve this goal through appropriate values of the characteristic parameters which control water content. These are mainly $x_{\Phi_{\Theta, \text { sat }}}$, $x_{\Psi_{\mathrm{H}_{2} \mathrm{O}}}$ and $x_{\Theta_{\max }}$, but also parameters that indirectly influence water content of the thallus, such as $x_{\alpha}, x_{A_{\text {spec }}}$ and $x_{\text {loc }}$. 


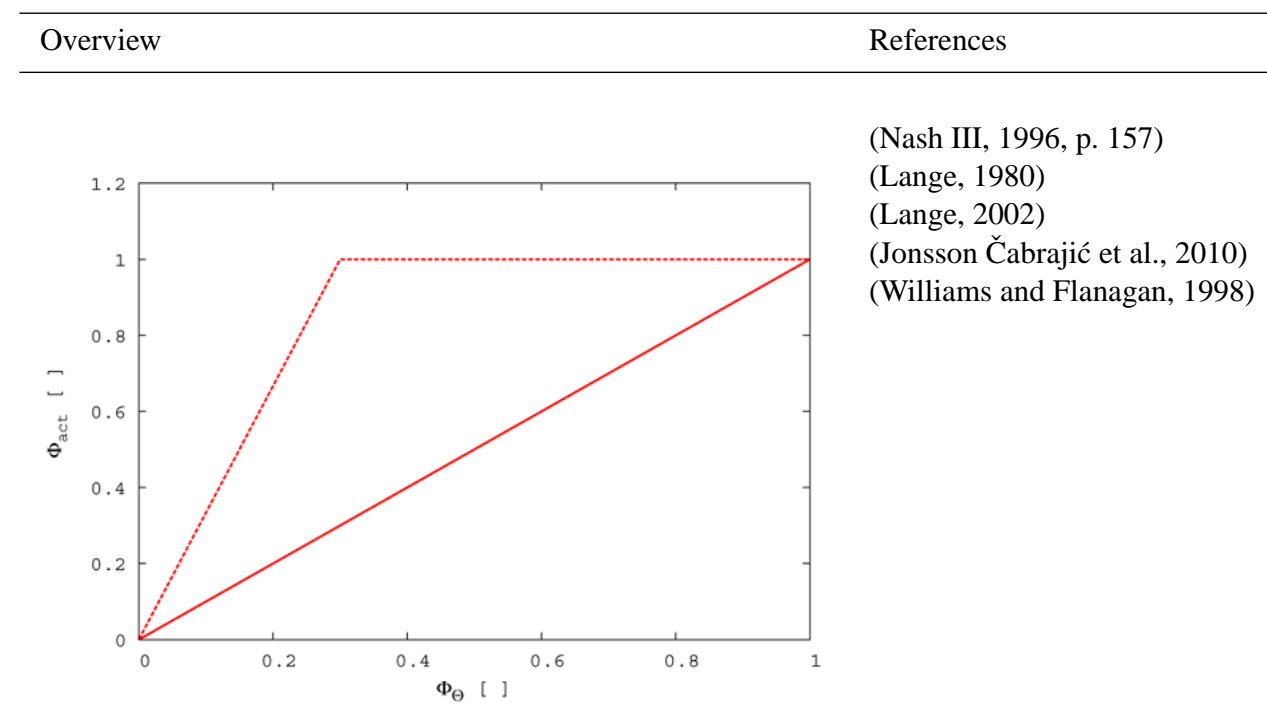

Fig. B11. Metabolic activity $\Phi_{\text {act }}$ as a function of water saturation $\Phi_{\Theta}$. The dashed line corresponds to $x_{\Phi_{\Theta, \text { sat }}}=0.3$ and the solid line corresponds to $x_{\Phi_{\Theta, \text { sat }}}=1.0$

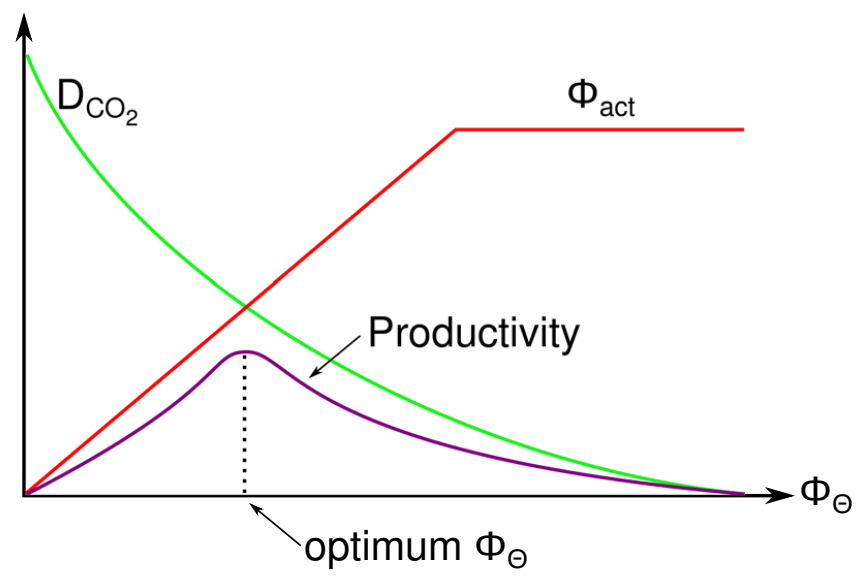

Fig. B12. Effect of water saturation $\Phi_{\Theta}$ on $\mathrm{CO}_{2}$ diffusivity $D_{\mathrm{CO}_{2}}$, metabolic activity $\Phi_{\text {act }}$ and on the associated productivity. The productivity has a maximum at an optimum $\Phi_{\Theta}$.

\section{B4 Climate relations}

The climate forcing (air temperature, wind speed, relative humidity, precipitation and downwelling short- and longwave radiation) influences almost all physiological processes of lichens and bryophytes (see Fig. 3). Furthermore, it determines potential evaporation and surface temperature. In the following sections the relations between potential evaporation (Sect. B4.3), surface temperature (Sect. B4.4) and climate forcing are described. The factors necessary for the calculation of these relations are the following:

1. Net radiation (see Sect. B4.1)

2. Saturation vapour pressure (see Sect. B4.2)
3. Aerodynamic resistance to heat transfer (see Sect. B2.4)

4. Relative humidity

Snow also affects physiological processes of lichens and bryophytes. The dynamics of the snow layer are explained in Sect. B4.5 while the effects of the snow layer on physiological processes are described in the sections related to these processes.

\section{B4.1 Net radiation}

Net radiation is the sum of downwelling short- and longwave radiation, upwelling longwave radiation and the ground heat flux. Ingoing short- and longwave radiation are derived from the climate forcing data.

Outgoing longwave radiation $f_{\operatorname{rad}_{\mathrm{LW}} \uparrow}$ is calculated as a function of surface temperature and air temperature:

$f_{\mathrm{rad}_{\mathrm{LW} \uparrow}}=\left(4.0 c_{\sigma} T_{\text {air }}^{3} T_{\text {surf }}-3.0 c_{\sigma} T_{\text {air }}^{4}\right) \Phi_{\text {area }}$

where $T_{\text {air }}$ is air temperature, $T_{\text {surf }}$ is surface temperature and $c_{\sigma}$ is the Stefan-Boltzmann constant. Equation (B22) is a linearisation of the standard equation for power emitted by the surface of a black body (Stefan-Boltzmann law). It is taken from Monteith (1981). The factor $\Phi_{\text {area }}$ is the fraction of available area that is covered by the thallus (see Eq. B9). This factor thus converts $f_{\mathrm{rad}_{\mathrm{LW}} \uparrow}$ to Watts per $\mathrm{m}^{2}$ ground.

The ground heat flux $f_{Q_{\text {soil }}}$ is written as a function of the temperature difference between the thallus of a lichen or bryophyte and the soil:

$f_{Q_{\text {soil }}}=k_{\text {soil }} \frac{T_{\text {surf }}-s_{T_{\text {soil }}}}{p_{\Delta_{\mathrm{z}}}} \Phi_{\text {area }} \chi_{\mathrm{G}}$ 
where $k_{\text {soil }}$ is the thermal conductivity of the soil (see Eq. B16), $T_{\text {surf }}$ is the surface temperature of the thallus, $s_{T_{\text {soil }}}$ is soil temperature and $p_{\Delta_{\mathrm{z}}}$ is the damping depth of the soil for a diurnal cycle (Bonan, 2008, p. 134). $\Phi_{\text {area }}$ is the fraction of available area that is covered by the thallus. $\chi_{\mathrm{G}}$ is a switch to set $f_{Q_{\text {soil }}}$ to zero if a lichen or bryophyte is living in the canopy (see Eq. B14).

To compute soil temperature $s_{T_{\text {soil }}}$, the balance for the soil heat reservoir is used:

$s_{T_{\text {soil }}}=s_{T_{\text {soil }}}+\frac{f_{Q_{\text {soil }}}}{C_{\text {soil }} \Phi_{\text {area }} p_{\Delta_{\mathrm{z}}}} p_{\Delta_{\mathrm{t}}}$

where $f_{Q_{\text {soil }}}$ is the ground heat flux, $C_{\text {soil }}$ is soil heat capacity, $\Phi_{\text {area }}$ is the fraction of available area covered by a lichen or bryophyte, $p_{\Delta_{\mathrm{Z}}}$ is the damping depth of the soil for a diurnal cycle and $p_{\Delta_{\mathrm{t}}}$ is the time step of the model.

Net radiation $f_{\mathrm{H}}$ is written as

$f_{\mathrm{H}}=\phi_{\text {rads }} f_{\text {radsw }} \Phi_{\text {area }}+\phi_{\text {rad }} f_{\text {radLW }} \Phi_{\text {area }}-\phi_{\text {radL }} f_{\text {radLW } \uparrow}-f_{Q_{\text {soil }}}$

where $\phi_{\text {rads }}$ is a conversion factor for shortwave radiation (see Eq. B3) and $\phi_{\mathrm{rad}_{\mathrm{L}}}$ is a conversion factor for longwave radiation (see Eq. B4). $f_{\mathrm{radsw}_{\downarrow}}$ and $f_{\mathrm{rad}_{\mathrm{LW}} \downarrow}$ are the downwelling shortwave and longwave radiation flows derived from the climate forcing data. $\Phi_{\text {area }}$ is a factor to reduce the radiation flows to the fraction per $\mathrm{m}^{2}$ ground that reaches the thallus of a lichen or bryophyte (see Eq. B9). $f_{\mathrm{rad}_{\mathrm{LW}} \uparrow}$ is already multiplied by $\Phi_{\text {area }}$ in Eq. (B22); the same applies for $f_{Q_{\text {soil }}}$ in Eq. (B23).

\section{B4.2 Saturation vapour pressure}

The saturation vapour pressure above an open water surface $e_{\mathrm{sat}, 0}$ is calculated as a function of air temperature according to Allen et al. (1998):

$e_{\mathrm{sat}, 0}=p_{e_{\mathrm{s}, 3}} \mathrm{e}^{\frac{p e_{\mathrm{s}, 1} T_{\mathrm{air}, \mathrm{C}}}{p_{\mathrm{s}, 2}+T_{\mathrm{ar}, \mathrm{C}}}}$

where $p_{e_{s, 1}}, p_{e_{s, 2}}$ and $p_{e_{\mathrm{s}, 3}}$ are empirical parameters and $T_{\mathrm{air}, \mathrm{C}}$ is the air temperature in degree Celsius, calculated as $T_{\text {air, } \mathrm{C}}=$ $T_{\text {air }}-c_{T_{\text {melt, } \mathrm{H}_{2} \mathrm{O}}}$.

If the water saturation of a lichen or bryophyte is below the threshold saturation $x_{\Phi_{\Theta} \text {, sat }}$ (see Sects. B1.5 and B3.3), the water potential at the surface of the thallus becomes negative. Hence, the saturation vapour pressure is reduced by the factor $\phi_{e_{\text {sat }}}$, which is calculated according to Nikolov et al. (1995):

$\phi_{e_{\mathrm{sat}}}=\frac{1.0 \times 10^{6} \Psi_{\mathrm{H}_{2} \mathrm{O}} c_{\mathrm{M}_{\mathrm{H}_{2} \mathrm{O}}}}{c_{R_{\mathrm{gas}}} T_{\mathrm{air}, \mathrm{C}} c_{\rho_{\mathrm{H}_{2} \mathrm{O}}}}$

where $\Psi_{\mathrm{H}_{2} \mathrm{O}}$ is the water potential of the thallus, $c_{\mathrm{M}_{\mathrm{H}_{2} \mathrm{O}}}$ is the molar mass of water, $c_{R_{\text {gas }}}$ is the universal gas constant, $T_{\text {air,C }}$ is the air temperature, $c_{\rho_{\mathrm{H}_{2} \mathrm{O}}}$ is the density of liquid water, and the factor $1.0 \times 10^{6}$ is used to convert from MPa to Pa.
Hence, the saturation vapour pressure above the thallus of a lichen or bryophyte, $e_{\text {sat }}$, is written as (Nikolov et al., 1995)

$e_{\text {sat }}=\mathrm{e}^{\phi_{\text {sat }}} e_{\text {sat }, 0 .}$

The slope of the saturation vapour pressure curve, $d_{e_{\text {sat }}}$, is calculated by differentiating $e_{\text {sat }}$ after $T_{\text {air,C}}$ :

$\left.d_{e_{\mathrm{sat}}}=\mathrm{e}^{\left(\frac{p_{e_{\mathrm{s}, 1}} T_{\mathrm{air}, \mathrm{C}}}{p e_{\mathrm{s}, 2}+T_{\mathrm{air}, \mathrm{C}}}+\phi_{e_{\mathrm{sat}}}\right.}\right)\left(\frac{p_{e_{\mathrm{s}, 1}} p_{e_{\mathrm{s}, 2}} p_{e_{\mathrm{s}, 3}}}{\left(p_{e_{\mathrm{s}, 2}}+T_{\mathrm{air}, \mathrm{C}}\right)^{2}}-\frac{\phi_{e_{\mathrm{sat}}}}{T_{\mathrm{air}}}\right)$.

\section{B4.3 Potential evaporation}

The potential evaporation $E_{\text {pot }}$ above the thallus of a lichen or bryophyte is written as the sum of two independent potential flows, one driven by net radiation and another one driven by the vapour pressure deficit of the atmosphere (Monteith, 1981):

$E_{\mathrm{pot}}=\frac{f_{\mathrm{H}} d_{e_{\mathrm{sat}}}+c_{\mathrm{C}_{\mathrm{air}}} \frac{e_{\mathrm{sat}}-\Phi_{\mathrm{RH}} e_{\mathrm{sat}}}{r_{\mathrm{H}}} \Phi_{\text {area }}}{\left(d_{e_{\mathrm{sat}}}+c_{\gamma}\right) c_{\Delta H_{\mathrm{vap}, \mathrm{H}_{2} \mathrm{O}}} c_{\rho_{\mathrm{H}_{2} \mathrm{O}}}}$

where $f_{\mathrm{H}}$ is net radiation, $d_{e_{\mathrm{sat}}}$ is the slope of the saturation vapour pressure curve, $e_{\mathrm{sat}}$ is saturation vapour pressure and $\Phi_{\mathrm{RH}}$ is relative humidity. $c_{C_{\text {air }}}$ is the heat capacity of air, $r_{\mathrm{H}}$ is the aerodynamic resistance to heat transfer, $c_{\gamma}$ is the psychrometric constant, $c_{\Delta H_{\mathrm{vap}, \mathrm{H}_{2} \mathrm{O}}}$ is the enthalpy of vaporisation and $c_{\rho_{\mathrm{H}_{2} \mathrm{O}}}$ is the density of liquid water. The factor $\Phi_{\text {area }}$ reduces the part of $E_{\text {pot }}$ related to vapour pressure deficit to the fraction per $\mathrm{m}^{2}$ ground covered by the thallus of a lichen or bryophyte. The part of $E_{\mathrm{pot}}$ driven by net radiation is already corrected for surface coverage in Eq. (B25).

Note that both parts of $E_{\text {pot }}$ can be negative. If net radiation is negative, the thallus emits more energy to the ground or the atmosphere than it receives. Consequently, dew forms on the thallus surface. This process can be an important source of moisture for lichens or bryophytes, especially in deserts (Nash III, 1996, p. 6). If relative humidity is larger than one and therefore the vapour pressure deficit is negative, fog forms above the thallus surface. This process can also contribute to the water supply of a lichen or bryophyte.

\section{B4.4 Surface temperature}

Lichen surface temperature $T_{\text {surf }}$ is derived from the same factors as potential evaporation. It is written according to Monteith (1981) as

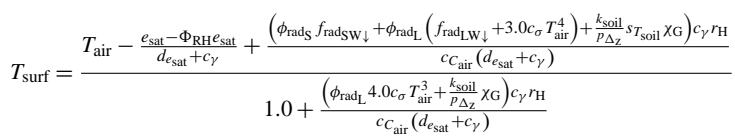

where $T_{\text {air }}$ is air temperature, $e_{\text {sat }}$ is saturation vapour pressure, $\Phi_{\mathrm{RH}}$ is relative humidity, $d_{e_{\mathrm{sat}}}$ is the slope of the saturation vapour pressure curve and $c_{\gamma}$ is the psychrometric constant. $\phi_{\text {rads }}$ and $\phi_{\mathrm{rad}_{\mathrm{L}}}$ are conversion factors for shortwave 
and longwave radiation, $f_{\mathrm{radsw}}$ and $f_{\mathrm{rad}_{\mathrm{LW}} \downarrow}$ are the downwelling shortwave and longwave radiation flows and $c_{\sigma}$ is the Stefan-Boltzmann constant. $k_{\text {soil }}$ is the thermal conductivity of the soil, $p_{\Delta_{z}}$ is the damping depth of the soil for a diurnal cycle, $s_{T_{\text {soil }}}$ is soil temperature and $\chi_{\mathrm{G}}$ is a switch to set $f_{Q_{\text {soil }}}$ to zero if a lichen or bryophyte is living in the canopy. $c_{C_{\text {air }}}$ is the heat capacity of air and $r_{\mathrm{H}}$ is the aerodynamic resistance to heat transfer.

\section{B4.5 Snow layer}

The snow cover leads to a reduction of light input for lichens and bryophytes. Furthermore, it changes the dynamics of the water supply and the temperature regime compared to a situation without snow cover. It is assumed in the model that lichens and bryophytes are not able to photosynthesise if the snow cover above them exceeds a certain critical thickness $p_{\Delta_{\text {snow }}}$ (Pannewitz et al., 2003). Since it is impractical to simulate the water content of the organisms under snow, dark respiration is also assumed to be negligible in this situation. This means that no metabolic activity takes place except for turnover of biomass.

To calculate the thickness of the snow cover, a mass balance is used. It consists of input by snowfall and output by snowmelt and slow, lateral movement of the snow pack due to gravity. The latter term has only a negligible effect on a seasonal snow cover. The snow balance for Greenland, however, would always be positive without ice moving laterally towards the ocean in form of glaciers.

Snowmelt $f_{\text {snowmelt }}$ is calculated as a function of air temperature (Bergström, 1992):

$f_{\text {snowmelt }}=\min \left(3.22 \frac{\max \left(0.0, T_{\text {air }}-c_{T_{\text {melt, } \mathrm{H}_{2} \mathrm{O}}}\right)}{86400 \cdot 1000}, \frac{s_{\text {snow }}}{p_{\Delta_{\mathrm{t}}}}+f_{\text {snow, atm }}\right)$

where $T_{\text {air }}$ is air temperature and $c_{T_{\text {melt, } \mathrm{H}_{2} \mathrm{O}}}$ is the melting temperature of water, the factor 86400 is the number of seconds per day, the factor 1000 converts from $\mathrm{mm}$ to $\mathrm{m}$, and the factor 3.22 is a dimensionless empirical parameter. $s_{\text {snow }}$ is the snow reservoir on the surface, measured in $\mathrm{m}^{3}$ liquid water equivalents per $\mathrm{m}^{2}, p_{\Delta_{\mathrm{t}}}$ is the time step of the model and $f_{\text {snow, atm }}$ is the input flow of snow from the atmosphere.

The balance of the snow reservoir $s_{\text {snow }}$ is written as

$s_{\text {snow }}=\max \left(0.0, s_{\text {snow }}+\left(f_{\text {snow, atm }}-f_{\text {snowmelt }}-s_{\text {snow }} p_{\tau_{\text {ice }}}\right) p_{\Delta_{\mathrm{t}}}\right)$

where the last term describes lateral movement of the snow pack. The parameter $p_{\tau_{\text {ice }}}$ represents the turnover of ice shields and it is set by best guess to $1 \%$ per year.

To convert the snow reservoir $s_{\text {snow }}$ from water equivalents to thickness of snow cover $\Delta_{\text {snow }}$ in metres, $s_{\text {snow }}$ is multiplied by the fraction of density of water and density of snow (Domine et al., 2011):

$\Delta_{\text {snow }}=s_{\text {snow }} \frac{c_{\rho_{\mathrm{H}_{2} \mathrm{O}}}}{p_{\rho_{\text {snow }}}}$
In case a lichen or bryophyte is covered by a snow layer that exceeds the critical thickness $p_{\Delta_{\text {snow }}}$, a different method than Eq. (B31) is used to compute the surface temperature $T_{\text {surf }}$ of the thallus:

$T_{\text {surf }}= \begin{cases}T_{\text {air }}, & \text { if organism in canopy } \\ \frac{p_{\text {knnow }}}{\Delta_{\text {snow }}} T_{\text {air }}+\frac{k_{\text {soil }}}{p_{\Delta}} T_{\text {soil }} \\ \frac{p_{\text {snow }}}{\Delta_{\text {snow }}}+\frac{k_{\text {soil }}}{p_{\Delta_{z}}} & \text { if organism on ground }\end{cases}$

where $p_{k_{\text {snow }}}$ is the thermal conductivity of snow (Domine et al., 2011), $\Delta_{\text {snow }}$ is the thickness of the snow layer, $T_{\text {air }}$ is air temperature, $k_{\text {soil }}$ is the thermal conductivity of the soil, $p_{\Delta_{\mathrm{Z}}}$ is the damping depth of the soil for a diurnal cycle and $s_{T_{\text {soil }}}$ is soil temperature. Note that Eq. (B35) does not have any effects on the metabolism of lichens or bryophytes since they are assumed to be inactive under snow. Equation (B35) is only implemented in the model to compute approximate values for the surface temperature under snow. In a snowcovered canopy, the surface temperature is assumed to be equal to air temperature for simplicity. On the snow-covered ground, the surface temperature is assumed to be controlled only by heat conduction from atmosphere to surface and from surface to soil. Equation (B35) results from assuming a steady state of the surface.

\section{B5 Carbon exchange flows}

The model simulates the following flows of carbon related to lichens and bryophytes:

1. Inflow of $\mathrm{CO}_{2}$ from the atmosphere into the pore space of the thallus (see Sect. B5.1)

2. Uptake of $\mathrm{CO}_{2}$ from the pore space (gross primary productivity, GPP) and storage as sugars (see Sect. B5.2)

3. Maintenance and growth respiration (see Sect. B5.4)

4. Growth, which is the transformation of the stored sugars into biomass (see Sect. B5.4)

5. Biomass loss (see Sect. B5.6)

The relations of these flows to the balances of the carbon reservoirs of a lichen or bryophyte are described in Sect. B5.7.

\section{B5.1 Inflow of $\mathrm{CO}_{2}$ into the thallus}

The inflow of $\mathrm{CO}_{2}$ from the atmosphere into the pore space of the thallus, $f_{\mathrm{CO}_{2}}$, in , is proportional to the gradient between the partial pressures of $\mathrm{CO}_{2}$ in the atmosphere and in the pore space. It is written as

$f_{\mathrm{CO}_{2}, \text { in }}=D_{\mathrm{CO}_{2}} \frac{\mathrm{CO}_{2, \text { atm }}-\mathrm{CO}_{2, \text { thallus }}}{1.0 \times 10^{6}} \Phi_{\text {area }}$ 
where $D_{\mathrm{CO}_{2}}$ is the diffusivity of the thallus for $\mathrm{CO}_{2}$, $\mathrm{CO}_{2, \text { atm }}$ is the atmospheric $\mathrm{CO}_{2}$ concentration, $\mathrm{CO}_{2 \text {,thallus }}$ is the $\mathrm{CO}_{2}$ concentration in the pore space of the thallus and the factor $1.0 \times 10^{6}$ is used to convert the gradient from ppm to a fraction between 0 and 1 . The variable $\Phi_{\text {area }}$ converts $f_{\mathrm{CO}_{2} \text {,in }}$ from a flow per $\mathrm{m}^{2}$ lichen or bryophyte into a flow

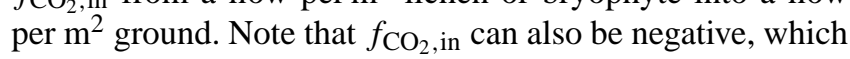
means that the $\mathrm{CO}_{2}$ concentration inside the thallus is higher than in the atmosphere and consequently $\mathrm{CO}_{2}$ flows out of the thallus.

\section{B5.2 GPP}

The uptake of $\mathrm{CO}_{2}$ from the pore space (gross primary productivity, GPP) is computed according to Farquhar and von Caemmerer (1982) as a minimum of a light-limited rate and a $\mathrm{CO}_{2}$-limited rate. The light-limited rate is an increasing function of the absorption of light by a lichen or bryophyte. The organism, however, cannot absorb light to an arbitrary extent. Hence, the light-limited rate is constrained to a maximum rate $J_{\max }$. The $\mathrm{CO}_{2}$-limited rate is an increasing function of the $\mathrm{CO}_{2}$ concentration in the chloroplasts of a lichen or bryophyte. It saturates, however, at very high values of $\mathrm{CO}_{2}$ concentration. The maximum rate at saturation is $V_{\mathrm{C}, \max }$.

The maximum carboxylation rate $V_{\mathrm{C}, \max }$ of a lichen or bryophyte is calculated as

$V_{\mathrm{C}, \max }=x_{V_{\mathrm{C}, \max }} \Xi_{\mathrm{Rub}} \mathrm{e}^{-\left(\frac{T_{\mathrm{surf}}-x_{\mathrm{opt}, \mathrm{PS}}}{p_{\Omega}}\right)^{2}}$

where $x_{V_{\mathrm{C}, \max }}$ is the molar carboxylation rate of Rubisco (see Sect. B1.6) and $\Xi_{\text {Rub }}$ is the specific Rubisco content of a lichen or bryophyte. The exponential describes the influence of surface temperature $T_{\text {surf }}$ on $V_{\mathrm{C}, \max }$ (Medlyn et al., 2002). $V_{\mathrm{C}, \max }$ is assumed to peak around an optimum surface temperature $x_{T_{\mathrm{opt} \text { PS }}}$ (see Sect. B1.9) and the shape of the temperature response curve is determined by the parameter $p_{\Omega}$ (June et al., 2004).

The Rubisco content $\Xi_{\text {Rub }}$ is a function of the reference respiration rate at $10^{\circ} \mathrm{C}, x_{R_{\text {ref }}}$. This relationship represents a tradeoff and results from a physiological constraint, namely maintenance costs of enzymes (see Sect. 2.2). The exact shape of this relation could not be determined since we could not find enough studies where both $\Xi_{\text {Rub }}$ and $x_{R_{\text {ref }}}$ are measured. Thus, we assume a simple linear function:

$\Xi_{\mathrm{Rub}}=w_{\mathrm{Rub}, \mathrm{R}} x_{R_{\mathrm{ref}}}$

where the tradeoff-parameter $w_{\text {Rub,R, }}$, which represents the slope of the line, is determined by two points: the origin $(0,0)$ and the point $\left(\overline{\Xi_{\mathrm{Rub}}}, \overline{x_{R_{\mathrm{ref}}}}\right)$, where $\overline{x_{R_{\mathrm{ref}}}}$ is the average reference respiration rate and $\bar{\Xi}_{\mathrm{Rub}}$ is the average Rubisco content. $\overline{x_{R_{\text {ref }}}}$ is calculated by Eq. (B2) with $N=0.5$. The limits of the range of possible values of $x_{R_{\text {ref }}}$ can be found in Table B9. To compute $\overline{\Xi_{\text {Rub }}}$ we also use Eq. (B2) with $N=0.5$, although the range of possible values of $\Xi_{\text {Rub }}$ (see
Table B6. Overview of the Rubisco content $\Xi_{\text {Rub }}$ of lichens and bryophyte.

\begin{tabular}{lc}
\hline$\Xi_{\text {Rub }}\left[(\mathrm{mol} \mathrm{Rubisco})\left(\mathrm{kg} \mathrm{C}^{-1}\right]\right.$ & Reference \\
\hline $1.4 \times 10^{-5}$ & (Balaguer et al., 1999) \\
$2.1 \times 10^{-5}$ & (Sundberg et al., 2001) \\
$9.0 \times 10^{-6}$ & (Sundberg et al., 2001) \\
\hline
\end{tabular}

Table B6) does not span several orders of magnitude. This small range of values is probably due to the small sample size (3 data points). The assumption of a linear relationship for Eq. (B38), however, implies that both the range of $x_{R_{\text {ref }}}$ and the range of $\Xi_{\text {Rub }}$ have the same shape. Hence, using Eq. (B2) to estimate $\overline{\Xi_{\text {Rub }}}$ is a consistent approach. Note that using the median of the values from Table B6 to compute $\overline{\Xi_{\text {Rub }}}$ instead of using Eq. (B2) does not significantly change the value of $w_{\text {Rub,R }}$.

The maximum electron transport rate $J_{\max }$ of a lichen or bryophyte is calculated as

$J_{\max }=\phi_{\mathrm{JV}} V_{\mathrm{C}, \max }$

where $V_{\mathrm{C}, \max }$ is the maximum carboxylation rate and $\phi_{\mathrm{JV}}$ is the ratio of $J_{\max }$ to $V_{\mathrm{C} \text {,max }}$. $\phi_{\mathrm{JV}}$ depends on the surface temperature of a lichen or bryophyte and is written as

$\phi_{\mathrm{JV}}=\max \left(0.0, w_{\mathrm{JV}, 1}\left(T_{\text {surf }}-c_{T_{\mathrm{melt}, \mathrm{H}_{2} \mathrm{O}}}\right)+w_{\mathrm{JV}, 2}\right)$

where $T_{\text {surf }}$ is surface temperature and $c_{T_{\text {melt, } \mathrm{H}_{2} \mathrm{O}}}$ is the melting temperature of water. The two parameters $w_{\mathrm{JV}, 1}$ and $w_{\mathrm{JV}, 2}$ are derived by the data shown in Fig. B13. $\phi_{\mathrm{JV}}$ is limited to nonnegative values since a negative $J_{\max }$ would make no sense from a physiological viewpoint.

The fact that $V_{\mathrm{C} \text {,max }}$ and $J_{\max }$ are positively correlated implies a tradeoff between these two variables. This tradeoff results from physiological constraints (see Sect. 2.2) in form of metabolic costs of $V_{\mathrm{C}, \max }$ and $J_{\max }$. Since both the maximum of the light-dependent rate and the maximum of the $\mathrm{CO}_{2}$-dependent rate are associated with costs for the organism, but GPP is computed as a minimum of the two rates, it would be inefficient if $V_{\mathrm{C} \text {,max }}$ and $J_{\max }$ were independent from each other.

The actual rate of electron transport $J$ is calculated as the minimum of the maximum rate of the photosystems $J_{\max }$ and the supply by shortwave radiation:

$J=\min \left(f_{\text {rad }_{\mathrm{Sw}} \downarrow} \phi_{\text {rads }} p_{\text {PAR }} p_{\text {quant }} w_{\mathrm{CCM}, \mathrm{e}} \Phi_{\text {area }}, J_{\max } S_{\mathrm{B}}\right)$

where $f_{\text {radsw } \downarrow}$ is the flow of shortwave radiation, $\phi_{\text {rads }}$ is a conversion factor that includes albedo and LAI (see Sect. B2.1), $p_{\text {PAR }}$ is a factor that converts shortwave radiation into photosynthetically active radiation and $p_{\text {quant }}$ converts quanta of light into electrons. $w_{\mathrm{CCM}, \mathrm{e}}$ is a factor that represents the investment of electrons in a carbon concentration mechanism if present (see Sect. B5.3 below). $\Phi_{\text {area }}$ 


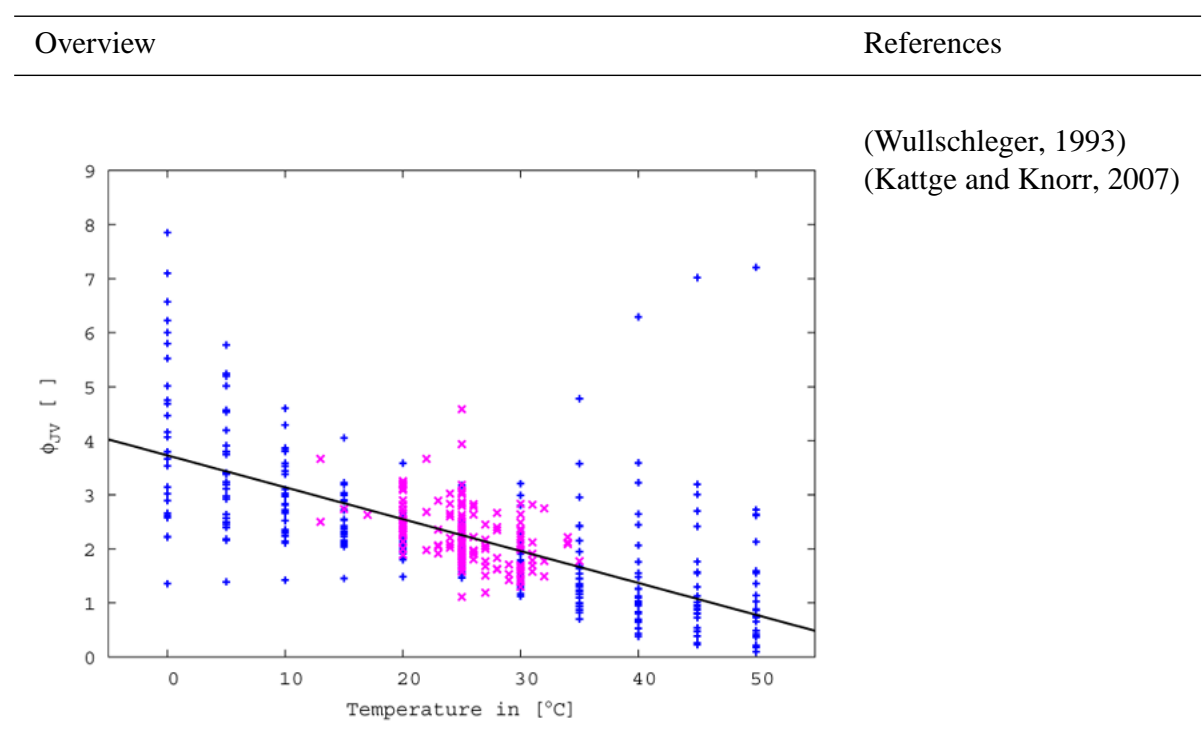

Fig. B13. Ratio of $J_{\max }$ to $V_{\mathrm{C}, \max }, \phi_{\mathrm{JV}}$ (black line) as a function of temperature. The magenta data points are taken from the study of Wullschleger (1993), while the blue points are derived by the equations used in Kattge and Knorr (2007).

reduces the electron flow to the area covered by a lichen or bryophyte and $s_{\mathrm{B}}$ is the biomass of the organism.

Besides $V_{\mathrm{C}, \max }$ and $J_{\max }$, the Michaelis-Menten constants of the carboxylation and oxygenation reactions of Rubisco, $K_{\mathrm{C}}$ and $K_{\mathrm{O}}$, affect the shape of the light-dependent rate and the $\mathrm{CO}_{2}$-dependent rate of GPP. They are calculated as

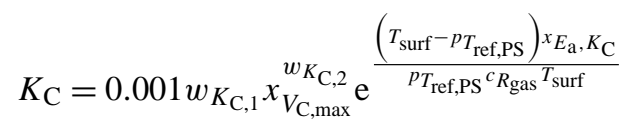

and

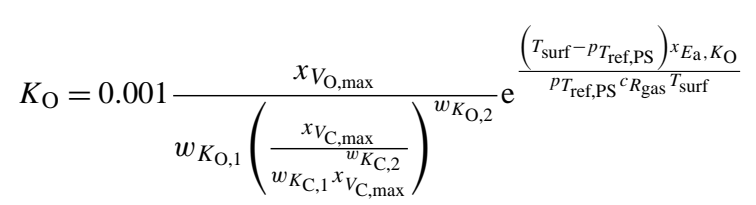

where $x_{V_{\mathrm{C} \text { max }}}$ is the molar carboxylation rate of Rubisco (see Sect. B1.6) and $x_{V_{\mathrm{O}, \max }}$ is the molar oxygenation rate of Rubisco (see Sect. B1.7). The factor 0.001 is used to convert $K_{\mathrm{C}}$ and $K_{\mathrm{O}}$ into mol per $\mathrm{m}^{3}$. The exponentials in Eqs. (B42) and (B43) describe the influence of surface temperature $T_{\text {surf }}$ on $K_{\mathrm{C}}$ and $K_{\mathrm{O}} . p_{T_{\text {ref,PS }}}$ is the reference temperature of photosynthesis and $c_{R_{\text {gas }}}$ is the universal gas constant. $x_{E_{\mathrm{a}}, K_{\mathrm{C}}}$ and $x_{E_{\mathrm{a}}, K_{\mathrm{O}}}$ are the enzyme activation energies of the carboxylation and oxygenation reactions, respectively (see Sect. B1.10).

The parameters $w_{K_{\mathrm{C}, 1}}, w_{K_{\mathrm{C}, 2}}, w_{K_{\mathrm{O}, 1}}$ and $w_{K_{\mathrm{O}, 2}}$ relate $K_{\mathrm{C}}$ and $K_{\mathrm{O}}$ to $x_{V_{\mathrm{C}, \max }}$ and $x_{V_{\mathrm{O}, \max }}$. According to Savir et al. (2010), these relations result from a tradeoff between the carboxylation velocity and the $\mathrm{CO}_{2}$ affinity of the Rubisco enzyme.

The variable $\Gamma_{*}$ represents the $\mathrm{CO}_{2}$ compensation point of photosynthesis in the absence of respiration as described in
Farquhar and von Caemmerer (1982). It is written as

$$
\Gamma_{*}=0.5 \mathrm{O}_{2, \text { cell }} \frac{x_{V_{\mathrm{O}, \max } K_{\mathrm{C}}}}{x_{V_{\mathrm{C}, \max }} K_{\mathrm{O}}}
$$

where $\mathrm{O}_{2}$,cell is the concentration of $\mathrm{O}_{2}$ in the chloroplast of a lichen or bryophyte, $x_{V_{\mathrm{C}, \max }}$ and $x_{V_{\mathrm{O} \text {, max }}}$ are the maximum velocities and $K_{\mathrm{C}}$ and $K_{\mathrm{O}}$ are the Michaelis-Menten constants of the carboxylation and oxygenation reactions, respectively.

The $\mathrm{O}_{2}$ concentration in the chloroplast $\mathrm{O}_{2 \text {,cell }}$ is calculated as a function of the $\mathrm{O}_{2}$ concentration in the pore space of the thallus, which is assumed to be equal to the atmospheric one:

$\mathrm{O}_{2, \mathrm{cell}}=\frac{1000.0}{p_{\mathrm{S}_{2}}} \mathrm{O}_{2, \mathrm{~atm}}$

where $\mathrm{O}_{2, \text { atm }}$ is the atmospheric $\mathrm{O}_{2}$ concentration and $p_{\mathrm{O}_{2}}$ is the solubility of $\mathrm{O}_{2}$ (von Caemmerer, 2000, p. 9). The factor 1000 is used to write $\mathrm{O}_{2, \text { cell }}$ in mol per $\mathrm{m}^{3}$.

Accordingly, the $\mathrm{CO}_{2}$ concentration in the chloroplast $\mathrm{CO}_{2 \text {,cell }}$ is calculated as a function of the $\mathrm{CO}_{2}$ concentration in the pore space of the thallus, which depends on the exchange flows of carbon between the organism and the atmosphere:

$\mathrm{CO}_{2, \text { cell }}=\frac{1000.0}{p_{S_{\mathrm{CO}_{2}}}} \mathrm{CO}_{2, \text { thallus }}$

where $\mathrm{CO}_{2}$,thallus is the pore space $\mathrm{CO}_{2}$ concentration and $p_{\mathrm{SO}_{2}}$ is the solubility of $\mathrm{CO}_{2}$ (von Caemmerer, 2000, p. 9). The factor 1000 is used to write $\mathrm{CO}_{2, \text { cell }}$ in mol per $\mathrm{m}^{3}$.

Knowing $\mathrm{CO}_{2 \text {,cell }}, \mathrm{O}_{2 \text {,cell }}, J, K_{\mathrm{C}}, K_{\mathrm{O}}, x_{V_{\mathrm{C} \text {, max }}}$ and $x_{V_{\mathrm{O} \text {,max }}}$, the light-limited rate and the $\mathrm{CO}_{2}$-limited rate of 


\begin{tabular}{ll}
\hline Overview & References \\
\hline
\end{tabular}

(Reinhold et al., 1989)

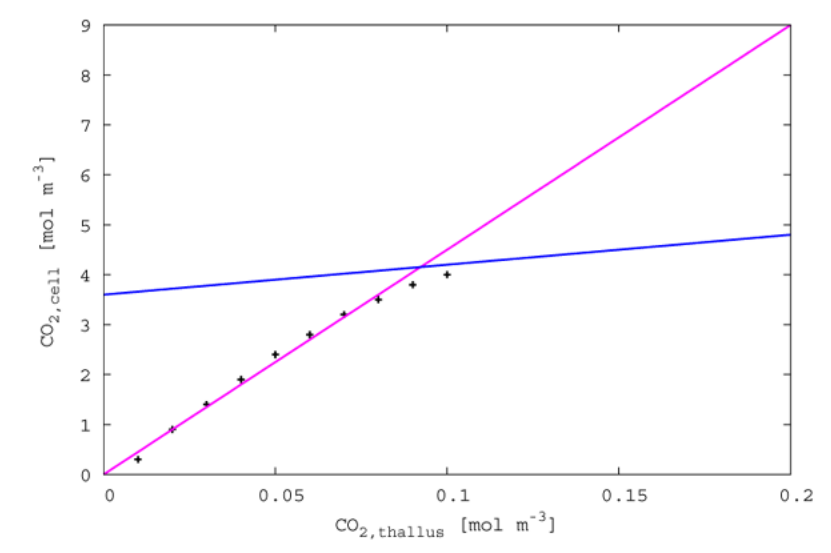

Fig. B14. $\mathrm{CO}_{2}$ concentration in the chloroplasts, $\mathrm{CO}_{2}$,cell, as a function of pore space $\mathrm{CO}_{2}$ concentration $\mathrm{CO}_{2, \text { thallus }}$ The black data points are taken from the study of Reinhold et al. (1989). The minimum of the magenta and blue lines is used to fit the data.

photosynthesis can be calculated. They are written according to Farquhar and von Caemmerer (1982) as

$f_{\mathrm{GPP}, \mathrm{L}}=J \frac{\mathrm{CO}_{2, \mathrm{cell}}-\Gamma_{*}}{4.0 \mathrm{CO}_{2, \text { cell }}+8.0 \Gamma_{*}} \Phi_{\text {act }}$

and

$f_{\mathrm{GPP}, \mathrm{W}}=x_{V_{\mathrm{C}, \max }} s_{\mathrm{B}} \frac{\mathrm{CO}_{2, \text { cell }}-\Gamma_{*}}{\mathrm{CO}_{2, \text { cell }}+K_{\mathrm{C}} \frac{1.0+\mathrm{O}_{2, \mathrm{cell}}}{K_{\mathrm{O}}}} \Phi_{\mathrm{act}}$

where $\mathrm{CO}_{2 \text {,cell }}$ is the concentration of $\mathrm{CO}_{2}$ in the chloroplast, $\Gamma_{*}$ is the $\mathrm{CO}_{2}$ compensation point, $K_{\mathrm{C}}$ and $K_{\mathrm{O}}$ are the Michaelis-Menten constants of the carboxylation and oxygenation reactions, respectively, and $\mathrm{O}_{2, \text { cell }}$ is the $\mathrm{O}_{2}$ concentration in the chloroplast. $\Phi_{\text {act }}$ is the metabolic activity of a lichen or bryophyte (see Sect. B3.4). It accounts for the effect of poikilohydry on photosynthesis and it represents an extension to the original equations of Farquhar and von Caemmerer (1982). $x_{V_{\mathrm{C}, \max }}$ is the maximum specific carboxylation rate and $s_{\mathrm{B}}$ is the biomass of a lichen or bryophyte.

The GPP of a lichen or bryophyte is then calculated as the minimum of $f_{\mathrm{GPP}, \mathrm{L}}$ and $f_{\mathrm{GPP}, \mathrm{W}}$ :

$f_{\mathrm{GPP}}=\min \left(f_{\mathrm{GPP}, \mathrm{L}}, f_{\mathrm{GPP}, \mathrm{W}}\right)$

\section{B5.3 Carbon concentration mechanism}

Some lichens and bryophytes possess a carbon concentration mechanism (CCM, see Sects. 2.2 and B1.11). If a CCM is active, a fraction of the electrons generated by the photosystems is invested in increasing the $\mathrm{CO}_{2}$ concentration in the chloroplasts instead of being used in the Calvin cycle. It is assumed here that the CCM in lichens works similarly to those in free-living cyanobacteria. The increased $\mathrm{CO}_{2}$ concentration in the chloroplasts can then be calculated as a function of pore space $\mathrm{CO}_{2}$ concentration:

$\mathrm{CO}_{2, \text { ell }}=\min \left(w_{\mathrm{CCM}, 1} \mathrm{CO}_{2, \text { thallus }}, w_{\mathrm{CCM}, 2} \mathrm{CO}_{2 \text {,thallus }}+w_{\mathrm{CCM}, 3}\right)$

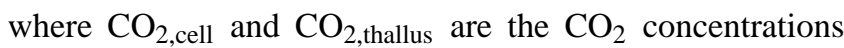
in the chloroplast and the pore space, respectively. $w_{\mathrm{CCM}, 1}$, $w_{\mathrm{CCM}, 2}$ and $w_{\mathrm{CCM}, 3}$ are parameters derived from the data of Reinhold et al. (1989), which is shown in Fig. B14.

The form of the CCM implemented in the model represents a tradeoff for a lichen or bryophyte: the increased $\mathrm{CO}_{2}$ concentration in the chloroplasts, which depends on $w_{\mathrm{CCM}, 1}$, $w_{\mathrm{CCM}, 2}$ and $w_{\mathrm{CCM}, 3}$, directly leads to higher productivity, but the maintenance of the high concentration requires energy which is taken from the electron transport chain in the thylakoid membranes. These costs are represented by the parameter $w_{\mathrm{CCM}, \mathrm{e}}$ (see Eq. B41). The relation between pore space $\mathrm{CO}_{2}$ and $\mathrm{CO}_{2}$ in the chloroplasts as well as the costs of establishing this relation constitute the physiological constraints of the CCM.

\section{B5.4 Respiration and growth}

Respiration consists of two parts: maintenance respiration and growth respiration. The specific maintenance respiration rate $R_{\text {spec }}$ is modelled by a $Q_{10}$ relationship (Kruse et al., 2011). It is illustrated in Fig. B8 in Sect. B1.8 and it is written as

$R_{\text {spec }}=x_{R_{\text {ref }}} x_{Q_{10}}{ }^{\frac{T_{\text {surf }, \mathrm{R}}-p^{-c} T_{\text {ref }, \mathrm{R}}}{p_{\text {melt } \mathrm{H}_{2} \mathrm{O}}}}$

where $x_{R_{\text {ref }}}$ is the reference respiration rate at $10^{\circ} \mathrm{C}, x_{Q_{10}}$ is the $Q_{10}$ value of respiration, $T_{\text {surf }}$ is the surface temperature 


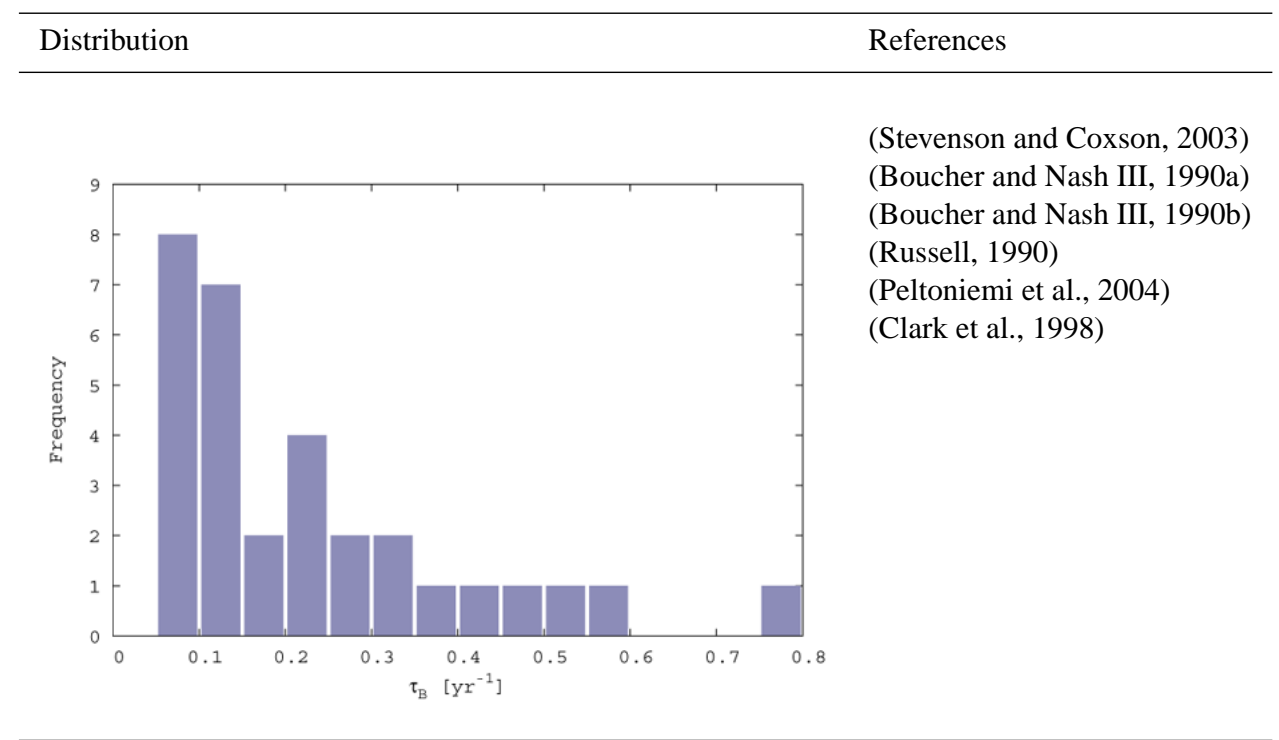

Fig. B15. Overview of the distribution of turnover rate $\tau_{\mathrm{B}}$.

of the organism, $p_{T_{\text {ref,R }}}$ is the reference temperature and $c_{T_{\text {melt, } \mathrm{H}_{2} \mathrm{O}}}$ is the melting temperature of water.

The maintenance respiration of a lichen or bryophyte, $f_{R_{\text {main }}}$, is then calculated as a function of $R_{\text {spec }}$ and the biomass of the organism:

$f_{R_{\text {main }}}=\min \left(\frac{s_{\mathrm{C}}}{c_{\mathrm{M}_{\mathrm{C}}} p_{\Delta_{\mathrm{t}}}}, R_{\mathrm{spec}} s_{\mathrm{B}} \Phi_{\mathrm{act}}\right)$

where $s_{\mathrm{C}}$ is the sugar reserve of a lichen or bryophyte, $c_{\mathrm{M}_{\mathrm{C}}}$ is the molar mass of carbon, $p_{\Delta_{\mathrm{t}}}$ is the time step of the model, $R_{\text {spec }}$ is the specific maintenance respiration rate, $s_{\mathrm{B}}$ is the biomass of the organism and $\Phi_{\text {act }}$ is its metabolic activity.

The minimum in Eq. (B52) is used because a lichen or bryophyte cannot respire more carbon per time step than is stored in the sugar reservoir. The respired $\mathrm{CO}_{2}$ is released into the pore space.

The growth of a lichen or bryophyte is computed as the minimum of the available amount of sugar per time step and a potential flow, which is a function of the sugar reservoir:

$f_{\text {growth }}=\min \left(\frac{s_{\mathrm{C}}}{c_{\mathrm{M}_{\mathrm{C}}} p_{\Delta_{\mathrm{t}}}}-f_{R_{\text {main }}}, x_{\text {alloc }} \frac{s_{\mathrm{C}}}{c_{\mathrm{M}_{\mathrm{C}}} 86400} \Phi_{\text {act }}\right) p_{\eta_{\text {growth }}}$

where $s_{\mathrm{C}}$ is the sugar reserve of a lichen or bryophyte, $c_{\mathrm{M}_{\mathrm{C}}}$ is the molar mass of carbon, $p_{\Delta_{\mathrm{t}}}$ is the time step of the model and $f_{R_{\text {main }}}$ is maintenance respiration. $x_{\text {alloc }}$ is the fraction of the sugar reservoir allocated to growth per day, 86400 is the number of seconds per day, $\Phi_{\text {act }}$ is metabolic activity, and $p_{\eta_{\text {growth }}}$ is the efficiency of the transformation of sugars to biomass.
The respiration associated with growth, $f_{R_{\text {growth }}}$ is then written as a function of growth efficiency $p_{\eta_{\text {growth }}}$ and growth $f_{\text {growth: }}$

$f_{R_{\text {growth }}}=\left(\frac{1.0}{p_{\eta_{\text {growth }}}}-1.0\right) f_{\text {growth }}$

\section{B5.5 Steady state of internal $\mathrm{CO}_{2}$}

Two carbon exchange flows depend on the internal $\mathrm{CO}_{2}$ concentration of the thallus $\mathrm{CO}_{2}$, thallus, namely the inflow of $\mathrm{CO}_{2}$ from the atmosphere into the pore space, $f_{\mathrm{CO}_{2}}$,in (Eq. B36), and the uptake of $\mathrm{CO}_{2}$ from the pore space by GPP, $f_{\mathrm{GPP}}$ (Eq. B49). The model, however, does not simulate explicitly the pore space of the thallus. Hence, it is not possible to determine the absolute amount of $\mathrm{CO}_{2}$ in the thallus. Instead, a steady-state approach is used to calculate $\mathrm{CO}_{2 \text {,thallus }}$ It is assumed that the exchange flow of $\mathrm{CO}_{2}$ between pore space and atmosphere, $f_{\mathrm{CO}_{2}}$, in , balances the net $\mathrm{CO}_{2}$ exchange flow between pore space and the cells of the organism. This net exchange flow is equal to the sum of uptake from the pore space $f_{\mathrm{GPP}}$ and release of $\mathrm{CO}_{2}$ into the pore space, consisting of maintenance respiration $f_{R_{\text {main }}}$ and growth respiration $f_{R_{\text {growth }}}$ (Eqs. B52 and B54). The equation for the steady state of pore space $\mathrm{CO}_{2}$ is thus written as

$f_{\mathrm{CO}_{2}, \text { in }}=f_{R_{\text {main }}}+f_{R_{\text {growth }}}-f_{\mathrm{GPP}}$

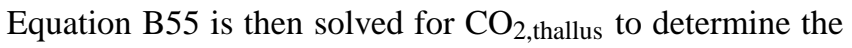
values for $f_{\mathrm{CO}_{2} \text {,in }}$ and $f_{\mathrm{GPP}}$. 


\section{B5.6 Biomass loss}

The turnover rate of the biomass of lichens or bryophytes, $\tau_{\mathrm{B}}$, is calculated similarly to the Rubisco content (see Sect. B5.2) as a function of the reference respiration rate at $10{ }^{\circ} \mathrm{C}, x_{R_{\mathrm{ref}}}$. The relation between $\tau_{\mathrm{B}}$ and $x_{R_{\mathrm{ref}}}$ represents a tradeoff and results from a physiological constraint, namely metabolic stability of enzymes (see Sect. 2.2). The exact shape of this relation could not be determined since we could not find enough studies where both $\tau_{\mathrm{B}}$ and $x_{R_{\mathrm{ref}}}$ are measured. Thus, we assume a simple linear function:

$\tau_{\mathrm{B}}=w_{\text {loss, }, \mathrm{R}} x_{R_{\mathrm{ref}}}$

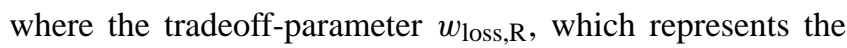
slope of the line, is determined by two points, the origin $(0,0)$ and the point $\left(\overline{\tau_{\mathrm{B}}}, \overline{x_{R_{\text {ref }}}}\right)$, where $\overline{x_{R_{\text {ref }}}}$ is the average reference respiration rate and $\overline{\tau_{\mathrm{B}}}$ is the average turnover rate. $\overline{x_{R_{\mathrm{ref}}}}$ is calculated by Eq. (B2) with $N=0.5$. The limits of the range of possible values of $x_{R_{\text {ref }}}$ can be found in Table B9. To compute $\overline{\tau_{\mathrm{B}}}$ we also use Eq. (B2) with $N=0.5$ (see Fig. B15). The range of possible values of $\tau_{\mathrm{B}}$ is set to $0.03-1.5$ (see Sect. B1).

The flow of biomass loss $f_{\text {loss }}$ is then calculated as a function of $\tau_{\mathrm{B}}$ and the biomass of the organism:

$f_{\text {loss }}=\tau_{\mathrm{B}} \frac{s_{\mathrm{B}}}{c_{\mathrm{M}_{\mathrm{C}}} 3.1536 \times 10^{7}}$

where $\tau_{\mathrm{B}}$ is the turnover rate, $s_{\mathrm{B}}$ is the biomass of a lichen or bryophyte and $c_{\mathrm{M}_{\mathrm{C}}}$ is the molar mass of carbon. The factor of $3.1536 \times 10^{7}$ is used to convert $\tau_{\mathrm{B}}$ from $\mathrm{yr}^{-1}$ to s ${ }^{-1}$. Note that $f_{\text {loss }}$ also includes leaching of carbohydrates and small-scale regular herbivory.

\section{B5.7 Carbon balance}

Two carbon reservoirs of lichens and bryophytes are simulated in the model: biomass and sugar reserves. The balance of the sugar reservoir $s_{\mathrm{C}}$ is written as

$s_{\mathrm{C}}=\max \left(0.0, s_{\mathrm{C}}+\left(f_{\mathrm{GPP}}-f_{R_{\text {main }}}-f_{R_{\text {growth }}}-f_{\text {growth }}\right) c_{\mathrm{M}_{\mathrm{C}}} p_{\Delta_{\mathrm{t}}}\right)$

where $f_{\mathrm{GPP}}$ is GPP, $f_{R_{\text {main }}}$ is maintenance respiration, $f_{R_{\text {growth }}}$ is growth respiration, $f_{\text {growth }}$ is growth $c_{\mathrm{M}_{\mathrm{C}}}$ is the molar mass of carbon and $p_{\Delta_{\mathrm{t}}}$ is the time step of the model.

\section{B6 Water exchange flows}

The water exchange between a lichen or bryophyte and its environment is represented by three flows: water uptake via rainfall or snowmelt, evaporation from the surface of the thallus, and runoff.

Water uptake $f_{\text {water,up is calculated as }}$

$f_{\text {water,up }}=\left(f_{\text {rain,atm }}+f_{\text {snowmelt }}\right) \phi_{\text {prec }} \Phi_{\text {area }}$

where $f_{\text {rain,atm }}$ is rainfall, $f_{\text {snowmelt }}$ is snowmelt, $\phi_{\text {prec }}$ is the fraction of precipitation that reaches the thallus surface, and
$\Phi_{\text {area }}$ reduces water uptake to the area covered by a lichen or bryophyte.

Evaporation $f_{\text {evap }}$ is calculated as a minimum of demand by potential evaporation and supply by the water reservoir of a lichen or bryophyte:

$f_{\text {evap }}=\min \left(\frac{s_{\Theta}}{p_{\Delta_{\mathrm{t}}}}, E_{\mathrm{pot}}\right)$

where $s_{\Theta}$ is the water content of a lichen or bryophyte, $p_{\Delta_{\mathrm{t}}}$ is the time step of the model and $E_{\text {pot }}$ is potential evaporation (see Eq. B30).

Runoff $f_{\text {runoff }}$ is generated when net water uptake exceeds the water storage capacity of the thallus:

$f_{\text {runoff }}=\frac{\max \left(0.0, s_{\Theta}+\max \left(0.0, f_{\text {water,up }}-f_{\text {evap }}\right) p_{\Delta_{\mathrm{t}}}-\Theta_{\max }\right)}{p_{\Delta_{\mathrm{t}}}}$

where $s_{\Theta}$ is the water content of a lichen or bryophyte, $f_{\text {water,up }}$ is water uptake, $f_{\text {evap }}$ is evaporation, $p_{\Delta_{\mathrm{t}}}$ is the time step of the model and $\Theta_{\max }$ is the water storage capacity of the thallus (see Eq. B17).

The water balance is then written as

$s_{\Theta}=\max \left(0.0, s_{\Theta}+\left(f_{\text {water,up }}-f_{\text {evap }}-f_{\text {runoff }}\right) p_{\Delta_{\mathrm{t}}}\right)$

where $s_{\Theta}$ is the water content of a lichen or bryophyte, $f_{\text {water,up }}$ is water uptake, $f_{\text {evap }}$ is evaporation, $f_{\text {runoff }}$ is runoff and $p_{\Delta_{\mathrm{t}}}$ is the time step of the model.

\section{B7 Exchange flows of energy}

In addition to exchange flows of carbon and water, the model computes the exchange of energy between lichens and bryophytes and the atmosphere. The flow of latent heat, $f_{Q_{\text {atm, }}}$, is calculated from evaporation as

$f_{Q_{\text {atm }, \mathrm{L}}}=f_{\text {evap }} c_{\Delta H_{\text {vap }, \mathrm{H}_{2} \mathrm{O}} c_{\rho_{\mathrm{H}_{2} \mathrm{O}}}}$

where $f_{\text {evap }}$ is evaporation, $c_{\Delta H_{\text {vap }, \mathrm{H}_{2} \mathrm{O}}}$ is the enthalpy of vaporisation and $c_{\rho_{\mathrm{H}_{2} \mathrm{O}}}$ is the density of liquid water. The flow of sensible heat, $f_{Q_{\text {atm }, S}}$, is written as

$f_{Q_{\text {atm }, \mathrm{S}}}=\frac{\left(T_{\text {surf }}-T_{\text {air }}\right) c_{\mathrm{C}_{\text {air }}}}{r_{\mathrm{H}}} \Phi_{\text {area }}+\left(E_{\mathrm{pot}}-f_{\text {evap }}\right) c_{\Delta H_{\text {vap }, \mathrm{H}_{2}} c c_{\mathrm{H}_{2} \mathrm{O}}}$

where $T_{\text {surf }}$ is surface temperature, $T_{\text {air }}$ is air temperature, $c_{C_{\text {air }}}$ is the heat capacity of air, $r_{\mathrm{H}}$ is the aerodynamic resistance to heat transfer and $\Phi_{\text {area }}$ is the fraction of available area covered by a lichen or bryophyte. $E_{\text {pot }}$ is potential evaporation, $f_{\text {evap }}$ is actual evaporation, $c_{\Delta H_{\mathrm{vap}, \mathrm{H}_{2} \mathrm{O}}}$ is the enthalpy of vaporisation and $c_{\rho_{\mathrm{H}_{2} \mathrm{O}}}$ is the density of liquid water. Note that $f_{Q_{\text {atm }, \mathrm{S}}}$ consists of two parts. The first part depends on the gradient between surface temperature of the organism and air temperature. The second part is the difference between the potential flow of latent heat and the actual one (see Eq. B63). This means that the ratio of latent heat to sensible heat decreases if the supply of water is not sufficient to support potential evaporation. 
Table B7. Overview of natural constants used in the model.

\begin{tabular}{lllll}
\hline Parameter & Description & Value & Unit & Reference \\
\hline$c_{\sigma}$ & Stefan-Boltzmann constant & $5.67 \times 10^{-8}$ & $\mathrm{~W} \mathrm{~m}^{-2} \mathrm{~K}^{-4}$ & Eqs. (B22), (B31) \\
$c_{\Delta H_{\mathrm{vap}, \mathrm{H}_{2} \mathrm{O}}}$ & Enthalpy of vaporisation & $2.45 \times 10^{6}$ & $\mathrm{~J} \mathrm{~kg}^{-1}$ & Eqs. (B30), (B63), (B64) \\
$c_{C_{\text {air }}}$ & Heat capacity of air & 1297.0 & $\mathrm{~J} \mathrm{~m}^{-3} \mathrm{~K}^{-1}$ & Eqs. (B30), (B31), (B64) \\
$c_{\rho_{\mathrm{H}_{2} \mathrm{O}}}$ & Density of liquid water & 1000.0 & $\mathrm{~kg} \mathrm{~m}^{-3}$ & Eqs. (B17), (B27), (B30), (B34), (B63) \\
$c_{\gamma}$ & Psychrometric constant & 65.0 & $\mathrm{~Pa} \mathrm{~K}^{-1}$ & Eqs. (B30), (B31) \\
$c_{\mathrm{M}_{\mathrm{H}_{2} \mathrm{O}}}$ & Molar mass of water & 0.018 & $\mathrm{~kg} \mathrm{~mol}^{-1}$ & Eq. (B27) \\
$c_{\mathrm{M}_{\mathrm{C}}}$ & Molar mass of carbon & 0.012 & $\mathrm{~kg} \mathrm{~mol}^{-1}$ & Eqs. (B52), (B53), (B57), (B58), (B66) \\
$c_{R_{\text {gas }}}$ & Universal gas constant & 8.3145 & $\mathrm{~J} \mathrm{~mol}^{-1} \mathrm{~K}^{-1}$ & Eqs. (B27), (B42), (B43) \\
$c_{T_{\mathrm{mel}, \mathrm{H}_{2} \mathrm{O}}}$ & Melting temperature of water & 273.0 & $\mathrm{~K}$ & Eqs. (B32), (B40), (B51) \\
\hline
\end{tabular}

Table B8. Overview of model parameters describing environmental conditions. Parameters marked by the ${ }^{\star}$-symbol are included in a sensitivity analysis (see Table 2 ) because their values are not known very accurately.

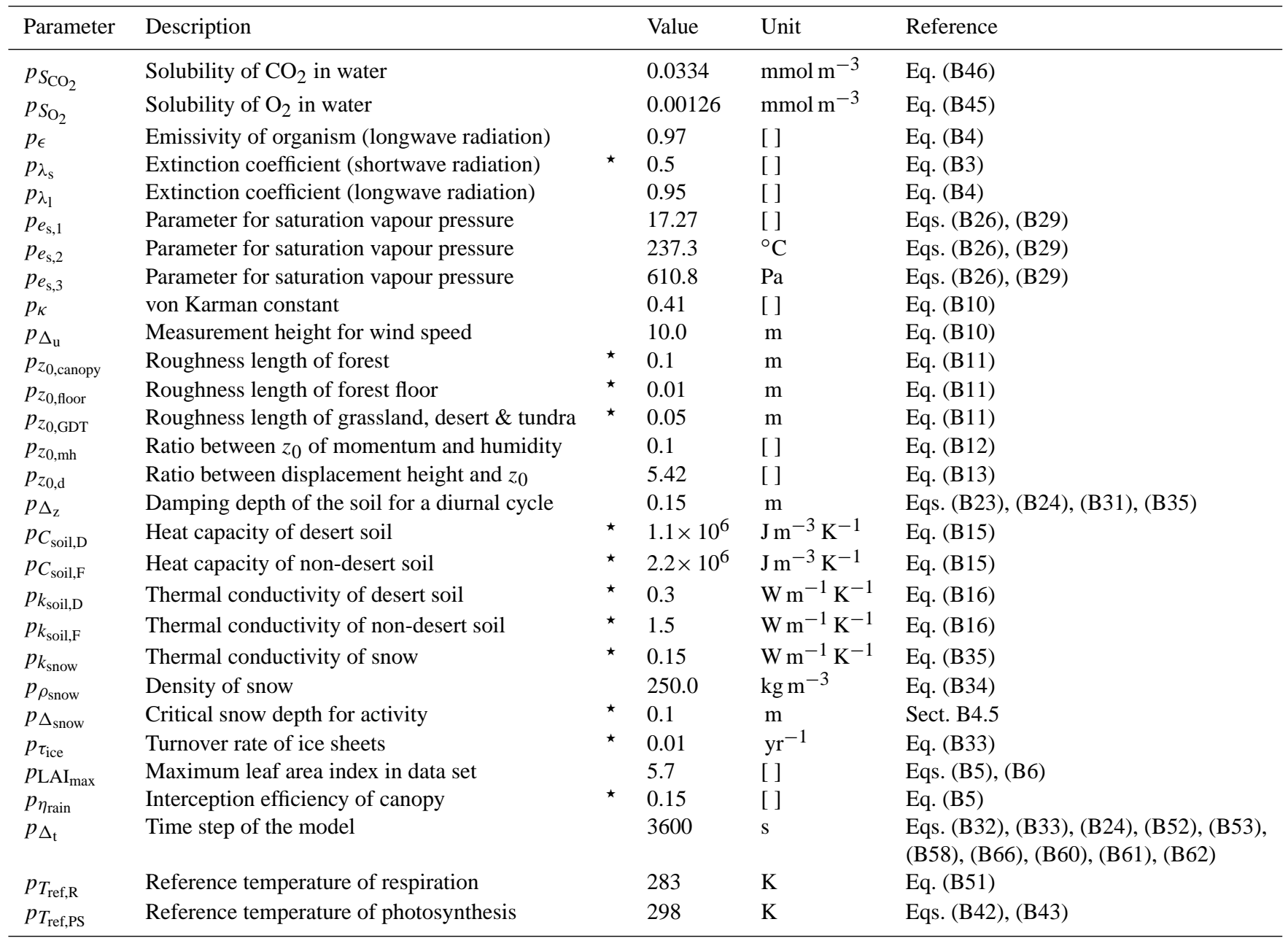


Table B9. Overview of lichen or bryophyte random parameters used in the model.

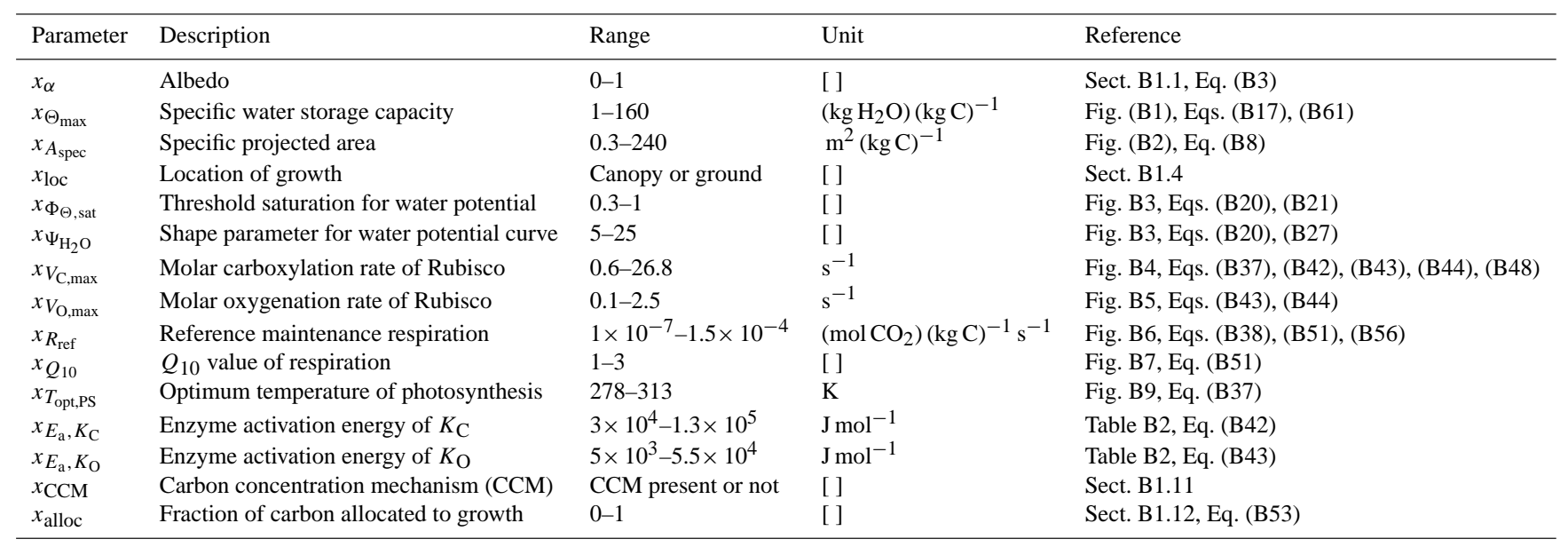

Table B10. Overview of model parameters associated with lichen or bryophyte tradeoffs. Parameters marked by the ${ }^{\star}$-symbol are included in a sensitivity analysis (see Table 2) because their values are not known very accurately. Note that in some cases several parameters are changed simultaneously to test model sensitivity towards a certain property, e.g. both $w_{D_{\mathrm{CO}_{2} \text {, max }}}$ and $w_{D_{\mathrm{CO}_{2} \text {, min }}}$ for $\mathrm{CO}_{2}$ diffusivity. Only one of the CCM parameters is included in the sensitivity analysis: changing $w_{\mathrm{CCM}, \mathrm{e}}$ would be redundant since decreasing the costs of the $\mathrm{CCM}$ is analogous to increasing its positive effect. $w_{\mathrm{CCM}, 2}$ and $w_{\mathrm{CCM}, 3}$ are only relevant at a transient state of very high pore space $\mathrm{CO}_{2}$ levels.

\begin{tabular}{|c|c|c|c|c|c|}
\hline Parameter & Description & & Value & Unit & Reference \\
\hline$w_{D_{\mathrm{CO}_{2}, \max }}$ & Maximum thallus diffusivity for $\mathrm{CO}_{2}$ & * & 0.14 & $\left(\mathrm{molCO}_{2}\right) \mathrm{m}^{-2} \mathrm{~s}^{-1}$ & Eq. (B19) \\
\hline$w_{D_{\mathrm{CO}_{2}, \min }}$ & Minimum thallus diffusivity for $\mathrm{CO}_{2}$ & $\star$ & $5.7 \times 10^{-4}$ & $(\mathrm{~mol} \mathrm{CO} 2) \mathrm{m}^{-2} \mathrm{~s}^{-1}$ & Eq. (B19) \\
\hline$w_{\mathrm{CO}_{2}}$ & Factor for water $\mathrm{CO}_{2}$ diffusivity curve & & 12 & [ ] & Fig. B10, Eq. (B19) \\
\hline$w_{\text {Rub,R }}$ & Rubisco per respiration & $\star$ & 3.6 & $\left(\mathrm{~mol}\right.$ Rubisco) $\left(\mathrm{mol} \mathrm{CO}_{2}\right)^{-1} \mathrm{~s}$ & Eq. (B38) \\
\hline$w_{\text {loss }, \mathrm{R}}$ & Turnover per respiration & $\star$ & 54771 & $(\mathrm{kgC}) \mathrm{s}\left(\mathrm{molCO}_{2}\right)^{-1} \mathrm{yr}^{-1}$ & Eq. (B56) \\
\hline$w_{\mathrm{JV}, 1}$ & Slope of $\phi_{\mathrm{JV}}$ & * & -0.06 & [ ] & Eq. (B40) \\
\hline$w_{\mathrm{JV}, 2}$ & Intercept of $\phi_{\mathrm{JV}}$ & $\star$ & 3.7 & [ ] & Eq. (B40) \\
\hline$w_{K_{\mathrm{C}, 1}}$ & Parameter for $K_{\mathrm{C}}$ & & 1.32 & [ ] & Eqs. (B42), (B43) \\
\hline$w_{K_{\mathrm{C}, 2}}$ & Parameter for $K_{\mathrm{C}}$ & & 2.03 & [ ] & Eqs. (B42), (B43) \\
\hline$w_{K_{\mathrm{O}, 1}}$ & Parameter for $K_{\mathrm{O}}$ & & $5.7 \times 10^{-3}$ & [ ] & Eq. (B43) \\
\hline$w_{K_{\mathrm{O}, 2}}$ & Parameter for $K_{\mathrm{O}}$ & & 0.51 & {[]} & Eq. (B43) \\
\hline$w_{\mathrm{CCM}, \mathrm{e}}$ & Cost parameter for CCM & & 0.67 & [ ] & Eq. (B41) \\
\hline$w_{\mathrm{CCM}, 1}$ & Parameter for CCM & $\star$ & 45 & [ ] & Eq. (B50) \\
\hline$w_{\mathrm{CCM}, 2}$ & Parameter for $\mathrm{CCM}$ & & 3.6 & [ ] & Eq. (B50) \\
\hline$w_{\mathrm{CCM}, 3}$ & Parameter for $\mathrm{CCM}$ & & 6 & [ ] & Eq. (B50) \\
\hline
\end{tabular}

Table B11. Constant model parameters associated with lichen or bryophyte properties.

\begin{tabular}{lllll}
\hline Parameter & Description & Value & Unit & Reference \\
\hline$p_{\text {PAR }}$ & Conversion factor for photosynthetically active radiation & $2.0699 \times 10^{-6}$ & $\mathrm{~mol} \mathrm{~J}^{-1}$ & Eq. (B41) \\
$p_{\text {quant }}$ & Conversion of quanta light into electrons & 0.5 & {[]} & Eq. (B41) \\
$p_{\Omega}$ & Shape parameter for T response of photosynthesis & 18 & $\mathrm{~K}$ & Eq. (B37) \\
$p_{\eta_{\text {growth }}}$ & Efficiency of sugar to biomass conversion & 0.75 & {[]} & Eqs. (B53), (B54) \\
\hline
\end{tabular}


Table B12. Boundary conditions for the model.

\begin{tabular}{|c|c|c|c|}
\hline Variable & Description & Unit & Reference \\
\hline $\mathrm{CO}_{2, \mathrm{~atm}}$ & Atmospheric $\mathrm{CO}_{2}$ concentration & ppm & Eq. (B36) \\
\hline $\mathrm{O}_{2, \mathrm{~atm}}$ & Atmospheric $\mathrm{O}_{2}$ concentration & ppm & Eq. (B45) \\
\hline$T_{\text {air }}$ & Air temperature & $\mathrm{K}$ & $\begin{array}{l}\text { Eqs. (B22), (B26), (B27), (B29), } \\
\text { (B31), (B32), (B35), (B64) }\end{array}$ \\
\hline$f_{\mathrm{rad}_{\mathrm{SW} \downarrow}}$ & Ingoing shortwave radiation & $\mathrm{W} \mathrm{m}^{-2}$ & Eqs. (B25), (B31), (B41) \\
\hline$f_{\mathrm{rad}_{\mathrm{LW} \downarrow}}$ & Ingoing longwave radiation & $\mathrm{W} \mathrm{m}{ }^{-2}$ & Eqs. (B25), (B31) \\
\hline$f_{\text {rain,atm }}$ & Rainfall & $\mathrm{m}^{3} \mathrm{~m}^{-2} \mathrm{~s}^{-1}$ & Eq. (B59) \\
\hline$f_{\text {snow,atm }}$ & Snowfall & $\mathrm{m}^{3} \mathrm{~m}^{-2} \mathrm{~s}^{-1}$ & Eqs. (B32), (B33) \\
\hline$\Phi_{\mathrm{RH}}$ & Relative humidity & [ ] & Eqs. (B30), (B31) \\
\hline$u$ & Near surface wind speed & $\mathrm{ms}^{-1}$ & Eq. (B10) \\
\hline$A_{\text {baresoil }}$ & Area fraction of unoccupied soil & $\mathrm{m}^{2} \mathrm{~m}^{-2}$ & Eq. (B6) \\
\hline$A_{\mathrm{LAI}}$ & Leaf area index (monthly resolution) & $\mathrm{m}^{2} \mathrm{~m}^{-2}$ & Eqs. (B3), (B4), (B5), (B6), (B7) \\
\hline$A_{\mathrm{SAI}}$ & Stem area index (monthly resolution) & $\mathrm{m}^{2} \mathrm{~m}^{-2}$ & Eqs. (B3), (B4), (B7) \\
\hline
\end{tabular}

Table B13. Variables associated with the environment.

\begin{tabular}{|c|c|c|c|}
\hline Variable & Description & Unit & Reference \\
\hline$z_{0}$ & Roughness length of surface for momentum & $\mathrm{m}$ & Eqs. (B10), (B11), (B12), (B13) \\
\hline$z_{0, \mathrm{~h}}$ & Roughness length of surface for humidity & $\mathrm{m}$ & Eqs. (B10), (B12) \\
\hline$r_{\mathrm{H}}$ & Aerodynamic resistance to heat transfer & $\mathrm{s} \mathrm{m}^{-1}$ & Eqs. (B10), (B30), (B31), (B64) \\
\hline$\Delta_{\mathrm{d}}$ & Displacement height for wind speed & $\mathrm{m}$ & Eqs. (B10), (B13) \\
\hline$\tau_{\mathrm{veg}}$ & Disturbance interval & $\mathrm{yr}$ & Table B3 \\
\hline$C_{\text {soil }}$ & Soil heat capacity & $\mathrm{J} \mathrm{m}^{-3} \mathrm{~K}^{-1}$ & Eqs. (B15), (B24) \\
\hline$k_{\text {Soil }}$ & Soil thermal conductivity & $\mathrm{W} \mathrm{m}{ }^{-1} \mathrm{~K}^{-1}$ & Eqs. (B16), (B25), (B31), (B35) \\
\hline$f_{\text {snowmelt }}$ & Snowmelt & $\mathrm{m}^{3} \mathrm{~m}^{-2} \mathrm{~s}^{-1}$ & Eqs. (B32), (B33), (B59) \\
\hline$s_{\text {snow }}$ & Snow reservoir & $\mathrm{m}^{3} \mathrm{~m}^{-2}$ & Eqs. (B32), (B33), (B34) \\
\hline$\Delta_{\text {snow }}$ & Thickness of snow cover & $\mathrm{m}$ & Eqs. (B34), (B35) \\
\hline$A_{\text {ground,max }}$ & Available area for growth on ground & $\mathrm{m}^{2} \mathrm{~m}^{-2}$ & Eqs. (B6), (B8) \\
\hline$A_{\text {canopy,max }}$ & Available area for growth in canopy & $\mathrm{m}^{2} \mathrm{~m}^{-2}$ & Eqs. (B7), (B8), (B9) \\
\hline$s_{T_{\text {soil }}}$ & Soil temperature & $\mathrm{K}$ & Eqs. (B23), (B24), (B31), (B35) \\
\hline$e_{\text {sat }}$ & Saturation vapour pressure & $\mathrm{Pa}$ & Eqs. (B28), (B30), (B31) \\
\hline$e_{\mathrm{sat}, 0}$ & Saturation vapour pressure (open water) & $\mathrm{Pa}$ & Eqs. (B26), (B28) \\
\hline$\phi_{e_{\text {sat }}}$ & Reduction factor for saturation vapour pressure & [ ] & Eqs. (B27), (B28), (B29) \\
\hline$d_{e_{\text {sat }}}$ & Slope of saturation vapour pressure curve & {[]} & Eqs. (B29), (B30), (B31) \\
\hline$E_{\text {pot }}$ & Potential evaporation & $\mathrm{m}^{3} \mathrm{~m}^{-2} \mathrm{~s}^{-1}$ & Eqs. (B30), (B60), (B64) \\
\hline
\end{tabular}

Table B14. State variables of lichens or bryophytes.

\begin{tabular}{llll}
\hline Variable & Description & Unit & Reference \\
\hline$s_{\mathrm{B}}$ & Biomass of lichen or bryophyte & $(\mathrm{kg} \mathrm{C}) \mathrm{m}^{-2}$ & Eqs. (B8), (B17), (B41), (B48), (B52), (B57), (B66) \\
$s_{\mathrm{C}}$ & Sugar reservoir of lichen or bryophyte & $(\mathrm{kg} \mathrm{C}) \mathrm{m}^{-2}$ & Eqs. (B52), (B53), (B58) \\
$s_{\Theta}$ & Thallus water content & $\mathrm{m}^{3} \mathrm{~m}^{-2}$ & Eqs. (B18), (B60), (B61), (B62) \\
\hline
\end{tabular}


Table B15. Variables describing flows between lichens or bryophytes and their environment.

\begin{tabular}{|c|c|c|c|}
\hline Variable & Description & Unit & Reference \\
\hline$f_{\mathrm{rad}_{\mathrm{LW} \uparrow}}$ & Outgoing longwave radiation & $\mathrm{W} \mathrm{m}^{-2}$ & Eqs. (B22), (B25) \\
\hline$f_{Q_{\text {soil }}}$ & Ground heat flux & $\mathrm{W} \mathrm{m}^{-2}$ & Eqs. (B23), (B24), (B25) \\
\hline$f_{\mathrm{H}}$ & Net radiation & $\mathrm{W} \mathrm{m}^{-2}$ & Eqs. (B25), (B30) \\
\hline$f_{Q_{\mathrm{atm}, \mathrm{L}}}$ & Latent heat flow & $\mathrm{W} \mathrm{m}^{-2}$ & Eqs. (B63), (B65) \\
\hline$f_{Q_{\mathrm{atm}, \mathrm{S}}}$ & Sensible heat flow & $\mathrm{W} \mathrm{m}^{-2}$ & Eqs. (B64), (B65) \\
\hline$f_{\text {water,up }}$ & Water uptake & $\mathrm{m}^{3} \mathrm{~m}^{-2} \mathrm{~s}^{-1}$ & Eqs. (B59), (B61), (B62) \\
\hline$f_{\text {evap }}$ & Evaporation from thallus surface & $\mathrm{m}^{3} \mathrm{~m}^{-2} \mathrm{~s}^{-1}$ & Eqs. (B60), (B61), (B62), (B63), (B64) \\
\hline$f_{\text {runoff }}$ & Runoff & $\mathrm{m}^{3} \mathrm{~m}^{-2} \mathrm{~s}^{-1}$ & Eqs. (B61), (B62) \\
\hline$f_{\mathrm{CO}_{2}, \text { in }}$ & Inflow of $\mathrm{CO}_{2}$ into the thallus & $\left(\mathrm{mol} \mathrm{CO}_{2}\right) \mathrm{m}^{-2} \mathrm{~s}^{-1}$ & Eqs. (B36), (B55) \\
\hline$f_{\mathrm{GPP}, \mathrm{L}}$ & Light-limited rate of photosynthesis & $\left(\mathrm{molCO}_{2}\right) \mathrm{m}^{-2} \mathrm{~s}^{-1}$ & Eqs. (B47), (B49) \\
\hline$f_{\mathrm{GPP}, \mathrm{W}}$ & $\mathrm{CO}_{2}$-limited rate of photosynthesis & $\left(\mathrm{molCO}_{2}\right) \mathrm{m}^{-2} \mathrm{~s}^{-1}$ & Eqs. (B48), (B49) \\
\hline$f_{\mathrm{GPP}}$ & Gross primary productivity (GPP) & $\left(\mathrm{mol} \mathrm{CO}_{2}\right) \mathrm{m}^{-2} \mathrm{~s}^{-1}$ & Eqs. (B49), (B55), (B58) \\
\hline$f_{R_{\text {main }}}$ & Maintenance respiration & $\left(\mathrm{molCO}_{2}\right) \mathrm{m}^{-2} \mathrm{~s}^{-1}$ & Eqs. (B52), (B53), (B55), (B58) \\
\hline$f_{R_{\text {growth }}}$ & Growth respiration & $\left(\mathrm{mol} \mathrm{CO}_{2}\right) \mathrm{m}^{-2} \mathrm{~s}^{-1}$ & Eqs. (B54), (B55), (B58) \\
\hline$f_{\text {growth }}$ & Growth & $(\mathrm{molC}) \mathrm{m}^{-2} \mathrm{~s}^{-1}$ & Eqs. (B53), (B54), (B58), (B66) \\
\hline$f_{\text {loss }}$ & Biomass loss & $(\mathrm{molC}) \mathrm{m}^{-2} \mathrm{~s}^{-1}$ & Eqs. (B57), (B66) \\
\hline
\end{tabular}

Table B16. Variables associated with lichens or bryophytes.

\begin{tabular}{|c|c|c|c|}
\hline Variable & Description & Unit & Reference \\
\hline$\Psi_{\mathrm{H}_{2} \mathrm{O}}$ & Water potential & MPa & Fig. B3, Eq. (B20) \\
\hline$R_{\mathrm{spec}}$ & Specific maintenance respiration rate & $\left(\mathrm{molCO}_{2}\right)\left(\mathrm{kg} \mathrm{C}^{-1} \mathrm{~s}^{-1}\right.$ & Eqs. (B51), (B52) \\
\hline$\phi_{\mathrm{rads}}$ & Conversion factor for shortwave radiation & [ ] & Eqs. (B3), (B25), (B31), (B41) \\
\hline$\phi_{\mathrm{rad}}$ & Conversion factor for longwave radiation & [ ] & Eqs. (B4), (B25), (B310 \\
\hline$\phi_{\text {prec }}$ & Conversion factor for precipitation & [ ] & Eqs. (B5), (B59) \\
\hline$\Phi_{\text {area }}$ & Fraction of available area covered by organism & [ ] & $\begin{array}{l}\text { Eqs. (B9), (B22), (B23), (B24), (B25), } \\
\text { (B30), (B36), (B41), (B59), (B64) }\end{array}$ \\
\hline$A_{\text {thallus }}$ & Thallus area per $\mathrm{m}^{2}$ ground & $\mathrm{m}^{2} \mathrm{~m}^{-2}$ & Eqs. (B8), (B9) \\
\hline$\chi_{\mathrm{G}}$ & Switch for ground heat flux & [ ] & Eqs. (B14), (B23), (B31) \\
\hline$\Theta_{\max }$ & Water storage capacity & $\mathrm{m}$ & Eqs. (B17), (B18) \\
\hline$\Phi_{\Theta}$ & Water saturation & [ ] & Eqs. (B18), (B19), (B20), (B21) \\
\hline$D_{\mathrm{CO}_{2}}$ & Diffusivity for $\mathrm{CO}_{2}$ & $\left(\mathrm{molCO}_{2}\right) \mathrm{m}^{-2} \mathrm{~s}^{-1}$ & Eqs. (B19), (B36) \\
\hline$\Phi_{\text {act }}$ & Metabolic activity & 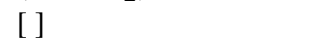 & Eqs. (B21), (B47), (B48), (B52), (B53) \\
\hline$T_{\text {surf }}$ & Surface temperature & $\mathrm{K}$ & $\begin{array}{l}\text { Eqs. (B22), (B23), (B31), (B35), } \\
\text { (B37), (B40), (B42), (B43), (B51), (B64) }\end{array}$ \\
\hline $\mathrm{CO}_{2, \text { thallus }}$ & $\mathrm{CO}_{2}$ concentration in thallus pore space & ppm & Eqs. (B36), (B46), (B50) \\
\hline $\mathrm{CO}_{2, \text { cell }}$ & $\mathrm{CO}_{2}$ concentration in chloroplast & $\mathrm{mol} \mathrm{m}^{-3}$ & Eqs. (B46), (B47), (B48), (B50) \\
\hline$V_{\mathrm{C}, \max }$ & Maximum carboxylation rate & $\left(\mathrm{molCO}_{2}\right)\left(\mathrm{kg} \mathrm{C}^{-1} \mathrm{~s}^{-1}\right.$ & Eqs. (B37), (B39) \\
\hline$J_{\max }$ & Maximum electron transport rate & $\left(\mathrm{mole}^{-}\right)(\mathrm{kgC})^{-1} \mathrm{~s}^{-1}$ & Eqs. (B39), (B41) \\
\hline$\Xi_{\text {Rub }}$ & Specific Rubisco content & $(\operatorname{mol}$ Rubisco $)(\mathrm{kg} \mathrm{C})^{-1}$ & Eqs. (B37), (B38) \\
\hline$\phi_{\mathrm{JV}}$ & Ratio of $J_{\max }$ to $V_{\mathrm{C} \text {,max }}$ & [ ] & Eqs. (B39), (B40) \\
\hline$K_{\mathrm{C}}$ & Michaelis-Menten constant of carboxylation & $\left(\mathrm{mol} \mathrm{CO}_{2}\right) \mathrm{m}^{-3}$ & Eqs. (B42), (B44), (B48) \\
\hline$K_{\mathrm{O}}$ & Michaelis-Menten constant of oxygenation & $\left(\mathrm{molO}_{2}\right) \mathrm{m}^{-3}$ & Eqs. (B42), (B44), (B48) \\
\hline $\mathrm{O}_{2, \text { cell }}$ & $\mathrm{O}_{2}$ concentration in chloroplast & $\mathrm{mol} \mathrm{m}^{-3}$ & Eqs. (B44), (B45), (B48) \\
\hline$\Gamma_{*}$ & $\mathrm{CO}_{2}$ compensation point & $\left(\mathrm{mol} \mathrm{CO}_{2}\right) \mathrm{m}^{-3}$ & Eqs. (B44), (B47), (B48) \\
\hline$J$ & Actual electron transport rate & $\left(\mathrm{mol} \mathrm{e}^{-}\right) \mathrm{m}^{-2} \mathrm{~s}^{-1}$ & Eqs. (B41), (B47) \\
\hline$\tau_{\mathrm{B}}$ & Turnover rate of biomass & $\mathrm{yr}^{-1}$ & Fig. B15, Eqs. (B56), (B57) \\
\hline
\end{tabular}


The energy balance of the thallus surface, which can be either on the ground or in the canopy, is then calculated as

$f_{\mathrm{H}}=f_{Q_{\mathrm{atm}, \mathrm{L}}}+f_{Q_{\mathrm{atm}, \mathrm{S}}}$

where $f_{\mathrm{H}}$ is net radiation (see Eq. B25), $f_{Q_{\mathrm{atm}, \mathrm{L}}}$ is the flow of latent heat and $f_{Q_{\mathrm{atm} . \mathrm{S}}}$ is the flow of sensible heat.

The balance of the biomass reservoir $s_{\mathrm{B}}$ is written as

$s_{\mathrm{B}}=\max \left(0.0, s_{\mathrm{B}}+\left(f_{\text {growth }}-f_{\text {loss }}\right) c_{\mathrm{M}_{\mathrm{C}}} p_{\Delta_{\mathrm{t}}}\right)$

where $f_{\text {growth }}$ is growth, $f_{\text {loss }}$ is biomass loss, $c_{\mathrm{M}_{\mathrm{C}}}$ is the molar mass of carbon and $p_{\Delta_{\mathrm{t}}}$ is the time step of the model.

Acknowledgements. The authors are thankful to Ryan Pavlick, Fabian Gans, Nathaniel Virgo, Stan Schymanski, Jens Kattge and Lee Miller for useful discussions about the topic. We thank Steffen Richter and Ulrich Weber for technical support and we give thanks to two anonymous reviewers for helping with the improvement of the manuscript. We thank the Helmholtz Alliance "Planetary Evolution and Life" for funding.

The service charges for this open access publication have been covered by the Max Planck Society.

Edited by: M. Bahn

\section{References}

Allen, R. G., Pereira, L. S., Raes, D., and Smith, M.: Crop evapotranspiration - Guidelines for computing crop water requirements, FAO - Food and Agriculture Organization of the United Nations, Rome, Italy, 56 pp., 1998.

Angelstam, P.: Maintaining and restoring biodiversity in European boreal forests by developing natural disturbance regimes, J. Vegetat. Sci., 9, 593-602, doi:10.2307/3237275, 1998.

Anisimov, O., Shiklomanov, N., and Nelson, F.: Global warming and active-layer thickness: results from transient general circulation models, Glob. Planet. Change, 15, 61-77, doi:10.1016/S0921-8181(97)00009-X, 1997.

Balaguer, L., Manrique, E., de los Rios, A., Ascaso, C., Palmqvist, K., Fordham, M., and Barnes, J.: Long-term responses of the green-algal lichen Parmelia caperata to natural $\mathrm{CO}_{2}$ enrichment, Oecologia, 119, 166-174, doi:10.1007/s004420050773, 1999.

Belnap, J. and Lange, O. (eds.): Biological Soil Crusts: Structure, Function, and Management, 2nd Edn., Springer, Berlin, 2003.

Bergström, S.: The HBV model: Its structure and applications, Swedish Meteorol. Hydrol. Instit., 1992.

Berthelin, J.: Microbial weathering processes in natural environments, Physical and Chemical Weathering in Geochemical Cycles, 33-59, doi:10.1007/978-94-009-3071-1_3, 1988.

Billings, W.: Carbon Balance of Alaskan Tundra and Taiga Ecosystems: Past, Present and Future, Quatern. Sci. Rev., 6, 165-177, doi:10.1016/0277-3791(87)90032-1, 1987.

Bisbee, K., Gower, S., Norman, J., and Nordheim, E.: Environmental controls on ground cover species composition and productivity in a boreal black spruce forest, Oecologia, 129, 261-270, doi:10.1007/s004420100719, 2001.
Bloom, A., Chapin III, F., and Mooney, H.: Resource Limitation in Plants-An Economic Analogy, Ann. Rev. Ecol.Syst., 16, 363392, doi:10.1146/annurev.es.16.110185.002051, 1985.

Bonan, G., ed.: Ecological Climatology, 2nd ed., Cambridge University Press, New York, 2008.

Bonan, G., Oleson, K., Vertenstein, M., Levis, S., Zeng, X., Dai, Y., Dickinson, R., and Yang, Z.-L.: The land surface climatology of the Community Land Model coupled to the NCAR Community Climate Model, J. Clim., 15, 3123-3149, doi:10.1175/15200442(2002)015<3123:TLSCOT>2.0.CO;2, 2002.

Bond-Lamberty, B. and Gower, S.: Estimation of stand-level leaf area for boreal bryophytes, Oecologia, 151, 584-592, doi:10.1007/s00442-006-0619-5, 2007.

Bond-Lamberty, B., Wang, C., and Gower, S.: Net primary production and net ecosystem production of a boreal black spruce wildfire chronosequence, Global Change Biology, 10, 473-487, doi:10.1111/j.1529-8817.2003.0742.x, 2004.

Bongers, E., Popma, J., Meave del Castillo, J., and Carabias, J.: Structure and floristic composition of the lowland rain forest of Los Tuxtlas, Mexico, Vegetatio, 74, 55-80, doi:10.1007/BF00045614, 1988.

Boucher, V. and Nash III, T. H.: Growth Patterns in Ramalina menziesii in California: Coastal vs. Inland Populations, The Bryologist, 93, 295-302, doi:10.2307/3243516, 1990a.

Boucher, V. and Nash III, T. H.: The role of the fruticose lichen Ramalina menziesii in the annual turnover of biomass and macronutrients in a blue oak woodland, Bot. Gaz., 151, 114-118, doi:10.1086/337810, 1990b.

Brostoff, W., Sharifi, M., and Rundel, P.: Photosynthesis of cryptobiotic soil crusts in a seasonally inundated system of pans and dunes in the western Mojave Desert, CA: Field studies, Flora, 200, 592-600, doi:10.1016/j.flora.2005.06.008, 2005.

Büdel, B., Weber, B., Kühl, M., Pfanz, H., Sültemeyer, D., and Wessel, D.: Reshaping of sandstone surfaces by cryptoendolithic cyanobacteria: Bioalkalization causes chemical weathering in arid landscapes, Geobiology, 2, 261-268, doi:10.1111/j.14724677.2004.00040.x, 2004.

Camill, P., Lynch, J., Clark, J., Adams, J., and Jordan, B.: Changes in Biomass, Aboveground Net Primary Production, and Peat Accumulation following Permafrost Thaw in the Boreal Peatlands of Manitoba, Canada, Ecosystems, 4, 461-478, doi:10.1007/s10021-001-0022-3, 2001.

Chandrashekara, U. and Ramakrishnan, P.: Vegetation and gap dynamics of a tropical wet evergreen forest in the Western Ghats of Kerala, India, J. Trop. Ecol., 10, 337-354, doi:10.1017/S0266467400008014, 1994.

Chen, J., Blume, H.-P., and Beyer, L.: Weathering of rocks induced by lichen colonization - a review, Catena, 39, 121-146, doi:10.1016/S0341-8162(99)00085-5, 2000.

Clark, K., Nadkarni, N., and Gholz, H.: Growth, Net Production, Litter Decomposition, and Net Nitrogen Accumulation by Epiphytic Bryophytes in a Tropical Montane Forest, Biotropica, 30, 12-23, doi:10.1111/j.1744-7429.1998.tb00365.x, 1998.

Condit, R., Hubbell, S., and Foster, R.: Assessing the response of plant functional types to climatic change in tropical forests, J. Vegetat. Sci., 7, 405-416, doi:10.2307/3236284, 1996.

Cowan, I., Lange, O., and Green, T.: Carbon-dioxide exchange in lichens: Determination of transport and carboxylation characteristics, Planta, 187, 282-294, doi:10.1007/BF00201952, 1992. 
Dahlman, L. and Palmqvist, K.: Growth in two foliose tripartite lichens, Nephroma arcticum and Peltigera aphthosa: Empirical modelling of external vs. internal factors, Functional Ecology, 17, 821-831, doi:10.1046/j.0269-8463.2003.00804.x, 2003.

Demmig-Adams, B., Maguas, C., Adams III, W., Meyer, A., Kilian, E., and Lange, O.: Effect of high light on the efficiency of photochemical energy conversion in a variety of lichen species with green and blue-green phycobionts, Planta, 180, 400-409, doi:10.1007/BF01160396, 1990.

Dilks, T. and Proctor, M.: Photosynthesis, Respiration and Water Content in Bryophytes, New Phytologist, 82, 97-114, doi:10.1111/j.1469-8137.1979.tb07564.x, 1979.

Domine, F., Bock, J., Morin, S., and Giraud, G.: Linking the effective thermal conductivity of snow to its shear strength and density, Journal of Geophysical Research, 116, F04027, doi:10.1029/2011JF002000, 2011.

Elbert, W., Weber, B., Burrows, S., Steinkamp, J., Büdel, B., Andreae, M., and Pöschl, U.: Contribution of cryptogamic covers to the global cycles of carbon and nitrogen, Nat. Geosci., 5, 459462, doi:10.1038/ngeo1486, 2012.

Escudero, A. and Mediavilla, S.: Decline in photosynthetic nitrogen use efficiency with leaf age and nitrogen resorption as determinants of leaf life span, J. Ecology, 91, 880-889, doi:10.1046/j.1365-2745.2003.00818.x, 2003.

Euskirchen, E., McGuire, A., Chapin III, F., Yi, S., and Thompson, C.: Changes in vegetation in northern Alaska under scenarios of climate change, 2003-2100: Implications for climate feedbacks, Ecol. Appl., 19, 1022-1043, doi:10.1890/08-0806.1, 2009.

Farquhar, G. and von Caemmerer, S.: Modelling of Photosynthetic Response to Environmental Conditions., in: Encyclopedia of Plant Physiology, edited by Lange, O., Nobel, P., Osmond, C., and Ziegler, H., Vol. 12B, Springer, Heidelberg, 1982.

Ferreira de Lima, R., Martini, A., Gandolfi, S., and Rodrigues, R.: Repeated disturbances and canopy disturbance regime in a tropical semi-deciduous forest, J. Trop. Ecol., 24, 85-93, doi:10.1017/S0266467407004658, 2008.

Follows, M. and Dutkiewicz, S.: Modeling diverse communities of marine microbes, Ann. Rev. Mar. Sci., 3, 427-451, doi:10.1146/annurev-marine-120709-142848, 2011.

Foster, J. and Reiners, W.: Size distribution and expansion of canopy gaps in a northern Appalachian spruce-fir forest., Vegetatio, 68, 109-114, 1986.

Frolking, S., Roulet, N., Moore, T., Lafleur, P., Bubier, J., and Crill, P.: Modeling seasonal to annual carbon balance of Mer Bleue Bog, Ontario, Canada, Global Biogeochem. Cy., 16, doi:10.1029/2001GB001457, 2002.

Frolking, S., Roulet, N., Tuittila, E., Bubier, J., Quillet, A., Talbot, J., and Richard, P.: A new model of Holocene peatland net primary production, decomposition, water balance, and peat accumulation, Earth Syst. Dynam., 1, 1-21, doi:10.5194/esd-1-12010, 2010.

Gaio-Oliveira, G., Moen, J., Danell, O., and Palmqvist, K.: Effect of simulated reindeer grazing on the re-growth capacity of mat-forming lichens, Basic and Applied Ecology, 7, 109-121, doi:10.1016/j.baae.2005.05.007, 2006.

Garcia-Pichel, F. and Belnap, J.: Microenvironments and microscale productivity of cyanobacterial desert crusts., Journal of Phycology, 32, 774-782, doi:10.1111/j.0022-3646.1996.00774.x, 1996.
Gauslaa, Y. and Solhaug, K.: The significance of thallus size for the water economy of the cyanobacterial old-forest lichen Degelia plumbea, Oecologia, 116, 76-84, doi:10.1007/s004420050565, 1998.

Gauslaa, Y. and Ustvedt, E.: Is parietin a UV-B or a blue-light screening pigment in the lichen Xanthoria parietina?, Photochem. Photobiol. Sci., 2, 424-432, doi:10.1039/b212532c, 2003.

Gower, S., Vogel, J., Norman, J., Kucharik, C., Steele, S., and Stow, T.: Carbon distribution and aboveground net primary production in aspen, jack pine and black spruce stands in Saskatchewan and Manitoba, Canada, J. Geophys. Res., 102, 29029-29041, doi:10.1029/97JD02317, 1997.

Gradstein, S.: The lowland cloud forest of French Guiana: a liverwort hotspot, Cryptogamie. Bryologie, 27, 141-152, 2006.

Gray, D., Lewis, L., and Cardon, Z.: Photosynthetic recovery following desiccation of desert green algae (Chlorophyta) and their aquatic relatives, Plant, Cell Environ., 30, 1240-1255, doi:10.1111/j.1365-3040.2007.01704.x, 2007.

Green, T. and Snelgar, W.: A Comparison of Photosynthesis in Two Thalloid Liverworts, Oecologia, 54, 275-280, doi:10.1007/BF00378404, 1982.

Green, T., Schroeter, B., Kappen, L., Seppelt, R., and Maseyk, K.: An assessment of the relationship between chlorophyll a fluorescence and $\mathrm{CO}_{2}$ gas exchange from field measurements on a moss and lichen, Planta, 206, 611-618, doi:10.1007/s004250050439, 1998.

Grigal, D.: Sphagnum production in forested bogs of northern Minnesota, Canad. J. Botany, 63, 1204-1207, doi:10.1139/b85-166, 1985.

Gunnarsson, U.: Global patterns of Sphagnum productivity, J. Bryol., 27, 269-279, doi:10.1179/174328205X70029, 2005.

Hall, C., Stanford, J., and Hauer, F.: The distribution and abundance of organisms as a consequence of energy balances along multiple environmental gradients, Oikos, 65, 377-390, doi:10.2307/3545553, 1992.

Harden, J., O’Neill, K., Trumbore, S., Veldhuis, H., and Stocks, B.: Moss and soil contributions to the annual net carbon flux of a maturing boreal forest, J. Geophys. Res., 102, 28805-28816, doi:10.1029/97JD02237, 1997.

Harrisson, P., Walton, D. W. H., and Rothery, P.: The Effects of Temperature and Moisture on Dark Respiration in the Foliose Lichen Umbilicaria antarctica, New Phytologist, 103, 443-455, doi:10.1111/j.1469-8137.1986.tb02882.x, 1986.

Harvey, B., Leduc, A., Gauthier, S., and Bergeron, Y.: Standlandscape integration in natural disturbance-based management of the southern boreal forest, Forest Ecol. Manag., 155, 369-385, doi:10.1016/S0378-1127(01)00573-4, 2002.

Hill, D. and Woolhouse, H.: Aspects of the autecology of Xanthoria parietina agg., The Lichenologist, 3, 207-214, doi:10.1017/S0024282966000227, 1966.

Hilmo, O.: Growth and morphological response of oldforest lichens transplanted into a young and an old Picea abies forest, Ecography, 25, 329-335, doi:10.1034/j.16000587.2002.250309.x, 2002.

Huttunen, S., Lappalainen, N., and Turunen, J.: UV-absorbing compounds in subarctic herbarium bryophytes, Environmental Pollution, 133, 303-314, doi:10.1016/j.envpol.2004.05.041, 2005. 
Ito, A.: A historical meta-analysis of global terrestrial net primary productivity: are estimates converging?, Glob. Change Biol., 17, 3161-3175, doi:10.1111/j.1365-2486.2011.02450.x, 2011.

Jackson, T. and Keller, W.: A comparative study of the role of lichens and "inorganic" processes in the chemical weathering of recent Hawaiian lava flows, American J. Sci., 269, 446-466, doi:10.2475/ajs.269.5.446, 1970.

Jans, L., Poorter, L., van Rompaey, R., and Bongers, F.: Gaps and Forest Zones in Tropical Moist Forest in Ivory Coast, Biotropica, 25, 258-269, doi:10.2307/2388784, 1993.

Jeffries, D., Link, S., and Klopatek, J.: $\mathrm{CO}_{2}$ fluxes of cryptogamic crusts I. Response to resaturation, New Phytol., 125, 163-173, doi:10.1111/j.1469-8137.1993.tb03874.x, 1993.

Jonsson, A., Moen, J., and Palmqvist, K.: Predicting lichen hydration using biophysical models, Oecologia, 156, 259-273, doi:10.1007/s00442-008-0990-5, 2008.

Jonsson Čabrajić, A., Lidén, M., Lundmark, T., OttossonLöfvenius, M., and Palmqvist, K.: Modelling hydration and photosystem II activation in relation to in situ rain and humidity patterns: a tool to compare performance of rare and generalist epiphytic lichens, Plant, Cell Environ., 33, 840-850, doi:10.1111/j.1365-3040.2009.02110.x, 2010.

June, T., Evans, J., and Farquhar, G.: A simple new equation for the reversible temperature dependence of photosynthetic electron transport: A study on soybean leaf, Functional Plant Biol., 31, 275-283, doi:10.1071/FP03250, 2004.

Kattge, J. and Knorr, W.: Temperature acclimation in a biochemical model of photosynthesis: a reanalysis of data from 36 species, Plant, Cell and Environment, 30, 1176-1190, doi:10.1111/j.1365-3040.2007.01690.x, 2007.

Kappen, L., Lewis Smith, R., and Meyer, M.: Carbon Dioxide Exchange of Two Ecodemes of Schistidium antarctici in Continental Antarctica, Polar Biology, 9, 415-422, doi:10.1007/BF00443227, 1989.

Kershaw, K.: Studies on lichen-dominated systems, XII. The ecological significance of thallus color, Can. J. Bot., 53, 660-667, doi:10.1139/b75-081, 1975.

Kleidon, A. and Mooney, H.: A global distribution of biodiversity inferred from climatic constraints: results from a process-based modelling study, Glob. Change Biol., 6, 507-523, doi:10.1046/j.1365-2486.2000.00332.x, 2000.

Klopatek, J.: Cryptogamic crusts as potential indicators of disturbance in semi-arid landscapes, in: Ecological indicators, Springer, 773-786, 1992.

Köhler, L., Tobon, C., Frumau, K., and Bruijnzeel, L.: Biomass and water storage dynamics of epiphytes in old-growth and secondary montane cloud forest stands in Costa Rica, Plant Ecology, 193, 171-184, doi:10.1007/s11258-006-9256-7, 2007.

Kruse, J., Rennenberg, H., and Adams, M.: Steps towards a mechanistic understanding of respiratory temperature responses, New Phytologist, 189, 659-677, doi:10.1111/j.14698137.2010.03576.x, 2011.

Kustas, W. and Norman, J.: A Two-Source Energy Balance Approach Using Directional Radiometric Temperature Observations for Sparse Canopy Covered Surfaces, Agronomy J., 92, 847-854, doi:10.2134/agronj2000.925847x, 2000.

Lange, O.: Moisture content and $\mathrm{CO}_{2}$ exchange of lichens I. Influence of temperature on moisture-dependent net photosynthe- sis and dark respiration in Ramalina maciformis, Oecologia, 45, 82-87, doi:10.1007/BF00346710, 1980.

Lange, O.: Photosynthetic productivity of the epilithic lichen Lecanora muralis: Long-term field monitoring of $\mathrm{CO}_{2}$ exchange and its physiological interpretation I. Dependence of photosynthesis on water content, light, temperature, and $\mathrm{CO}_{2}$ concentration from laboratory measurements, Flora, 197, 233-249, doi:10.1078/0367-2530-00038, 2002.

Lange, O. and Green, T.: Lichens show that fungi can acclimate their respiration to seasonal changes in temperature, Oecologia, 142, 11-19, doi:10.1007/s00442-004-1697-x, 2005.

Lange, O., Geiger, I., and Schulze, E.-D.: Ecophysiological Investigations on Lichens of the Negev Desert V. A Model to Simulate Net Photosynthesis and Respiration of Ramalina maciformis, Oecologia, 28, 247-259, 1977.

Lange, O., Hahn, S., Meyer, A., and Tenhunen, J.: Upland Tundra in the Foothills of the Brooks Range, Alaska, USA: Lichen LongTerm Photosynthetic $\mathrm{CO}_{2}$ Uptake and Net Carbon Gain, Arc. Alpine Res., 30, 252-261, doi:10.2307/1551972, 1998.

Lange, O., Büdel, B., Heber, U., Meyer, A., Zellner, H., and Green, T.: Temperate rainforest lichens in New Zealand: High thallus water content can severely limit photosynthetic $\mathrm{CO}_{2}$ exchange, Oecologia, 95, 303-313, doi:10.1007/BF00320981, 1993.

Larson, D.: Lichen Water Relations Under Drying Conditions, New Phytologist, 82, 713-731, doi:10.1111/j.14698137.1979.tb01666.x, 1979.

Lawrence, D. and Slater, A.: Incorporating organic soil into a global climate model, Clim Dyn, 30, 145-160, doi:10.1007/s00382007-0278-1, 2008.

Lawton, R. and Putz, F.: Natural Disturbance and Gap-Phase Regeneration in a Wind-Exposed Tropical Cloud Forest, Ecology, 63, 764-777, doi:10.2307/1941025, 1988.

Lenton, T., Crouch, M., Johnson, M., Pires, N., and Dolan, L.: First plants cooled the Ordovician, Nature Geosci., 5, 86-89, doi:10.1038/ngeo1390, 2012.

Lidén, M., Jonsson Čabrajić, A., Ottosson-Löfvenius, M., Palmqvist, K., and Lundmark, T.: Species-specific activation time-lags can explain habitat restrictions in hydrophilic lichens, Plant, Cell and Environment, 33, 851-862, doi:10.1111/j.13653040.2009.02111.x, 2010.

Liu, S., Lu, L., Mao, D., and Jia, L.: Evaluating parameterizations of aerodynamic resistance to heat transfer using field measurements, Hydrol. Earth Syst. Sci., 11, 769-783, doi:10.5194/hess11-769-2007, 2007.

Mack, M., Treseder, K., Manies, K., Harden, J., Schuur, E., Vogel, J., Randerson, J., and Chapin III, F.: Recovery of aboveground plant biomass and productivity after fire in mesic and dry black spruce forests of interior Alaska, Ecosystems, 11, 209-225, doi:10.1007/s10021-007-9117-9, 2008.

Martin, P. and Fahey, T.: Fire history along environmental gradients in the subtropical pine forests of the Cordillera Central, Dominican Republic, J. Trop. Ecol., 22, 289-302, doi:10.1017/S0266467406003178, 2006.

Martinez-Ramos, M., Alvarez-Buylla, E., Sarukhan, J., and Pinero, D.: Treefall Age Determination and Gap Dynamics in a Tropical Forest, J. Ecology, 76, 700-716, doi:10.2307/2260568, 1988.

McKay, M., Conover, W., and Bechman, R.: A comparison of three methods for selecting values of input variables in the analysis 
of output from a computer code, Technometrics, 21, 239-245, doi:10.2307/1268522, 1979.

Medlyn, B., Dreyer, E., Ellsworth, D., Forstreuters, M., Harley, P., Kirschbaum, M., Le Roux, X., Montpied, P., Strassemeyer, J., Walcroft, A., Wang, K., and Loustau, D.: Temperature response of parameters of a biochemically based model of photosynthesis. II. A review of experimental data, Plant, Cell and Environment, 25, 1167-1179, doi:10.1046/j.1365-3040.2002.00891.x, 2002.

Melick, D. and Seppelt, R.: Loss of soluble carbohydrates and changes in freezing point of Antarctic bryophytes after leaching and repeated freeze-thaw cycles, Antarctic Science, 4, 399-404, doi:10.1017/S0954102092000592, 1992.

Miura, K., Kohinata, T., Yoshioka, S., Ohyama, K., and Fukuzawa, H.: Regulation of a carbon concentrating mechanism through CCM1 in Chlamydomonas reinhardtii, Funct. Plant Biol., 29, 211-219, 2002.

Monteith, J.: Evaporation and surface temperature, Quart. J. R. Met. Soc., 107, 1-27, doi:10.1002/qj.49710745102, 1981.

Mouillot, F. and Field, C.: Fire history and the global carbon budget: a $1^{\circ} \times 1^{\circ}$ fire history reconstruction for the 20th century, Global Change Biology, 11, 398-420, doi:10.1111/j.13652486.2005.00920.x, 2005.

Nash III, T.: Lichen Biology, 2nd Edn., Cambridge University Press, New York, 1996.

Navas, M.-L., Ducout, B., Roumet, C., Richarte, J., Garnier, J., and Garnier, E.: Leaf life span, dynamics and construction cost of species from Mediterranean old-fields differing in successional status, New Phytologist, 159, 213-228, doi:10.1046/j.14698137.2003.00790.x, 2003.

Nikolov, N., Massman, W., and Schoettle, A.: Coupling biochemical and biophysical processes at the leaf level: An equilibrium photosynthesis model for leaves of $\mathrm{C}_{3}$ plants, Ecol. Modell., 80, 205-235, doi:10.1016/0304-3800(94)00072-P, 1995.

Nungesser, M.: Modelling microtopography in boreal peatlands: hummocks and hollows, Ecol. Modell., 165, 175-207, doi:10.1016/S0304-3800(03)00067-X, 2003.

Oechel, W. and Collins, N.: Comparative $\mathrm{CO}_{2}$ exchange patterns in mosses from two tundra habitats at Barrow, Alaska., Can. J. Bot., 54, 1355-1369, doi:10.1139/b76-148, 1976.

Oechel, W. and Van Cleve, K.: The role of bryophytes in nutrient cycling in the taiga., in: Forest ecosystems in the Alaskan taiga. A synthesis of structure and function., edited by Van Cleve, K., Chapin III, F., Flanagan, P., Vierect, L., and Dyrness, C., Springer, New York, 122-137, 1986.

Olson, D., Dinerstein, E., Wikramanayake, E., Burgess, N., Powell, G., Underwood, E., D’Amico, J., Itoua, I., Strand, H., Morrison, J., Loucks, C., Allnutt, T., Ricketts, T., Kura, Y., Lamoreux, J., Wettengel, W., Hedao, P., and Kassem, K.: Terrestrial Ecoregions of the World: A New Map of Life on Earth, BioScience, 51, 933-938, doi:10.1641/00063568(2001)051[0933:TEOTWA]2.0.CO;2, 2001.

Palmqvist, K.: Tansley Review No. 117. Carbon Economy in Lichens, New Phytologist, 148, 11-36, doi:10.1046/j.14698137.2000.00732.x, 2000.

Palmqvist, K.: Cyanolichens: Carbon Metabolism, in: Cyanobacteria in Symbiosis, edited by Rai, A., Bergman, B., and Rasmussen, U., Kluwer, Dordrecht, doi:10.1007/0-306-48005-0_5, 2002.

Palmqvist, K. and Sundberg, B.: Light use efficiency of dry matter gain in five macrolichens: Relative impact of microclimate con- ditions and species-specific traits, Plant, Cell and Environment, 23, 1-14, doi:10.1046/j.1365-3040.2000.00529.x, 2000.

Palmqvist, K., Campbell, D., Ekblad, A., and Johansson, H.: Photosynthetic capacity in relation to nitrogen content and its partitioning in lichens with different photobionts, Plant, Cell Environ., 21, 361-372, doi:10.1046/j.1365-3040.1998.00279.x, 1998.

Palmqvist, K., Dahlman, L., Valladares, F., Tehler, A., Sancho, L., and Mattsson, J.: $\mathrm{CO}_{2}$ exchange and thallus nitrogen across 75 contrasting lichen associations from different climate zones, Oecologia, 133, 295-306, doi:10.1007/s00442-002-1019-0, 2002.

Pannewitz, S., Schlensog, M., Green, T., Sancho, L., and Schroeter, B.: Are lichens active under snow in continental Antarctica?, Oecologia, 135, 30-38, 2003.

Pavlick, R., Drewry, D., Bohn, K., Reu, B., and Kleidon, A.: The Jena Diversity-Dynamic Global Vegetation Model (JeDiDGVM): A diverse approach to representing terrestrial biogeography and biogeochemistry based on plant functional tradeoffs, Biogeosciences Discuss., 9, 4627-4726, doi:10.5194/bgd9-4627-2012, 2012.

Payette, S., Filion, L., and Delwaide, A.: Disturbance regime of a cold temperate forest as deduced from tree-ring patterns: the Tantare Ecological Reserve, Quebec, Can. J. For. Res., 20, 12281241, doi:10.1139/x90-162, 1990.

Peters-Lidard, C., Blackburn, E., Liang, X., and Wood, E.: The Effect of Soil Thermal Conductivity Parameterization on Surface Energy Fluxes and Temperatures, J. Atmos. Sci., 55, 1210-1224, doi:10.1175/1520-0469(1998)055<1209:TEOSTC>2.0.CO;2, 1998.

Peltoniemi, M., Mäkipää, R., Liski, J., and Tamminen, P.: Changes in soil carbon with stand age - an evaluation of a modelling method with empirical data, Global Change Biology, 10, 20782091, doi:10.1111/j.1365-2486.2004.00881.x, 2004.

Pintado, A. and Sancho, L.: Ecological significance of net photosynthesis activation by water vapour uptake in Ramalina capitata from rain-protected habitats in central Spain, Lichenologist, 34, 403-413, doi:10.1006/lich.2002.0414, 2002.

Proctor, M.: The bryophyte paradox: tolerance of desiccation, evasion of drought, Plant Ecology, 151, 41-49, 2000.

Proctor, M.: Recovery rates of chlorophyll-fluorescence parameters in desiccation-tolerant plants: fitted logistic curves as a versatile and robust source of comparative data, Plant Growth Regul, 62, 233-240, doi:10.1007/s10725-010-9456-y, 2010.

Randerson, J., Hoffman, F., Thornton, P., Mahowald, N., Lindsay, K., Lee, Y.-H., Nevison, C., Doney, S., Bonan, G., Stöckli, R., Covey, C., Running, S., and Fung, I.: Systematic assessment of terrestrial biogeochemistry in coupled climate-carbon models, Glob. Change Biol., 15, 2462-2484, doi:10.1111/j.13652486.2009.01912.x, 2009.

Reader, R. and Stewart, J.: The relationship between net primary production and accumulation for a peatland in southeastern Manitoba, Ecology, pp. 1024-1037, 1972.

Reich, P., Walters, M., Ellsworth, D., Vose, J., Volin, J., Gresham, C., and Bowman, W.: Relationships of leaf dark respiration to leaf nitrogen, specific leaf area and leaf life-span: a test across biomes and functional groups, Oecologia, 114, 471-482, doi:10.1007/s004420050471, 1998

Reinhold, L., Zviman, M., and Kaplan, A.: A quantitative model for inorganic carbon fluxes and photosynthesis in cyanobacteria, Plant Physiol. Biochem., 27, 945-954, 1989. 
Ried, A.: Nachwirkungen der Entquellung auf den Gaswechsel von Krustenflechten, Biologisches Zentralblatt, 79, 657-678, 1960.

Ruess, R., Hendrick, R., Burton, A., Pregitzer, K., Sveinbjornsson, B., Allen, M., and Maurer, G.: Coupling fine root dynamics with ecosystem carbon cycling in black spruce forests of interior Alaska, Ecol. Monogr., 73, 643-662, doi:10.1890/02-4032, 2003.

Russell, S.: Bryophyte production and decomposition in tundra ecosystems, Botanical Journal of the Linnean Society, 104, 322, doi:10.1111/j.1095-8339.1990.tb02208.x, 1990.

Savir, Y., Noor, E., Milo, R., and Tlusty, T.: Cross-species analysis traces adaptation of Rubisco toward optimality in a low-dimensional landscape, PNAS, 107, 3475-3480, doi:10.1073/pnas.0911663107, 2010.

Schuur, E., Crummer, K., Vogel, J., and Mack, M.: Plant Species Composition and Productivity following Permafrost Thaw and Thermokarst in Alaskan Tundra, Ecosystems, 10, 280-292, doi:10.1007/s10021-007-9024-0, 2007.

Scheidegger, C., Schroeter, B., and Frey, B.: Structural and functional processes during water vapour uptake and desiccation in selected lichens with green algal photobionts, Planta, 197, 399409, doi:10.1007/BF00202663, 1995.

Schwartzmann, D. and Volk, T.: Biotic enhancement of weathering and the habitability of Earth, Nature, 340, 457-460, doi:10.1038/340457a0, 1989.

Shaver, G. and Chapin III, F.: Production: Biomass relationships and element cycling in contrasting arctic vegetation types, Ecological Monographs, 61, 1-31, doi:10.2307/1942997, 1991.

Stull, R., ed.: An Introduction to Boundary Layer Meteorology, Kluwer, Dordrecht, 1988.

Sundberg, B., Palmqvist, K., Esseen, P.-A., and Renhorn, K.-E.: Growth and vitality of epiphytic lichens II. Modelling of carbon gain using field and laboratory data, Oecologia, 109, 10-18, doi:10.1007/s004420050052, 1997.

Sundberg, B., Ekblad, A., Näsholm, T., and Palmqvist, K.: Lichen respiration in relation to active time, temperature, nitrogen and ergosterol concentrations, Functional Ecology, 13, 119-125, doi:10.1046/j.1365-2435.1999.00295.x, 1999.

Sundberg, B., Näsholm, T., and Palmqvist, K.: The effect of nitrogen on growth and key thallus components in the two tripartite lichens, Nephroma arcticum and Peltigera aphthosa, Plant, Cell Environ., 24, 517-527, doi:10.1046/j.1365-3040.2001.00701.x, 2001.

Stevenson, S. and Coxson, D.: Litterfall, growth, and turnover of arboreal lichens after partial cutting in an Engelmann sprucesubalpine fir forest in north-central British Columbia, Can. J. For. Res., 33, 2306-2320, doi:10.1139/x03-161, 2003.

Swanson, R. and Flanagan, L.: Environmental regulation of carbon dioxide exchange at the forest floor in a boreal black spruce ecosystem, Agricultural and Forest Meteorology, 108, 165-181, doi:10.1016/S0168-1923(01)00243-X, 2001.

Szumigalski, A. and Bayley, S.: Net above-ground primary production along a bog-rich fen gradient in central Alberta, Canada, Wetlands, 16, 467-476, doi:10.1007/BF03161336, 1996.

Valladares, F., Sancho, L., and Ascaso, C.: Water storage in the lichen family Umbilicariaceae, Botanica Acta, 111, 99-107, 1998.

Weber, B., Graf, T., and Bass, M.: Ecophysiological analysis of moss-dominated biological soil crusts and their separate com- ponents from the Succulent Karoo, South Africa, Planta, 236, 129-139, doi:10.1007/s00425-012-1595-0, 2012.

Tanaka, H. and Nakashizuka, T.: Fifteen years of canopy dynamics analyzed by aerial photographs in a temperate deciduous forest, Japan, Ecology, 78, 612-620, doi:10.2307/2266034, 1997.

Thonicke, K., Venevsky, S., Sitch, S., and Cramer, W.: The role of fire disturbance for global vegetation dynamics: coupling fire into a Dynamic Global Vegetation Model, Global Ecology \& Biogeography, 10, 661-677, doi:10.1046/j.1466822X.2001.00175.x, 2001.

Thormann, M.: Primary production and decomposition in fens and marshes in the boreal region of Alberta, Canada., Ph.D. thesis, University of Alberta, Edmonton, Alta., 1995.

Tretiach, M. and Geletti, A.: $\mathrm{CO}_{2}$ exchange of the endolithic lichen Verrucaria baldensis from karst habitats in northern Italy, Oecologia, 111, 515-522, doi:10.1007/s004420050265, 1997.

Turetsky, M., Bond-Lamberty, B., Euskirchen, E., Talbot, J., Frolking, S., McGuire, A., and Tuittila, E.-S.: The resilience and functional role of moss in boreal and arctic ecosystems, New Phytologist, 196, 49-67, doi:10.1111/j.1469-8137.2012.04254.x, 2012.

Turner, M., Romme, W., Gardner, R., O’Neill, R., and Kratzi, T.: A revised concept of landscape equilibrium: Disturbance and stability on scaled landscapes, Landscape Ecol., 8, 213-227, doi:10.1007/BF00125352, 1993.

Uchida, M., Muraoka, H., Nakatsubo, T., Bekku, Y., Ueno, T., Kanda, H., and Koizumi, H.: Net Photosynthesis, Respiration, and Production of the Moss Sanionia uncinata on a Glacier Foreland in the High Arctic, Ny-Ålesund, Svalbard, Arctic, Antarctic, and Alpine Research, 34, 287-292, doi:10.2307/1552486, 2002.

Uchida, M., Nakatsubo, T., Kanda, H., and Koizumi, H.: Estimation of the annual primary production of the lichen Cetrariella delise $i$ in a glacier foreland in the High Arctic, Ny-Ålesund, Svalbard, Polar Res., 25, 39-49, doi:10.3402/polar.v25i1.6237, 2006.

Valladares, F., Sancho, L., and Ascaso, C.: Water storage in the lichen family Umbilicariaceae, Botanica Acta, 111, 99-107, 1998.

Vogel, J., Bond-Lamberty, B., Schuur, E., Gower, S., Mack, M., O'Connell, K., Valentine, D., and Ruess, R.: Carbon allocation in boreal black spruce forests across regions varying in soil temperature and precipitation, Global Change Biology, 14, 1503-1516, doi:10.1111/j.1365-2486.2008.01600.x, 2008.

von Caemmerer, S.: Biochemical Models of Leaf Photosynthesis, CSIRO Publishing, Collingwood, Australia, 2000.

Walters, M. and Reich, P.: Low-light carbon balance and shade tolerance in the seedlings of woody plants: do winter deciduous and broad-leaved evergreen species differ?, New Phytol., 143, 143154, doi:10.1046/j.1469-8137.1999.00425.x, 1999.

Wania, R., Ross, I., and Prentice, I.: Integrating peatlands and permafrost into a dynamic global vegetation model: 2. Evaluation and sensitivity of vegetation and carbon cycle processes, Global Biogeochemical Cycles, 23, doi:10.1029/2008GB003413, 2009.

Weber, B., Scherr, C., Bicker, F., Friedl, T., and Büdel, B.: Respiration-induced weathering patterns of two endolithically growing lichens, Geobiology, 9, 34-43, doi:10.1111/j.14724669.2010.00256.x, 2011.

Weber, B., Graf, T., and Bass, M.: Ecophysiological analysis of moss-dominated biological soil crusts and their separate components from the Succulent Karoo, South Africa, Planta, 236, 129-139, doi:10.1007/s00425-012-1595-0, 2012. 
Weedon, G., Gomes, S., Viterbo, P., Shuttleworth, W., Blyth, E., Österle, H., Adam, J., Bellouin, N., Boucher, O., and Best, M.: Creation of the WATCH Forcing Data and Its Use to Assess Global and Regional Reference Crop Evaporation over Land during the Twentieth Century, J. Hydrometeorol., 12, 823-848, doi:10.1175/2011JHM1369.1, 2011.

Wieder, R. and Lang, G.: Net primary production of the dominant bryophytes in a Sphagnum-dominated wetland in West Virginia, Bryologist, 86, 280-286, doi:10.2307/3242723, 1983.

Williams, T. and Flanagan, L.: Measuring and modelling environmental influences on photosynthetic gas exchange in Sphagnum and Pleurozium, Plant, Cell Environ., 21, 555-564, doi:10.1046/j.1365-3040.1998.00292.x, 1998.
Withington, J., Reich, P., Oleksyn, J., and Eissenstat, D.: Comparisons of structure and life span in roots and leaves among temperate trees, Ecolog. Monographs, 76, 381-397, doi:10.1890/00129615(2006)076[0381:COSALS]2.0.CO;2, 2006.

Wullschleger, S.: Biochemical Limitations to Carbon Assimilation in C3 Plants - A Retrospective Analysis of the $\mathrm{A} / \mathrm{C}_{\mathrm{i}}$ Curves from 109 Species, J. Experiment. Botany, 44, 907-920, doi:10.1093/jxb/44.5.907, 1993.

Yurova, A., Wolf, A., Sagerfors, J., and Nilsson, M.: Variations in net ecosystem exchange of carbon dioxide in a boreal mire: Modeling mechanisms linked to water table position, J. Geophys. Res., 112, doi:10.1029/2006JG000342, 2007.

Zhuang, Q., Melillo, J., Sarofim, M., Kicklighter, D., McGuire, A., Felzer, B., Sokolov, A., Prinn, R., Steudler, P., and Hu, S.: $\mathrm{CO}_{2}$ and $\mathrm{CH}_{4}$ exchanges between land ecosystems and the atmosphere in northern high latitudes over the 21 st century, Geophys. Res. Lett., 33, doi:10.1029/2006GL026972, 2006. 